Bundesgesundheitsbl 2012 $\cdot 55: 1311-1354$

DOI 10.1007/s00103-012-1549-5

c) Springer-Verlag 2012

\title{
Hygienemaßnahmen bei Infektionen oder Besiedlung mit multiresistenten gramnegativen Stäbchen
}

\author{
Empfehlung der Kommission für Kranken- \\ haushygiene und Infektionsprävention \\ (KRINKO) beim Robert Koch-Institut (RKI)
}

Ursachen und Konsequenzen der Verbreitung und der Wirksamkeit verschiedener Maßnahmen geschuldet.

Andererseits erfordert die derzeitige Epidemiologie ein abgestimmtes Vorgehen, welches transparent sowohl für die behandelnden Ärzte, als auch für die betroffenen Patienten ist. Daher wurde auf Basis der vorliegenden Literatur eine Empfehlung zum Umgang mit Patienten mit Infektion oder Besiedelung mit multiresistenten gramnegativen Stäbchen erstellt. Die zum Teil noch unzulängliche Datenlage macht eine Anpassung einzelner empfohlener Maßnahmen an neue Erkenntnisse in kürzeren Abständen wahrscheinlich. Hier sei auf entsprechende Publikationen der KRINKO verwiesen.

\subsection{Zielgruppe dieser Empfehlung}

Diese Empfehlung richtet sich primär an die Träger und Mitarbeiter von Krankenhäusern. Auch in anderen medizinischen Einrichtungen, in denen invasive Therapien z. B. Beatmungen in der neurologischen Rehabilitation durchgeführt werden, kann sie hilfreich sein. Andere Einrichtungen, die den Lebensbereich der Patienten darstellen (Alten- und Pflegeheime), werden in dieser Empfehlung derzeit nicht berücksichtigt. Hier ist eine eigene individuelle Risikoabwägung empfehlenswert, wie sie in den Empfehlungen zur Infektionsprävention in Heimen [6] dargestellt wird. Aufgrund der Eigenschaften der gramnegativen Stäbchen sollten die Maßnahmen in Heimen jedoch nicht über die Maßnahmen, die für MRSA-positive Bewohner festgelegt sind, hinausgehen.

\subsection{Bezug zu vorausgegangenen Empfehlungen der KRINKO}

Die Empfehlungen stellen speziell Maßnahmen zur Prävention der Übertragung von multiresistenten gramnegativen Stäbchen zusammen. Hierbei wird ausdrücklich die endemische Situation oder das Auftreten von einzelnen Fällen behandelt. Für Maßnahmen, die bei Ausbrüchen zu ergreifen sind, sei auf die Empfehlungen zum Ausbruchsmanagement und strukturierten Vorgehen bei gehäuftem Auftreten nosokomialer Infektionen [7] verwiesen. Diese Maßnahmen sind selbstverständlich auch erforderlich, wenn die Häufung Mikroorganismen mit anderen Resistenzmustern als den hier behandelten betrifft.

Grundlegende Maßnahmen zur Infektionsprävention sind den entsprechenden weiteren Empfehlungen der KRINKO zu entnehmen. Hier sei ins- 
Tab. 1 Kategorien in der Richtlinie für Krankenhaushygiene und Infektionsprävention (2010)

Kategorie I A: Diese Empfehlung basiert auf gut konzipierten systematischen Reviews oder einzelnen hochwertigen randomisierten kontrollierten Studien.

Kategorie I B: Diese Empfehlung basiert auf klinischen oder hochwertigen epidemiologischen Studien und strengen, plausiblen und nachvollziehbaren theoretischen Ableitungen.

Kategorie II: Diese Empfehlung basiert auf hinweisenden Studien / Untersuchungen und strengen, plausiblen und nachvollziehbaren theoretischen Ableitungen.

Kategorie III: Maßnahmen, über deren Wirksamkeit nur unzureichende oder widersprüchliche Hinweise vorliegen, deshalb ist eine Empfehlung nicht möglich.

Kategorie IV: Anforderungen, Maßnahmen und Verfahrensweisen, die durch allgemein geltende Rechtsvorschriften zu beachten sind.

besondere auf die Empfehlungen zur Händehygiene [8] und Flächendesinfektion [9] verwiesen. Spezielle Maßnahmen für besonders gefährdete Patientenpopulationen finden sich in den entsprechenden Empfehlungen „Anforderungen an die Hygiene bei der medizinischen Versorgung von immunsupprimierten Patienten“ und „Empfehlung zur Prävention nosokomialer Infektionen bei neonatologischen Intensivpflegepatienten mit einem Geburtsgewicht unter $1500 \mathrm{~g}$ " [10].

$\mathrm{Da}$ es sich bei den behandelten Mikroorganismen um Erreger mit speziellen Resistenzen handelt, soll eine Surveillance entsprechend den Erläuterungen des Robert Koch-Institutes zur Surveillance von nosokomialen Infektionen sowie zur Erfassung von Erregern mit speziellen Resistenzen und Multiresistenzen gemäß $\$ 23$ Abs. 4 Infektionsschutzgesetz (IfSG) erfolgen [11].

Die hier aufgeführten Empfehlungen sind mit Kategorien entsprechend der Mitteilung „Die Kategorien in der Richtlinie für Krankenhaushygiene und Infektionsprävention - Aktualisierung der Definitionen" von 2010 [12] versehen (• Tab. 1).

\subsection{Definitionen und Hintergrund}

Zur Beschreibung der Epidemiologie von antibiotikaresistenten Mikroorganismen wurden traditionell bestimmte Leitantibiotika verwendet, gegen die die Erreger phänotypisch resistent waren, z. B. Methicillin-resistenter Staphylococcus aureus (MRSA) oder Vancomycin-resistente Enterokokken (VRE). Hierbei war die Resistenz gegenüber dem Leitantibiotikum oft mit der Resistenz gegenüber weiteren Antibiotika vergesellschaftet, so dass die Abkürzungen zum Synonym für multiresistente Isolate der Spezies wurden. Für die beispielhaft erwähnten Spezies gilt zudem, dass die Leitresistenz nur durch einen oder zwei Resistenzmechanismen ausgelöst werden, so dass die Bezeichnung auf phänotypischem wie auf genotypischem Niveau einheitlich ist. Die Mechanismen sind überdies bisher nur in wenigen Spezies der einzelnen Gattung von Bedeutung.

Auch für gramnegative Enterobakterien wurde die Resistenzeigenschaft zunächst phänotypisch als erweiterte Resistenz gegenüber $\beta$-Laktamantibiotika beschrieben $[13,14]$. Mit der voranschreitenden Aufklärung der Resistenzmechanismen und der Entdeckung immer neuer resistenzvermittelnder Enzyme mit ihren genetischen Determinanten wurden verschiedene Klassifikationen der $\beta$-Laktamasen vorgeschlagen $[13,15]$. In diesen Klassifikationen wurden neben den Substraten der $\beta$-Laktamasen die Möglichkeiten der Inhibition und die molekulare Struktur einbezogen [13]. Die Abkürzung ESBL zum Beispiel (extended spectrum $\beta$-lactamase) steht hierin für eine spezielle Gruppe von Resistenzenzymen, deckt jedoch bei weitem nicht alle Möglichkeiten der Resistenz gegenüber den Cephalosporinen der 3. Generation ab. Ähnliches gilt für Carbapenemasen [16]. Für bestimmte Carbapenemasen werden zudem die Bezeichnungen des jeweiligen Enzyms verwendet (z. B. Klebsiella pneumoniae Carbapenemase (KPC) oder New Delhi metallo- $\beta$-lactamase (NDM)), andere werden unter der Gruppe der Metallo- $\beta$ Laktamasen zusammengefasst. Komplizierend kommt hinzu, dass $\beta$-Lakta- masen in verschiedenen Bakterien-Gattungen anzutreffen sind. Daher eignet sich die Abkürzung ESBL nicht, um alle klinisch und epidemiologisch bedeutsamen multiresistenten gramnegativen Stäbchen zusammen zu fassen.

Für multiresistente gramnegative Stäbchen wurden in der Literatur verschiedene Definitionen verwendet. Gemeinsam ist den Definitionen, dass auf eine Eingruppierung auf Basis der Resistenzmechanismen verzichtet und stattdessen die Resistenz gegenüber verschiedenen Antibiotikagruppen zugrunde gelegt wird $[2,3,5,17,18]$. Dabei unterscheiden sich die Definitionen in der Anzahl der betrachteten Antibiotikagruppen und der Anzahl der nicht wirksamen Gruppen. Zudem wurden verschiedene Bezeichnungen für die Beschreibung der Resistenz verwendet, z. B. „multidrugresistant“ (MDR), „extensively drug-resistant" (XDR) oder "pandrug-resistant" (PDR) [19].

Kürzlich wurde durch eine internationale Arbeitsgruppe ein Vorschlag für Standarddefinitionen multiresistenter, extensiv-resistenter und panresistenter Mikroorganismen vorgelegt [19]. Die Definitionen für den gramnegativen Bereich unterscheiden sich je nach Spezies (Enterobakterien, Pseudomonas aeruginosa und Acinetobacter spp.) in den zu berücksichtigenden Antibiotikagruppen sowie den Leitsubstanzen für jede Gruppe. Hinsichtlich der Definition werden alle Antibiotikagruppen als gleichwertig betrachtet. So wird gemäß der vorgeschlagenen Definition ein E. coli, der resistent gegen Ampicillin, Cotrimoxazol und Tetracyclin ist, genauso als MDR bezeichnet, wie ein $E$. coli, der resistent gegen Cephalosporine der 3. Generation, Chinolone und Aminoglycoside ist, jedoch empfindlich gegenüber Carbapenemen, Glycylcyclinen und Colistin bleibt. Von den Autoren selbst wird betont, dass die Definition epidemiologischen Zwecken dient, aber nicht als Basis für die Infektionskontrolle geeignet ist.

Die KRINKO hat sich daher entschlossen, für die Erarbeitung von Empfehlungen von Maßnahmen zur Prävention eine eigene Definition der Multiresistenz bei gramnegativen Stäbchen zu verwenden. Dabei wurde vor allem 
Tab. 2 Klassifizierung multiresistenter gramnegativer Stäbchen auf Basis ihrer phänotypischen Resistenzeigenschaften ( $\mathrm{R}=$ resistent oder intermediär empfindlich, $\mathrm{S}=$ sensibel)

\begin{tabular}{|c|c|c|c|c|c|c|c|}
\hline \multirow[t]{2}{*}{ Antibiotikagruppe } & \multirow[t]{2}{*}{ Leitsubstanz } & \multicolumn{2}{|c|}{ Enterobakterien } & \multicolumn{2}{|c|}{ Pseudomonas aeruginosa } & \multicolumn{2}{|c|}{$\begin{array}{l}\text { Acinetobacter bau- } \\
\text { mannii }\end{array}$} \\
\hline & & $3 M_{R G N}{ }^{1}$ & $4 \mathrm{MRGN}^{2}$ & $3 \mathrm{MRGN}^{1}$ & $4 \mathrm{MRGN}^{2}$ & $3 \mathrm{MRGN}^{1}$ & $4 \mathrm{MRGN}^{2}$ \\
\hline Acylureidopenicilline & Piperacillin & $\mathrm{R}$ & $\mathrm{R}$ & \multirow{4}{*}{$\begin{array}{l}\text { Nur eine } \\
\text { der } 4 \text { Antibio- } \\
\text { tikagruppen } \\
\text { wirksam } \\
\text { (sensibel) }\end{array}$} & $\mathrm{R}$ & $\mathrm{R}$ & $\mathrm{R}$ \\
\hline $\begin{array}{l}\text { 3./4. Generations-Cephalo- } \\
\text { sporine }\end{array}$ & $\begin{array}{l}\text { Cefotaxim und/oder } \\
\text { Ceftazidim }\end{array}$ & $\mathrm{R}$ & $\mathrm{R}$ & & $\mathrm{R}$ & $\mathrm{R}$ & $\mathrm{R}$ \\
\hline Carbapeneme & $\begin{array}{l}\text { Imipenem und/oder } \\
\text { Meropenem }\end{array}$ & $\mathrm{S}$ & $\mathrm{R}$ & & $\mathrm{R}$ & $\mathrm{S}$ & $\mathrm{R}$ \\
\hline Fluorchinolone & Ciprofloxacin & $\mathrm{R}$ & $\mathrm{R}$ & & $\mathrm{R}$ & $\mathrm{R}$ & $\mathrm{R}$ \\
\hline
\end{tabular}

der Gesichtspunkt der klinischen Relevanz der Resistenz zu Grunde gelegt, d. h. Resistenz gegenüber den Antibiotika betrachtet, die als primäre bakterizide Therapeutika bei schweren Infektionen eingesetzt werden (Acylureidopenicilline, Cephalosporine der 3. und 4. Generation, Carbapeneme und Fluorchinolone). Andere Antibiotika wurden nicht berücksichtigt, da sie in der Regel nicht als Monotherapeutika eingesetzt werden (z. B. Aminoglycoside) oder als Reserveantibiotika (z. B. Glycylcycline) gelten. Aufgrund der Vielfältigkeit der möglichen zugrunde liegenden Resistenzgene und -enzyme wurde auf eine genetische Klassifizierung zugunsten rein phänotypischer Aspekte verzichtet. Als klinisch relevant wurde hier insbesondere der Verlust von mehr als zwei der genannten Antibiotikagruppen für die Therapie eingeschätzt. In diesem Sinne wurden Enterobakterien, die zwar als ESBLBildner erkannt werden, jedoch sensibel gegenüber Fluorchinolonen und Carbapenemen sind, nicht klassifiziert und in dieser Empfehlung nicht gesondert abgehandelt.

Dies schließt jedoch nicht aus, dass solche Isolate mit einer Resistenz gegen Penicilline und Cephalosporine in bestimmten Patientengruppen, in denen eine Therapie mit Chinolonen nicht in Frage kommt, z. B. bei Neugeborenen und Kindern, von besonderer Relevanz sein können.

Nicht zuletzt wurde versucht, einen möglichst einfachen und leicht erkennbaren Algorithmus zu verwenden. Zur Abgrenzung von den international vorgeschlagenen Standarddefinitionen schlägt die KRINKO bewusst andere Akronyme vor: 3MRGN (Multiresistente gramnegative Stäbchen mit Resistenz gegen $\mathbf{3}$ der 4 Antibiotikagruppen) und 4MRGN (Multiresistente gramnegative Stäbchen mit Resistenz gegen 4 der 4 Antibiotikagruppen), wobei $4 \mathrm{MRGN}$ auch die Panresistenz einschließt. Die entsprechenden Definitionen sind in $\bullet$ Tabelle 2 zusammengestellt, wobei für jede Antbiotikagruppe die Leitantibiotika angegeben sind, deren Unwirksamkeit zur jeweiligen Eingruppierung führt.

Die vorgeschlagene Einteilung bezieht sich ausschließlich auf das Resistenzverhalten der Bakterien ohne Berücksichtigung der Virulenzeigenschaften des jeweiligen Erregers. Wird ein Pathogen als besonders virulent eingestuft, so können sich hieraus zusätzliche Schutzmaßnahmen ergeben

\subsection{Hinweise für das diagnostische Labor}

Der 3MRGN-Phänotyp ist bei $K$. pneumoniae am häufigsten verursacht durch die Kombination aus Fluorchinolonresistenz aufgrund mehrerer Mutationen in den Topoisomerase IV-Genen $g y$ $r A$ und parC sowie Resistenz gegen Cephalosporine der 3. Generation. Letztere hat je nach Spezies andere Ursachen. Bei E. coli ist sie hauptsächlich bedingt durch ESBL, kann aber auch durch eine Überexpression der chromosomal-kodierten AmpC-Betalaktamase oder einer erworbenen AmpC-Betalaktamase verursacht sein. Bei K. pneumoniae ist die Resistenz gegen Cephalosporine der 3. Generation fast immer durch eine ESBL bedingt, selten auch durch eine plasmidkodierte AmpC-Betalaktamase. Bei Enterobac- ter spp., Citrobacter freundii, Morganella morganii, Serratia marcescens oder Providencia spp. steht eine Überexpression der bei diesen Spezies natürlicherweise chromosomal-kodierten AmpC-Betalaktamase im Vordergrund, eine ESBL kann ebenfalls ursächlich sein. Bei Proteus mirabilis sind erworbene plasmid-kodierte AmpC-Betalaktamasen oder auch ESBL beschrieben.

Der 4MRGN-Phänotyp beruht bei Enterobakterien auf mehreren Mutationen in den Topoisomerase IV-Genen gyrA und parC. Die Carbapenem-Resistenz kann zwei unterschiedliche molekulare Grundlagen haben:

a) eine Kombination aus intrinsischen $\beta$-Laktamasen (z. B. der chromosomal-kodierten AmpC-Betalaktamase bei Enterobacter spp.) oder erworbenen $\beta$-Laktamasen wie ESBL oder plasmid-kodierten AmpC Betalaktamasen zusammen mit einem Porinverlust kann zu einer Resistenz gegenüber Carbapenemen führen;

b) die Carbapenem-Resistenz kann durch Carbapenemasen bedingt sein.

Bei der Klassifizierung sollen folgende Besonderheiten berücksichtigt werden:

A Selten können Enterobakterien oder Acinetobacter spp. mit CarbapenemResistenz Ciprofloxacin-empfindlich sein. Aufgrund der hohen therapeutischen und epidemiologischen Relevanz der Carbapenem-Resistenz empfiehlt es sich, solche Isolate dennoch als 4MRGN zu werten (• Tab. 3). 
Tab. 3 Beispiele für die Eingruppierung gramnegativer Stäbchen als multiresistent

\begin{tabular}{|c|c|c|c|}
\hline Spezies & Resistenzeigenschaft $^{1}$ & Bewertung & Bemerkung \\
\hline K.pneumoniae & ESBL, Ciprofloxacin R & 3MRGN K. pneumoniae & \\
\hline E. coli & ESBL, Ciprofloxacin S & $\begin{array}{l}\text { E. coli (hier liegt kein } \\
\text { MRGN vor) }\end{array}$ & $\begin{array}{l}\text { bei dieser Konstellation liegt weder 3MRGN noch 4MRGN vor, da } \\
\text { Ciprofloxacin sensibel ist }\end{array}$ \\
\hline K.pneumoniae & $\begin{array}{l}\text { Piperacillin R, Cefotaxim } \\
\text { R, Ceftazidim S, Ciproflo- } \\
\text { xacin R }\end{array}$ & 3MRGN K. pneumoniae & $\begin{array}{l}\text { damit die Kriterien für 3MRGN erfüllt sind, muss Cefotaxim ODER } \\
\text { Ceftazidim I oder R sein (siehe Text Besonderheit C) }\end{array}$ \\
\hline E. coli & $\begin{array}{l}\text { Piperacillin R, Cefotaxim } \\
\text { I, Ceftazidim S, Ciproflo- } \\
\text { xacin I }\end{array}$ & 3MRGN E. coli & $\begin{array}{l}\text { damit die Kriterien für 3MRGN erfüllt sind, muss Cefotaxim ODER } \\
\text { Ceftazidim I oder R sein; auch eine intermediäre Empfindlichkeit } \\
\text { für Ciprofloxacin erfüllt in Kombination mit den anderen Bedin- } \\
\text { gungen die Kriterien für 3MRGN (siehe Text Besonderheit C) }\end{array}$ \\
\hline K.pneumoniae & $\begin{array}{l}\text { Piperacillin R, Cefotaxim } \\
\text { R, Ceftazidim S, Imipe- } \\
\text { nem R, Meropenem R, } \\
\text { Ciprofloxacin R }\end{array}$ & 4MRGN K. pneumoniae & \\
\hline K.pneumoniae & $\begin{array}{l}\text { Piperacillin R, Cefotaxim } \\
\text { R, Ceftazidim S, Imipe- } \\
\text { nem R, Meropenem R, } \\
\text { Ciprofloxacin S }\end{array}$ & 4MRGN K. pneumoniae & $\begin{array}{l}\text { seltene Konstellation, es empfiehlt sich, entsprechende Isolate } \\
\text { trotz Ciprofloxacin-Empfindlichkeit als 4MRGN zu werten (siehe } \\
\text { Text Besonderheit A) }\end{array}$ \\
\hline K.pneumoniae & $\begin{array}{l}\text { Piperacillin R, Cefotaxim } \\
\text { R, Ceftazidim S, Imipe- } \\
\text { nem S, Meropenem S, } \\
\text { Ciprofloxacin R, Nachweis } \\
\text { einer OXA-48 Carbape- } \\
\text { nemase }\end{array}$ & 4MRGN K. pneumoniae & $\begin{array}{l}\text { bei Vorliegen einer Carbapenemase wird das Isolat selbst dann } \\
\text { als 4MRGN gewertet, wenn Imipenem und Meropenem in vitro } \\
\text { sensibel sind (siehe Text Besonderheit B) }\end{array}$ \\
\hline P. mirabilis & $\begin{array}{l}\text { Piperacillin R, Cefotaxim } \\
\text { S, Ceftazidim S, Imipe- } \\
\text { nem R, Meropenem S, } \\
\text { Ciprofloxacin R }\end{array}$ & $\begin{array}{l}\text { P. mirabilis (hier liegt kein } \\
\text { MRGN vor) }\end{array}$ & $\begin{array}{l}\text { bei Proteus spp., Morganella morganii und Providencia spp. kann } \\
\text { eine verminderte Empfindlichkeit gegen Imipenem natürlicher- } \\
\text { weise vorkommen }\end{array}$ \\
\hline $\begin{array}{l}\text { E. cloacae oder andere } \\
\text { Spezies mit chromosoma- } \\
\text { ler AmpC (z. B. E. aergoge- } \\
\text { nes, C. freundii) }\end{array}$ & $\begin{array}{l}\text { Piperacillin R, Cefotaxim } \\
\text { R, Ceftazidim R, Imipe- } \\
\text { nem S, Meropenem S, } \\
\text { Ciprofloxacin S }\end{array}$ & $\begin{array}{l}\text { E. cloacae (hier liegt kein } \\
\text { MRGN vor) }\end{array}$ & $\begin{array}{l}\text { Cephalosporin-Resistenz in diesem Fall kann durch eine dere- } \\
\text { primierte chromosomale AmpC und/oder eine ESBL bedingt } \\
\text { sein. Wegen Ciprofloxacin-Empfindlichkeit ist das Isolat nicht als } \\
\text { MRGN zu werten. Ob es sich um ESBL handelt oder nicht, spielt } \\
\text { für die Klassifikation hier keine Rolle. }\end{array}$ \\
\hline $\begin{array}{l}\text { E. cloacae oder andere } \\
\text { Spezies mit chromosoma- } \\
\text { ler AmpC (z. B. E. aergoge- } \\
\text { nes, C. freundii) }\end{array}$ & $\begin{array}{l}\text { Piperacillin R, Cefotaxim } \\
\text { R, Ceftazidim R, Imipe- } \\
\text { nem S, Meropenem S, } \\
\text { Ciprofloxacin R }\end{array}$ & E. cloacae (3MRGN) & $\begin{array}{l}\text { Cephalosporin-Resistenz in diesem Fall kann durch eine dere- } \\
\text { primierte chromosomale AmpC und/oder eine ESBL bedingt } \\
\text { sein. Wegen Ciprofloxacin-Resistenz ist das Isolat als 3MRGN zu } \\
\text { werten. Ob es sich um ESBL handelt oder nicht, spielt für die Klas- } \\
\text { sifikation hier keine Rolle. }\end{array}$ \\
\hline $\begin{array}{l}\text { E. cloacae oder andere } \\
\text { Spezies mit chromosoma- } \\
\text { ler AmpC (z. B. E. aergoge- } \\
\text { nes, C. freundii) }\end{array}$ & $\begin{array}{l}\text { Piperacillin R, Cefotaxim } \\
\text { S, Ceftazidim S, Imipe- } \\
\text { nem S, Meropenem S, } \\
\text { Ciprofloxacin R }\end{array}$ & $\begin{array}{l}\text { E. cloacae (hier liegt kein } \\
\text { MRGN vor) }\end{array}$ & $\begin{array}{l}\text { Bei dieser Spezies liegt eine üblicherweise nicht exprimierte chro- } \\
\text { mosomale AmpC vor, die aber durch eine Mutation exprimiert } \\
\text { werden kann. Einige Labore setzen daher Cefotaxim und Cefta- } \\
\text { zidim auf I wegen der Möglichkeit von Therapieversagen durch } \\
\text { mutationsbedingte Resistenzen. Für die MRGN-Klassifikation soll- } \\
\text { ten diese interpretierten Ergebnisse in diesem Fall aber nicht ge- } \\
\text { wertet werden. Das Isolat wäre somit nicht als MRGN zu werten. }\end{array}$ \\
\hline P. aeruginosa & $\begin{array}{l}\text { Piperacillin S, Ceftazidim } \\
\text { S, Cefepim R, Imipenem } \\
\text { R, Meropenem R, Cipro- } \\
\text { floxacin R }\end{array}$ & $\begin{array}{l}\text { P. aeruginosa (hier liegt } \\
\text { kein MRGN vor) }\end{array}$ & $\begin{array}{l}\text { trotz Carbapenem-Resistenz gibt es noch aus zwei Antibiotika- } \\
\text { gruppen sensible Substanzen }\end{array}$ \\
\hline P. aeruginosa & $\begin{array}{l}\text { Piperacillin R, Cefotaxim } \\
\text { R, Ceftazidim S, Imipe- } \\
\text { nem R, Meropenem R, } \\
\text { Ciprofloxacin S }\end{array}$ & $\begin{array}{l}\text { P. aeruginosa (hier liegt } \\
\text { kein MRGN vor) }\end{array}$ & $\begin{array}{l}\text { trotz Carbapenem-Resistenz gibt es noch aus zwei Antibiotika- } \\
\text { gruppen sensible Substanzen. Cefotaxim darf bei } P \text {. aeruginosa } \\
\text { nicht für die Multiresistenz-Definition herangezogen werden } \\
\text { (siehe Text Besonderheit D). }\end{array}$ \\
\hline$P$. aeruginosa & $\begin{array}{l}\text { Piperacillin R, Ceftazidim } \\
\text { S, Cefepim S, Imipenem } \\
\text { R, Meropenem R, Cipro- } \\
\text { floxacin R }\end{array}$ & 3MRGN $P$. aeruginosa & $\begin{array}{l}\text { da Ceftazidim und Cefepim zur gleichen Antibiotikagruppe gehö- } \\
\text { ren, ist hier nur eine der } 4 \text { Antibiotikagruppen wirksam }\end{array}$ \\
\hline
\end{tabular}




\begin{tabular}{|c|c|c|c|}
\hline P. aeruginosa & $\begin{array}{l}\text { Piperacillin R, Ceftazidim } \\
\text { I, Cefepim R, Imipenem R, } \\
\text { Meropenem I, Ciproflo- } \\
\text { xacin R }\end{array}$ & 4MRGN $P$. aeruginosa & $\begin{array}{l}\text { intermediäre Ergebnisse werden wie resistente Ergebnisse ge- } \\
\text { wertet }\end{array}$ \\
\hline P. aeruginosa & $\begin{array}{l}\text { Piperacillin R, Ceftazidim } \\
\text { I, Cefepim R, Imipenem R, } \\
\text { Meropenem I, Ciprofloxa- } \\
\text { cin R, Colistin S }\end{array}$ & 4MRGN P. aeruginosa & $\begin{array}{l}\text { Colistin ist zwar sensibel, jedoch gibt es aus den vier Antibiotika- } \\
\text { gruppen, die zur Multiresistenzdefinition herangezogen werden, } \\
\text { keinen sensiblen Vertreter mehr }\end{array}$ \\
\hline A. baumannii & $\begin{array}{l}\text { Piperacillin R, Cefotaxim } \\
\text { R, Imipenem S, Merope- } \\
\text { nem S, Ciprofloxacin R }\end{array}$ & 3MRGN A. baumannii & \\
\hline A.baumannii & $\begin{array}{l}\text { Piperacillin R, Cefotaxim } \\
\text { R, Imipenem R, Merope- } \\
\text { nem R, Ciprofloxacin R }\end{array}$ & 4MRGN A. baumannii & \\
\hline A. baumannii & $\begin{array}{l}\text { Piperacillin R, Sulbactam } \\
\text { S, Cefotaxim R, Imipenem } \\
\text { R, Meropenem R, Cipro- } \\
\text { floxacin R }\end{array}$ & 4MRGN A. baumannii & Sulbactam geht nicht in die Multiresistenz-Definition ein \\
\hline A.baumannii & $\begin{array}{l}\text { Piperacillin R, Cefotaxim } \\
\text { R, Imipenem R, Merope- } \\
\text { nem R, Ciprofloxacin S }\end{array}$ & 4MRGN A. baumannii & $\begin{array}{l}\text { Sehr seltene Konstellation, es empfiehlt sich, entsprechende } \\
\text { Isolate trotz Ciprofloxacin-Empfindlichkeit als 4MRGN zu werten } \\
\text { (siehe Text Besonderheit A) }\end{array}$ \\
\hline
\end{tabular}

B Bei Enterobakterien kann es vorkommen, dass trotz Vorliegen einer Carbapenemase die Empfindlichkeit für Imipenem oder Meropenem formal noch im sensiblen Bereich liegt. Es wird kontrovers diskutiert, ob bei dieser Konstellation dennoch die Carbapeneme auf dem Befund als unwirksam angegeben werden sollen oder nicht. Das European Committee on Antimicrobial Susceptibility Testing (EUCAST) empfiehlt, in diesen Fällen keine Interpretation des Antibiogramms vorzunehmen, die Carbapeneme also ggf. als wirksam zu befunden. Unabhängig von der Resistenzkategorie auf dem Befund empfiehlt die KRINKO bei Nachweis von Carbapenemasen in Enterobakterien, sofern hierfür eine PCR durchgeführt wurde, entsprechende Isolate als 4MRGN zu klassifizieren.

C EUCAST empfiehlt bei Nachweis einer ESBL die Antibiogramme nicht mehr zu interpretieren, es sollen also nicht mehr alle Cephalosporine der 3. Generation als unwirksam interpretiert werden. Es kann also vorkommen, dass Enterobakterien nicht gegenüber beiden Leit-Antibiotika der Cephalosporine der 3. Generation (Ceftazidim und Cefotaxim) inter- mediär empfindlich oder resistent sind. Bei Enterobakterien wird dennoch empfohlen, Enterobakterien als 3MRGN zu klassifizieren, wenn eines der beiden Antibiotika, also Ceftazidim oder Cefotaxim, als nicht wirksam getestet wird.

D Für $P$. aeruginosa wird aufgrund der ohnehin geringeren PseudomonasWirksamkeit von Cefotaxim Ceftazidim für die Bewertung herangezogen.

Veränderungen der Antibiotikawirksamkeit auf Grund von Kombinationen mit $\beta$-Laktamase-Inhibitoren werden nicht berücksichtigt, da dies zu Fehlklassifikationen führen kann.

Die relative komplexe Eingruppierung der Mikroorganismen aufgrund der Resistenzmuster erfordert die Fachkenntnis des Mikrobiologen oder Labormediziners und kann auf Laborebene ggf. durch automatische Algorithmen unterstützt werden. Das Labor soll dem Einsender die Ergebnisse der Klassifizierung mitteilen.

\section{- Die Kommission emfiehlt:}

- dass das diagnostische Labor dem Einsender auf dem Befund die Klassifizierung als 3MRGN oder $4 \mathrm{MRGN}$ mitteilt;
- dass das diagnostische Labor dem Einsender den Nachweis eines 4MRGN vorab telefonisch mitteilt.

\subsection{Nicht behandelte Spezies}

Stenotrophomonas maltophilia ist bereits intrinsisch-resistent gegen eine große Anzahl von Antibiotika und es wird eine Zunahme der erworbenen Resistenz gegenüber Cotrimoxazol beschrieben [20]. Der Erreger löst Infektionen in der Regel nur in stark immunsupprimierten Patienten, vor allem Patienten mit soliden und hämatologischen Krebserkrankungen aus [20-24], bei denen die Infektion auch mit einer nennenswerten Letalität verbunden ist [20-25]. Als weitere Gruppe sind Patienten mit zystischer Fibrose betroffen.

Die Epidemiologie weist darauf hin, dass die Verbreitung mit Basishygienemaßnahmen gut kontrollierbar ist. So zeigt die genetische Analyse endemischer nosokomialer Isolate eine hohe genetische Variabilität [26]. Eine Analyse der in der Outbreak-Datenbank (www.outbreak-database.com, Zugriff 04.08.2011) verzeichneten Ausbrüche, an denen S. maltophilia beteiligt war, ergab 23 nosokomiale Ausbrüche. Bei 4 Ausbrüchen konnte keine Quelle identifiziert werden und bei jeweils nur einem Ausbruch 
wurde ein Patient oder ein Mitarbeiter als Quelle angesehen. In allen anderen Fällen wurde eine Quelle in der Umgebung (kontaminierte Medikamente oder Wasserreservoire) angenommen. Risikofaktoren für Kolonisation und Infektion mit antibiotikaresistenten S. maltophilia sind neben den Grunderkrankungen, vor allem die antibiotische Therapie [21,23], so dass als Ursache für die Verbreitung antibiotikaresistenter S. maltophilia vor allem der Selektionsdruck angenommen werden kann [27].

Daher wurde auf Empfehlungen zur Prävention der Übertragung von S. maltophilia verzichtet.

Ein weiterer nicht behandelter Erreger ist Burkholderia cepacia, da dieser Erreger überwiegend bei Patienten mit zystischer Fibrose zu Infektionen führt. Entsprechende Maßnahmen für diese $\mathrm{Pa}$ tientengruppe können den Empfehlungen zur Infektionsprävention bei Patienten mit Mukoviszidose entnommen werden [28].

Das Auftreten von $\beta$-Laktamasen mit breitem Wirkspektrum ist auch für Salmonellen [29], Shigellen [30] und Yersinien [31] beschrieben. Für Salmonellen ist zusätzlich auch das Vorliegen einer Carbapenem-Resistenz nachgewiesen worden [32]. Da die genannten Mikroorganismen jedoch als Pathogene keine typischen nosokomialen Infektionserreger darstellen, wurde auf eine eingehende Diskussion in diesem Rahmen verzichtet.

Gleiches gilt für E. coli mit besonderen Virulenzeigenschaften, z. B. EHEC. Wird ein Pathogen als besonders virulent eingestuft, so können sich hieraus andere Schutzmaßnahmen - unabhängig von der Antibiotikarresistenz - ergeben.

\section{Epidemiologie der Infektionen und Besiedelung mit multiresistenten gramnegativen Stäbchen}

\subsection{Enterobakterien}

\subsubsection{Escherichia coli}

E. coli ist weltweit einer der häufigsten Erreger von Infektionen des Urogenital- und Gastrointestinaltrakts. In den vergangenen Jahren hat die Antibiotikaresistenz bei $E$. coli erheblich zugenommen. Nach ihrer Erstbeschreibung 1983 wurden Breitspektrum- $\beta$-Laktamasen (zumeist TEM und SHV) hauptsächlich in K. pneumoniae nachgewiesen, die nosokomiale Ausbrüche verursachten [33]. Inzwischen erfahren $\beta$-Laktamasen vorwiegend vom Typ CTX-M eine weitere Verbreitung in E. coli sowohl im ambulanten Bereich als auch im Krankenhaus [33].

Exakte Daten zur Häufigkeit des 3MRGN- und 4MRGN-Phänotyps sind schwierig zu ermitteln, da in den publizierten Surveillance-Daten das Vorliegen kombinierter Resistenzen nur selten dargestellt ist. Es ist daher sinnvoll, für den 3MRGN-Phänotyp die Resistenz gegen Cephalosporine der 3. Generation oder einen ESBL-Phänotyp als Surrogat festzulegen.

Für den 4MRGN-Phänotyp kann die Resistenz gegen Carbapeneme als Surrogat gewählt werden. Vor dem Hintergrund, dass sowohl bei ESBL- als auch bei Carbapenemase-Stämmen sehr häufig eine Co-Resistenz gegenüber Fluorchinolonen vorliegt, erscheint dies gerechtfertigt [34-36].

Nach den Daten des European Antimicrobial Resistance Surveillance Systems (EARS) für Deutschland (ausgewertet wurden zwischen 806 und 2523 Isolate) ist die Resistenz gegenüber Cephalosporinen der 3. Generation von 1,7 \% im Jahr 2005 auf 8,2 \% im Jahr 2009 angestiegen (http://ecdc.europa.eu/en/ activities/surveillance/EARS-Net/database/Pages/table_reports.aspx, Zugang 05.11.2011). Auf den am Surveillance System of Antibiotic Use and Bacterial Resistance in Intensive Care Units (SARI) beteiligten deutschen Intensivstationen stieg die Resistenz gegenüber Cephalo- sporinen der 3. Generation von 1,2 \% im Jahr 2001 auf 19,7 \% im Jahr 2008 an [37].

Gardam et al. untersuchten $287 \mathrm{~Pa}$ tienten, die eine Organtransplantation durchliefen. Von diesen waren $16 \mathrm{mit}$ einem ESBL-Bildner kolonisiert. Der kolonisierende Stamm war bei 2 Patienten identisch, die übrigen 14 Isolate waren genotypisch unterschiedlich, das heißt, es handelte sich um eine polyklonale Verbreitung in der Endemiesituation [38]. Auch in einer Untersuchung an 96 ESBL-bildenden E. coli Blutkulturisolaten aus 13 spanischen Krankenhäusern waren die meisten Isolate genotypisch unterschiedlich [39].

Mendonca et al. [40] untersuchten 119 ESBL-bildende E. coli (3MRGN) aus 9 portugiesischen Krankenhäusern und bei ambulanten Patienten. $56 \%$ der Stämme waren außerhalb des Krankenhauses erworben. $75 \%$ der Isolate formten Cluster, bei denen Übertragungen im ambulanten Bereich, über die Notfallstationen und Praxen angenommen wurden. Hier lag eine oligoklonale Epidemiologie vorwiegend außerhalb des Krankenhauses vor.

In einer spanischen Untersuchung zeigte sich zudem, dass die Rate der Kolonisierung mit ESBL-bildenden E. coli bei ambulanten Patienten zwischen 1991 und 2003 von $1 \%$ auf $5 \%$ anstieg [41].

Die Zunahme ESBL-bildender E. coli wird somit auf die Verbreitung spezifischer Klone oder klonaler Gruppen und epidemischer Plasmide zurückgeführt $[33,42]$.

Carbapenemase-positive E. coli Isolate wurden in Deutschland bisher nur vereinzelt nachgewiesen [43]. So wurden im Jahr 2010 im Nationalen Referenzzentrum (NRZ) für gramnegative Krankenhauserreger neun Stämme mit Carbapenemasen der OXA-48 Gruppe, fünf Stämme mit VIM-1 sowie je zwei Stämme mit KPC oder NDM nachgewiesen [43]. Die klassische Übertragungsweise insbesondere bei ambulant erworbenen E. coli-Infektionen ist der fäkal-orale Weg.

Demgegenüber hat sich der als NDM bezeichnete und vom indischen Subkontinent ausgehende hochresistente E. coli insbesondere in Großbritannien ausgebreitet, Einzelfälle wurden jedoch auch 
aus Deutschland berichtet [44]. Die klassische Übertragungsweise insbesondere bei ambulant erworbenen, NDM-E. co$l i$ Infektionen in Indien war ebenfalls der fäkal-orale Weg und es zeigte sich eine weite Verbreitung des Resistenzgens in der Umwelt $[45,46]$.

Der nationale EHEC/HUS-Ausbruch im Jahr 2011, bei dem der enterohämorrhagische E. coli Ausbruchsstamm ein ESBL war, zeigte, dass die Übertragungsweise ganz überwiegend über kontaminierte Nahrungsmittel, vereinzelt durch Kontakte im häuslichen Umfeld und nur im Ausnahmefall "nosokomial“ erfolgte $[47,48]$.

Die Verbreitung antibiotikaresistenter E. coli erfolgt im hohen Maße außerhalb von Heimen und Einrichtungen, die Patienten stationär oder ambulant betreuen.

\subsubsection{Klebsiella spp.}

K. pneumoniae gehört mit einem Anteil von $6,7 \%$ und $10,1 \%$ zu den fünf häufigsten Erregern der bakteriellen Sepsis [49] bzw. der nosokomial erworbenen Pneumonie [50]. Die Literatur zu Klebsiellen bezieht sich überwiegend auf $K$. pneumoniae. Andere Klebsiella spp., wie z. B. K. oxytoca spielen eine deutlich untergeordnete Rolle, so dass diese Spezies in der Regel nicht gesondert aufgeführt wird.

Die Häufigkeit von Carbapenemasen bei K. pneumoniae unterscheidet sich in Deutschland von der Situation in anderen Ländern. Hierzulande ist OXA-48 die häufigste Carbapenemase gefolgt von KPC. Ferner kommen bei K. pneumoniae auch noch Metallo-Betalaktamasen vom Typ VIM, NDM und GIM vor.

Exakte Daten zur Häufigkeit des 3MRGN- und 4MRGN-Phänotyps sind schwierig zu ermitteln, da in den publizierten Surveillance-Daten das Vorliegen kombinierter Resistenzen nur selten dargestellt ist. Es ist daher sinnvoll, für den 3MRGN-Phänotyp die Resistenz gegen Cephalosporine der dritten Generation oder einen ESBL-Phänotyp als Surrogat festzulegen.

Für den 4MRGN-Phänotyp kann die Resistenz gegen Carbapeneme als Surrogat gewählt werden. Vor dem Hintergrund, dass sowohl bei ESBL- als auch bei Carbapenemase-Stämmen sehr häufig eine Co-Resistenz gegenüber Fluorchinolonen vorliegt, erscheint dies gerechtfertigt.

Nach den EARS-Daten für Deutschland (ausgewertet wurden zwischen 104 und 471 Isolate) ist die Resistenz gegenüber Cephalosporinen der 3. Generation von $6,73 \%$ im Jahr 2005 auf $13,16 \%$ im Jahr 2009 angestiegen. Aufgrund starker Schwankungen in den Angaben für die dazwischen liegenden Jahre bleibt unklar, ob es sich um einen signifikanten Anstieg handelt. Auf den am SARISurveillanceprogramm beteiligten deutschen Intensivstationen stieg die Resistenz gegenüber Cephalosporinen der dritten Generation von 2,2\% im Jahr 2000 auf 16,8 \% im Jahr 2010 an. In der Studie der Paul-Ehrlich-Gesellschaft (PEG) aus dem Jahr 2007 lag der Anteil der Resistenzen gegenüber Cefotaxim mit 10,6 \% höher als im Jahr 2001 mit 7,8 \%. Die Resistenz gegenüber Cefotaxim lag laut Antibiotikaresistenz-Surveillance-System des RKI (ARS) im Jahr 2008 bei 10,7 \%, im Jahr 2009 bei 12,2\% und 2010 bei $11,8 \%$ (https://ars.rki.de; Zugang: 27.07.2011).

Laut EARS-Daten gab es im Jahr 2009 unter 467 untersuchten Stämmen keine, die intermediär oder resistent gegenüber Carbapenemen getestet wurden. Nach den SARI-Daten waren im Jahr 2010 auf den beteiligten Intensivstationen 0,5\% und $0,6 \%$ resistent gegenüber Imipenem bzw. Meropenem. Ein signifikanter Anstieg im Vergleich zu den Vorjahren stellte sich nicht dar. Im Jahr 2007 zeigten sich in der PEG-Studie keine Resistenzen gegen Imipenem oder Meropenem. Laut ARS lag die Resistenz gegenüber Imipenem im Jahr 2010 bei $0,1 \%$. Die steigende Anzahl an Einsendungen Carbapenem-resistenter Isolate, beispielsweise an das NRZ für gramnegative Krankenhauserreger, deutet darauf hin, dass sich Deutschland gerade am Beginn einer Entwicklung befindet, bei der es zur Zunahme Carbapenem-resistenter K. pneumoniae-Stämme kommt. In einer internationalen Surveillance-Studie, in der $E$. coli und Klebsiella spp.-Isolate aus Lateinamerika, USA und Europa zusammengefasst wurden, zeigte sich ein signifikanter Anstieg der Carbapenemase-tragen- den Isolate von 1,2 \% im Jahr 2007 auf 1,8 $\%$ in 2009 [51].

Sowohl K. pneumoniae mit dem 3MRGN- als auch mit dem 4MRGNPhänotyp werden in der überwiegenden Zahl der Fälle im Krankenhaus übertragen. Eine Übertragung im ambulanten Bereich ist für NDM-produzierende K. pneumoniae beschrieben [52, 53], jedoch derzeit noch eine Rarität.

Es gibt zahlreiche Beschreibungen von Ausbrüchen mit klonal identischen Isolaten [54-69] im jeweiligen Krankenhaus. Es finden sich jedoch kaum Hinweise auf eine Ausbreitung von 3MRGN Klebsiella spp. zwischen verschiedenen Institutionen. Die Carbapenemasen KPC-2 und KPC-3 finden sich jedoch weltweit in einem bestimmten K. pneumoniae-Klon (ST258) [70].

Zusammenfassend lässt sich für die Resistenzen gegen Cephalosporine der dritten Generation (als Surrogat für 3MRGN) über die letzten zehn Jahre eine deutliche Zunahme zeigen.

Resistenzen gegen Carbapeneme (als Surrogat für 4MRGN) stellen sich in deutschen Surveillance-Systemen aufgrund ihrer Seltenheit praktisch noch nicht dar. Eine signifikante Zunahme lässt sich jedoch in internationalen Surveillance-Studien zeigen.

Das Auftreten von 4MRGN K. pneumoniae-Isolaten ist derzeit in Europa noch kein Problem in der ambulanten Versorgung, sondern manifestiert sich nahezu ausschließlich in Krankenhäusern. Die Verbreitung erfolgt hauptsächlich klonal.

Die Verbreitung von $3 M R G N$ ist in lokalen Ausbrüchen in der Regel klonal, es ist jedoch unklar ob eine überregionale Verbreitung von $3 M R G N$ K. pneumoniae, die mit Einrichtungen der stationären oder ambulanten Patientenversorgung assoziiert ist, erfolgt.

\subsubsection{Enterobacter spp.}

Enterobacter spp. sind in den USA achthäufigster Erreger nosokomialer Infektionen und machen $5 \%$ aller im Krankenhaus erworbenen Infektionen aus [71]. In Deutschland sind sie für 6,5 \% aller nosokomialen Infektionen auf Intensivstationen verantwortlich [72]. Enterobacter spp. verursachen insbesonde- 
re Pneumonien, Septikämien, Wundund Harnwegsinfektionen und bei Neugeborenen auch Meningitiden [73]. Erst in den letzten Jahrzehnten wurden Enterobacter vor allem als Verursacher nosokomialer Infektionen wahrgenommen [74].

Eine Abfrage der Outbreak-Datenbank (www.outbreak-database.com, Zugang 28.07.2011) ergab 90 publizierte Ausbrüche mit Enterobacter spp.. Die Ausbrüche waren zunehmend verursacht durch multiresistente Enterobacter spp.. Dies waren vor allem ESBL-produzierende Enterobacter, selten auch Carbapenemase produzierende E. cloacae [75].

Die Resistenz gegenüber Cephalosporinen der 3. Generation basiert bei Enterobacter spp. entweder auf einer $\mathrm{Mu}$ tation, die eine Überexpression der bei diesen Spezies natürlicherweise chromosomal-kodierten AmpC-Betalaktamase verursacht, oder auf ESBL.

Eine Carbapenem-Resistenz kann zwei unterschiedliche molekulare Grundlagen haben:

a) eine Kombination aus ESBL oder

AmpC-Betalaktamasen zusammen mit einem Porinverlust kann zu einer Resistenz gegenüber Carbapenemen führen;

b) die Carbapenem-Resistenz kann durch Carbapenemasen bedingt sein. Die häufigste Carbapenemase bei E. cloacae in Deutschland war im Jahr 2010 VIM-1 [43].

Die Resistenz von E. cloacae gegenüber Cephalosporinen der 3. Generation stieg im stationären Bereich in Deutschland über die letzten drei Jahre nicht an und lag bei $27 \%$ und bei $9 \%$ im ambulanten Bereich (Daten aus ARS); ResistenzDaten von deutschen Intensivstationen schwankten über die letzten 5 Jahre zwischen $34 \%$ und $40 \%$ (Daten aus SARI). Enterobacter-Isolate aus 11 Laboratorien in Deutschland zeigten, dass 4,2\% aller E. cloacae-Isolate $(\mathrm{n}=119)$ ESBL produzierten [76].

Einen Unterschied zu anderen Krankheitserregern stellt die große Heterogenität des E. cloacae Komplexes dar. Er besteht aus 13 genetischen Clustern, von denen neun mittlerweile als Spezies bzw. Subspezies beschrieben sind [77].
Enterobacter spp. haben darüber hinaus einen Selektionsvorteil, weil sie AmpC bilden. Ist AmpC durch eine Überproduktion in hohen Konzentrationen vorhanden, hydrolysiert es alle Cephalosporine und Penicilline und wird auch nicht durch $\beta$-Laktamaseinhibitoren gehemmt.

Klonale Ausbrüche sind selten. Eher sind Infektionen mit individuellen Erregern (endogene Infektionen) für die zunehmende Bedeutung des E. cloacae Komplexes verantwortlich [78].

In einer spanischen Arbeit wurden die E. cloacae-Stämme von 36 Patienten, die auf verschiedenen Stationen lagen, untersucht [79]. Die Stämme waren alle ESBL (SFO-1) positiv und nur noch Carbapenem empfindlich. Interessanterweise zeigte sich in der PCR bzw. PFGE, dass alle Stämme vom selben Klon stammten und dass eine klonale Ausbreitung - wahrscheinlich durch Transmission über Hände des medizinischen Personals - stattfand. Die Epidemiologie dieser bislang noch selten isolierten $\beta$-Laktamase SFO-1 ließ die Autoren Parallelen zu der oft klonalen Ausbreitung von Klebsiellen aufzeigen.

In einem israelischen Krankenhaus mit Zunahme von Imipenem-resistenten E. cloacae (bla $\mathrm{KPC}_{2}$ ) konnten 18 Stämme aus klinischen Kulturen genotypisiert werden; die Enterobacter-Stämme verteilten sich auf drei Klone: 11 Fälle zu Klon A, 5 zu Klon B und 2 zu Klon C [80].

Bisherige Erkenntnisse sprechen für vorwiegend endogene Infektionen mit individuellen Stämmen des E. cloacae Komplexes und einem nicht mit dem Krankenhaus assoziierten Verbreitungsweg. Trotz der großen Heterogenität von Enterobacter spp. kann die Ausbreitung jedoch im Rahmen von Ausbrüchen auch klonal erfolgen, $d$. h. eine Weiterverbreitung ist bei Lücken im Hygieneregime möglich.

\subsubsection{Andere Enterobakterien}

Weitere Spezies der Gattung der Enterobakterien, wie Proteus spp., Morganella morganii, Serratia spp. oder Citrobacter spp. führen deutlich seltener zu nosokomialen Infektionen. Serratia spp. gehört mit $2 \%$ bis $4 \%$ der Infektionen zu den häufigeren Erregern der nosoko- mialen Pneumonie [50]. Kürzlich wurde ein zunehmender Trend für gramnegative Mikroorganismen als Ursache der Katheter-assoziierten Sepsis beschrieben, wobei Serratia spp. 2,5\% und C. freundii, M. morganii und $P$. mirabilis jeweils $0,4 \%$ der Episoden $(n=1129)$ ausmachten [81]. Die oben genannten Spezies werden jedoch in der Regel bei der Darstellung infektionsepidemiologischer Daten zusammengefasst, so dass der Literatur keine genaueren Angaben zum Stellenwert der einzelnen Erreger zu entnehmen sind.

Im ARS-System des RKI (https://ars. rki.de; Zugang: 31.10.2011) macht $P$. mirabilis $3 \%$ der getesteten Mikroorganismen aus. C. freundii, P. vulgaris, $M$. morganii und $S$. marcescens stellen jeweils $0,4 \%$ bis $0,7 \%$ der Isolate. Die höchste Resistenz gegenüber Cephalosporinen der 3 . Generation wiesen Isolate von $C$. freundii (24\%) und M. morganii (15\%) aus der stationären Versorgung auf. C. freundii aus der ambulanten Versorgung waren mit 8,7 \% seltener resistent, während sich die Resistenz für M. morganii mit 12,3\% im ambulanten Bereich nicht wesentlich vom stationären Bereich unterschied. P. mirabilis und $S$. marcescens waren in $1,5 \%$ bzw. 2,7 \% der Isolate gegenüber den 3. Generations-Cephalosporinen resistent. In den USA wurde zwischen 1994 und 2004 eine Zunahme multiresistenter (definiert als Resistenz gegenüber 3. Generations-Cephalosporinen, Aminoglycosiden und Fluorchinolonen) C. freundii beobachtet, während der Anteil multiresistenter P. mirabilis gleich blieb [82].

Carbapenemasen wurden bei Proteus spp. und M. morganii in Deutschland noch nicht gefunden, jedoch wurden sie in S. marcescens und Citrobacter spp. in Einzelfällen in Deutschland nachgewiesen. Dabei wurden sowohl Carbapenemasen der OXA-48 Gruppe als auch Metallo-Betalaktamasen gefunden [43].

Serratien wurden mehrfach als Verursacher von Ausbrüchen nosokomialer Infektionen beschrieben, wobei in vielen Fällen eine klonale Verbreitung des Erregers nachgewiesen wurde (www.outbreak-database.com, Zugang 31.10.2011). In einem irischen Krankenhaus konnten Hejazi et al. das Vorherrschen eines Klons über acht Jahre nachweisen [83]. 
Proteus spp., Citrobacter spp. oder $M$. morganii sind selten als Verursacher von Ausbrüchen beschrieben.

Epidemiologische Untersuchungen im endemischen Setting zeigten kleinere Cluster klonaler Stämme dieser Spezies, jedoch keine eindeutige Dominanz einzelner Klone, die auf eine mit Einrichtungen des Gesundheitssystems zur stationären oder ambulanten Patientenversorgung oder Heimen-assoziierte Verbreitung hinweisen würden [84-86].

Das Auftreten von Carbapenemasen ist in den genannten Spezies noch selten, wobei in Europa Metallo-Carbapenemasen vorherrschen. Eine klonale Verbreitung Carbapenemase-tragender Stämme in einzelnen Krankenhäusern wurde beschrieben [87].

Daten zur Epidemiologie antibiotikaresistenter Isolate anderer, seltener nachgewiesener Enterobakterien (z. B. Proteus spp., M. morganii, Serratia spp. oder Citrobacter spp.) sind spärlich. Während für Serratien eine Persistenz einzelner Klone im Krankenhaus beschrieben ist, gibt es keine dringenden Hinweise darauf, dass eine Krankenhaus-assoziierte Verbreitung von Proteus spp., Citrobacter spp. oder M. morganii vorliegt.

\subsection{Nonfermenter}

\subsubsection{Pseudomonas aeruginosa}

$P$. aeruginosa ist ein häufiger Erreger nosokomialer Infektionen. Laut Daten des National Nosocomial Infections Surveillance system (NNIS) [88] war P. aeruginosa zwischen 1986-2003 der zweithäufigste Erreger nosokomialer Pneumonien, der dritthäufigste Erreger von Harnwegsinfektionen und lag an achter Stelle der Erreger der Sepsis [89].

Obgleich in den USA keine Zunahme des Anteils von Infektionen durch $P$. aeruginosa beobachtet wurde, zeigte sich eine signifikante Zunahme des Anteils antibiotikaresistenter Isolate [88]. So nahm der Anteil der Resistenz gegenüber Imipenem um $15 \%$, derjenige gegenüber Chinolonen um $9 \%$ und derjenige gegenüber 3 . Generations-Cephalosporinen um $20 \%$ zu. Der Anteil der Isolate, die gegen mindestens drei Antibiotika aus der Gruppe Imipenem,
Ciprofloxacin, Ceftazidim und Tobramycin resistent waren, stieg von $4 \%$ auf $14 \%$ [90].

In Europa nahm die Inzidenz der Bakteriämien durch $P$. aeruginosa zwischen 1997 und 2002 leicht zu (von 5,5\% auf 6,8 \%) [91]. Laut EARS waren im Jahr 200618 \% der P. aeruginosa-Isolate multiresistent, d.h. resistent gegenüber mindestens drei der Antibiotika aus den getesteten Wirkstoffen, bzw. Substanzklassen Piperacillin, Ceftazidim, Fluorchinolon, Aminoglycoside und Carbapeneme [92]. Im Jahr 2009 waren $16 \%$ der Isolate multiresistent, wobei Deutschland zu den 4 Ländern mit signifikantem Rückgang der Multiresistenz gehörte. Der Anteil multiresistenter Isolate lag in Deutschland bei 7,4 \% (http:// www.ecdc.europa.eu/en/publications/ Publications/1011_SUR_annual_EARS_ Net_2009.pdf, Zugang 08.09.2011).

Auf deutschen Intensivstation, die an SARI teilnahmen, lag der Anteil Imipenem-resistenter $P$. aeruginosa bei $25 \%$ und der der Ciprofloxacin-resistenten Isolate bei $16 \%$ ohne signifikante Veränderungen in den letzten Jahren [37]. Im Gegensatz zu Isolaten aus dem stationären Bereich finden sich bei Isolaten aus dem ambulanten Bereich deutlich niedrigere Resistenzraten gegenüber Imipenem $(5,4 \%$ ambulant versus $12,2 \%$ stationär) und Ceftazidim (2,7 \% ambulant versus $8,5 \%$ stationär). Resistenzraten gegenüber Ciprofloxacin, welches auch im ambulanten Bereich häufig eingesetzt wird, unterschieden sich hingegen kaum (13,5 \% ambulant versus $15,7 \%$ stationär) (https://ars.rki.de, Zugang 10.09.2011).

$P$. aeruginosa ist in der Lage, verschiedenste Resistenzmechanismen zu erwerben und zu exprimieren. Neben spezifischen Mechanismen, wie der Produktion verschiedener $\beta$-Laktamasen oder Carbapenemasen, können bestimmte Proteine oder Mechanismen verändert sein, die für den Transport der Antibiotika in die Zelle verantwortlich sind (Outer Membrane Proteine oder multidrug efflux Systeme). Bei $P$. aeruginosa stehen Resistenzmechanismen, die auf chromosomalen Mutationen beruhen, als Ursache einer Multiresistenz im Vordergrund. Unter den Isolaten, die im Jahr 2010 in das NRZ für gramnegative Kranken- hauserreger eingeschickt wurden, ließ sich beispielsweise eine CarbapenemResistenz in über $70 \%$ der Isolate durch solche Mechanismen erklären [43]. Dabei kann es zu einer Überexpression der intrinsischen AmpC-Betalaktamase oder verminderter Expression von Porinen als Ursache von Resistenzen gegen $\beta$-Laktame einschließlich Carbapenemen kommen. Mutationen in den Genen für Gyrase und Topoisomerase IV können eine Resistenz gegen Fluorchinolone bedingen.

Die Überexpression von Effluxpumpen kann eine Resistenz gegen Antibiotika aus unterschiedlichen Klassen verursachen. Letztlich können $P$ aerugino$s a$-Stämme durch Akkumulation unterschiedlichster chromosomaler Mutationen gegen alle klinisch einsetzbaren Antibiotika resistent werden. Daneben kommen erworbene Resistenzgene vor, die Resistenzen u. a. gegen Carbapeneme oder Aminoglykoside vermitteln. Die bei P. aeruginosa vorkommenden Carbapenemasen gehören ganz überwiegend in die Klasse der Metallo- $\beta$-Laktamasen. In Deutschland handelt es sich dabei hauptsächlich um VIM-2 sowie diverse IMPVarianten.

Für $P$. aeruginosa wurde eine epidemische Populationsstruktur angenommen, das heißt, dass eine begrenzte Anzahl von Klonen aus einer großen Anzahl von Genotypen heraus weltweit dominant ist [93]. Dies wird durch Daten zur Verbreitung Carbapenem-resistenter P. aeruginosa-Isolate unterstützt, die zeigten, dass die Verbreitung VIM- und IMP-Carbapenemase tragender Stämme auf wenige klonale Gruppen zurückgeführt werden kann [94-96]. Auch Untersuchungen in einzelnen Kliniken oder Regionen zeigen, dass in der endemischen Situation einzelne Stämme vorherrschen und verbreitet werden können [97, 98]. Andererseits wurden auch Situationen beschrieben, in denen die Epidemiologie durch genetische Heterogenität gekennzeichnet war $[99,100]$. Von den über 900 verzeichneten multilocus sequence typing (MLST) Typen von $P$. aeruginosa scheinen nur etwas mehr als 10 Typen pandemische Eigenschaften, mit Nachweisen über mehrere Jahre in verschiedenen Ländern zu haben [94]. 
Die Verbreitung resistenter Stämme durch Verlegung von Patienten wurde beschrieben [101].

Die Epidemiologie von P. aeruginosa ist komplex und nicht vollständig verstanden. Die Ausbreitung multiresistenter Stämme im Krankenhaus wurde beschrieben und ist wahrscheinlich durch einen hohen Selektionsdruck begünstigt.

\subsubsection{Acinetobacter baumannii}

A. baumannii gehört seit Jahren weltweit zu den 6 häufigsten Erregern der nosokomialen und der beatmungsassoziierten Pneumonie [50]. Es existieren nur wenige Daten zu Trends in der Häufigkeit von A. baumannii als Infektionserreger. Eine relevante Zunahme endemischer Nachweise ist jedoch nicht dokumentiert [102]. Andererseits hat die Häufigkeit von publizierten Berichten über Ausbrüche, die durch A. baumannii verursacht wurden, in den letzten Jahren erheblich zugenommen. Während im Jahr 2000 über 7 Ausbrüche berichtet wurde [103-109], waren es im Jahr 2010 bereits 16 Publikationen [110125]. Bei den meisten der beschriebenen Ausbrüche handelt es sich um solche, die durch Carbapenem-resistente Isolate verursacht wurden. Carbapenem-Resistenz bei Acinetobacter wurde zunächst in den 1980er Jahren beschrieben [126]. Carbapenem-Resistenz bei A. baumannii ist fast immer durch Carbapenemasen bedingt. Mit Abstand am häufigsten tritt weltweit und in Deutschland die OXA-23 Carbapenemase auf. Daneben finden sich in Deutschland auch Carbapenemasen aus der OXA-40 oder OXA58 Gruppe. Von zunehmender Bedeutung bei A. baumannii ist die MetalloBetalaktamase NDM. Neben diesen erworbenen Carbapenemasen als Ursache einer Carbapenem-Resistenz kann bei A. baumannii auch die intrinsische Betalaktamase OXA-51 durch vorgeschaltete genetische Elemente wie ISAbal überexprimiert werden und eine CarbapenemResistenz bedingen.

In verschiedenen Publikationen wird von einer Zunahme des Anteils Carbapenem-resistenter Isolate berichtet. Bei einer Analyse von A. baumannii-Isolaten deutscher Universitätskliniken zwischen
2002 und 2006 zeigte sich eine Zunahme der Multiresistenz, definiert als Resistenz gegenüber mindestens 3 der zur Therapie empfohlenen Antibiotikaklassen (Acylureidopenicilline, Carbapeneme, Fluorchinolone, Cephalosporine, Aminoglycoside, Cotrimoxazol) von $2 \%$ auf $8 \%$ [127]. Der Anteil an Carbapenem-resistenten A. baumannii bei Infektionserregern auf deutschen Intensivstationen schwankte laut SARI zwischen $1 \%$ und $20 \%$ mit ansteigendem Trend zwischen 2001 und 2008 [37].

Eine vergleichende Untersuchung weltweit gesammelter A. baumannii-Isolate zeigte, dass nur wenige klonale Linien kursieren. Das Vorkommen unterschiedlicher Resistenzgene in einzelnen klonalen Linien weist darauf hin, dass die Resistenzgene erst nach bzw. während der internationalen Verbreitung der Klone aufgenommen wurden [128]. Fehlende Übereinstimmungen bei vergleichenden Untersuchungen von Infektionsisolaten und möglichen Umgebungsquellen, z. B. Wasser oder Staub sowie eine ergebnislose Suche nach vorbestehender Kolonisation der Patienten bei Aufnahme wiesen darauf hin, dass Besiedelung und Infektion mit Carbapenem-resistenten A. baumannii im Rahmen der medizinischen Behandlung erworben wurde [129]. In einer spanischen Studie waren Imipenem-resistente A. baumannii signifikant häufiger epidemisch (von mehr als einem Patienten isoliert) als sensible Isolate [130].

Die weltweite Ausbreitung und Zunahme Carbapenem-resistenter A. baumannii-Klone (4MRGN) ist am ehesten als ein Problem, das mit der stationären oder ambulanten Versorgung von Patienten assoziiert ist, anzusehen. 3MRGN A. baumannii sind weniger gut untersucht und die Verbreitung über Einrichtungen des Gesundheitssystems ist nicht gesichert.

\section{Rationale Ableitung für die Durchführung erweiterter Hygienemaßnahmen bei Infektionen oder Besiedelung mit multiresistenten gramnegativen Stäbchen}

\subsection{Enterobakterien}

\subsubsection{Escherichia coli}

Reproduktionsrate $^{1}$ : In der endemischen Situation wurden Aufnahme- und Entlassungs-Screening auf ESBL-tragende E. coli (ESBL E. coli) durchgeführt. Harris et al. [131] screenten 1806 Patienten bei Aufnahme und Entlassung auf einer Intensivstation auf ESBL E. coli. 74 Patienten waren mit ESBL E. coli bei Aufnahme kolonisiert, 23 Patienten erwarben nosokomial einen ESBL E. coli. Der Nachweis von 14 unterschiedlichen PFGE Typen spricht für ein polyklonales Geschehen. In 3 von 23 Fällen (= $13 \%$ ) halten die Autoren eine Übertragung für plausibel (entspricht 3 sekundäre Fälle auf 74 Patienten oder einer Reproduktionsrate von 0,04). Die gleiche Autorengruppe beschrieb ein größeres gescreentes Kollektiv ( $n=5209)$ ebenfalls bei Aufnahme auf eine Intensivstation im Zeitraum 2001 bis 2005. 33 Patienten (0,6\%) erwarben einen ESBL E. coli bzw. Klebsiellen während ihres stationären Aufenthaltes [132].

Kohlenberg et al. beschrieben 1330 ESBL E. coli Fälle im Jahr 2008 in 39 deutschen Krankenhäusern, davon waren 60,5\% der Fälle ambulant erworben, $39,5 \%$ wurden erst nach einem stationären Aufenthalt von mehr als 48 Stunden nachgewiesen [133].

Fankhauser et al. untersuchten 177 Kontaktpatienten von 31 ESBL-Bildner-tragenden Patienten im endemischen Setting über einen Zeitraum von 8 Monaten. Bei 8 Kontaktpatienten wurde ebenfalls ein ESBL-Bildner nachgewiesen entsprechend einer Transmissionsrate von 0,9/1000 Expositionstagen,

\footnotetext{
1 Unter Reproduktionsrate wird im Rahmen der Ausführungen die Zahl der mit einem Indexfall in Zusammenhang stehenden sekundären Fälle verstanden, unabhängig davon, wie der mögliche Übertragungsweg ist.
} 
bzw. 0,26 sekundären Fällen pro positiven Patienten. In 3 Fällen lag ein identisches PFGE Muster vor, in 2 Fällen (beide $E$. coli) wurde ein identisches $\beta$-Laktamase-Gen nachgewiesen. Die mediane Kontaktzeit für die positiven Kontaktpatienten lag bei 18 Tagen [134].

Willemsen et al. untersuchten für einen Zeitraum von 6 Monaten die nosokomiale Übertragung für hochresistente Enterobakterien in 18 holländischen Krankenhäusern. Die Reproduktionsrate für alle Bakterienspezies lag zwischen 0 und 0,2 , wobei von 892 Isolaten 305 auf $E$. coli entfielen, von denen wiederum 57 \% ESBL E. coli waren. $66 \%$ der Isolate traten während der Studiendauer nur einmalig auf und unterstützen somit ebenfalls die Annahme einer polyklonalen Verbreitung [135].

Antibiotikaresistente E. coli haben eine niedrige Reproduktionsrate im Krankenhaus, die deutlich < 1 einzuschätzen ist.

Klinische Manifestationsrate ${ }^{2}$ : Für EHEC wurde gezeigt, dass bereits geringe Keimzahlen von 10-100 Erregern für eine Infektion mit $E$. coli ausreichen können (http://www.rki.de/cln_160/nn_467482/ DE/Content/Infekt/EpidBull/Merkblaetter/Ratgeber__EHEC.html, Zugang 10.11.2011), wobei zu berücksichtigen ist, dass hier ein spezieller Pathogenitätsfaktor vorliegt und diese Daten nicht uneingeschränkt auf alle $E$. coli übertragen werden können.

Die Infektionsrate liegt bei den vorliegenden Untersuchungen, die allerdings meist geringe Fallzahlen aufweisen, bei etwa $30 \%$ und somit in einem Rahmen, wie er auch für MRSA- und VRE-Patienten beschrieben wird.

Die größte Untersuchung in einer Endemiesituation stammt von Harris et al. Während ihres stationären Aufenthaltes wurde bei 35 von 117 Patienten (30\%), die mit ESBL-bildendem E. coli oder Klebsiellen besiedelt waren, der identi-

\footnotetext{
2 Unter klinischer Manifestationsrate wird im Rahmen der Ausführungen die Zahl der besiedelten Patienten verstanden, die im Verlauf einer stationären Behandlung eine Infektion erleiden.
}

sche Erreger auch aus einem klinischen Material nachgewiesen [132].

Kim et al. beobachteten 16 Patienten einer neurochirurgischen Intensivstation, deren Atemwege mit ESBL-bildendem E. coli besiedelt waren, über einen Zeitraum von 3 Monaten. Es trat keine Infektion auf [136]. Von 44 Pflegeheimbewohnern waren 24 (55\%) mit einem ESBL-bildendem E. coli kolonisiert. Acht dieser Patienten (33\%) entwickelten eine Harnwegsinfektion [137]. Moissenet et al. [138] beschrieben einen Ausbruch auf einer neonatologischen Intensivstation. Innerhalb von 4 Wochen waren 26 von 59 gescreenten Neugeborenen (44\%) mit ESBL-bildendem E. coli besiedelt. Eine Infektion (Meningitis) trat nur bei einem der Kinder auf.

Ebenfalls auf einer neonatologischen Intensivstation beobachteten TschudinSutter et al. eine Kolonisation mit ESBLbildendem $E$. coli bei 3 von 6 gescreenten Neugeborenen sowie 2 von 31 (7\%) Mitarbeitern ohne dass ein Infekt auftrat [136]. Kola et al. beschrieben in ihrer Beobachtung von 102 Patienten mit Besiedelung durch ESBL-Bildner 39 Infektionen, zumeist Wundinfektionen [139]. Von 69 Patienten mit Organtransplantation, die mit MRGN-Enterobakterien ohne Differenzierung zwischen E. co$l i$, Klebsiellen, Enterobacter oder Citrobacter kolonisiert waren, entwickelten 6 Patienten (9\%) eine Infektion [38]. In einer weiteren Studie ohne Differenzierung zwischen einzelnen Spezies entwickelten von 413 Hochrisiko-Patienten, die rektal mit ESBL-bildenden Enterobakterien besiedelt waren, 35 (8,5\%) eine Bakteriämie durch ESBL-Bildner [140]. Von 17.459 Patienten, bei denen bei Aufnahme kein ESBL-Bildner nachgewiesen wurde, entwickelten 4 Patienten eine Bakteriämie verursacht durch ESBL-Bildner (0,002 \%).

In einer weiteren Untersuchung von 18 mit ESBL E. coli besiedelten Patienten kam es bei 7 Patienten (39 \%) zu einer Infektion. Drei dieser Patienten, die alle eine schwere Grunderkrankung hatten, verstarben [141].

Aus diesen Untersuchungen ergibt sich, dass in der endemischen Situation unter mit multiresistenten E. coli besiedelten
Risikopatienten bis zu 1/3 im Krankenhaus eine Infektion erleiden können.

Mortalität: Eine Meta-Analyse von 16 Studien [142] ermittelte für Bakteriämien, die durch ESBL-positive im Vergleich zu ESBL-negativen Enterobakterien verursacht waren, ein erhöhtes gepooltes relatives Risiko an der Infektion zu versterben (RR 1,85; 95 \% CI 1,39-2,47; $\mathrm{p}<0,001)$. Die Autoren führten dies vor allem auf die verzögerte Einleitung einer effektiven antibiotischen Therapie zurück (RR bei verzögerter Therapie 5,56; $95 \%$ CI 2,94-10,51; $\mathrm{p}<0,001)$. Auch in einer retrospektiven Untersuchung von Wang et al. [143] war eine nicht adäquate antibiotische Therapie ein signifikanter Risikofaktor für eine erhöhte $14 \mathrm{Ta}$ ge Mortalität bei Bakteriämie durch ESBL-Bildner (OR 11,3; 95 \%CI 1,7-72,8; $\mathrm{p}=0,011$ ).

Rodriguez-Bano analysierte 96 nosokomiale E. coli Bakteriämien durch ESBL-Bildner. Resistenz gegen mehr als drei Antibiotika neben Penicillinen und Cephalosporinen war ein Risikofaktor zu versterben $(\mathrm{OR}=6,5 ; 95 \% \mathrm{CI}=1,4-30,0)$. Keines der Isolate war Carbapenem-resistent. Eine ungeeignete empirische Antibiotikatherapie war in dieser Studie kein Risikofaktor für erhöhte Sterblichkeit [137]. Ahmed et al. [144] verglichen nosokomiale Bakteriämien in einem ägyptischen Krankenhaus. Dort verstarben $76 \%$ der Patienten mit ESBL-bildenden E. coli bzw. Klebsiellen Bakteriämie gegenüber $17 \%$ der Patienten, die eine Bakteriämie mit ESBL-negativen E. coli bzw. Klebsiellen aufwiesen.

Arnan et al. [145] untersuchten 217 Neutropenie-Episoden bei 162 hämatologischen Patienten. In 29 \% der Episoden wurde eine fäkale Kolonisation mit polyklonalen ESBL-positiven E. coli nachgewiesen. Kolonisation mit ESBL-positiven $E$. coli hatte in diesem Kollektiv keinen negativen Effekt auf die Verweildauer im Krankenhaus oder die Sterblichkeit.

Die reine Besiedlung mit $3 M R G N$ E. coli ist nach bisherigen Erkenntnissen nicht mit einem ungünstigem klinischen Verlauf und Behandlungserfolg (Outcome) assoziiert, während insbesondere schwere Infektionen (Sepsis) mit einer erhöh- 
ten Mortalität gegenüber empfindlichen Stämmen verbunden sind. Zur Abschätzung des Outcomes von $4 M R G N$ E. coli im Vergleich zu empfindlichen Stämmen liegen bisher keine ausreichenden Daten vor.

\section{Reservoire und Übertragungswege:} Für ESBL-bildende E. coli sind unterschiedliche Reservoire außerhalb des Krankenhauses beschrieben. Hierzu gehören Trinkwasser bei ungenügender Aufbereitung, Lebensmittel, lebensmittellproduzierende Betriebe, Tierarztpraxen und Haustiere [146-150].

Bei der molekularepidemiologischen Aufarbeitung CTX-M positiver ESBL E. coli Ausbruchs-Stämme wurde eine klonale Ausbreitung für Kanada [151], Frankreich [152], Israel und Japan [153] beschrieben, nicht jedoch für Spanien [145] und Italien [154]. In Großbritannien fanden sich sowohl oligoklonale als auch polyklonale Verbreitungswege [155]. Vereinzelt wurden Punktquellen im Krankenhaus als Ausgangspunkt für ESBL E. coli-Ausbrüche identifiziert. So wiesen Kim et al. den Ausbruchsstamm im Aufbewahrungsfach für Absaugkatheter einer Intensivstation nach [156]. Dennoch kommt der Kontamination von Oberflächen z. B. im Patientenzimmer nur eine untergeordnete Rolle zu [157]. Auch in Ausbruchssituationen wurden ESBL-bildende E. coli zumeist nicht in Umgebungsabklatschen angezüchtet [158, 159].

ESBL-positive E. coli wurden jedoch mehrfach auf den Händen medizinischen Personals nachgewiesen $[136,156]$. Die intestinale Kolonisation als Quelle für eine Verbreitung ist häufig anzunehmen. March et al. [160] fanden bei 41,4\% der Bewohner sowie bei 11,6 \% des medizinischen Personals einer italienischen Langzeitpflegeeinrichtung eine Kolonisation mit ESBL-bildenden E. coli. Ähnliche Zahlen finden sich zur intestinalen Kolonisation mit ESBL-bildenden E. coli von $41 \%$ der Bewohner einer Langzeitpflegeeinrichtung in Nordirland [161]. Ausgehend von der Kolonisation kann es zur Übertragung von Person zu Person kommen. In einer Studie an $54 \mathrm{~Pa}$ tienten mit ambulant erworbener ESBL E. coli-Harnwegsinfektion war das Ko- lonisationsrisiko für Familienmitglieder im gleichen Haushalt 16fach erhöht, für Familienmitglieder in getrennt lebendem Haushalt 6fach [162].

Die Übertragung von MRGN E. coli erfolgt somit in erster Linie durch Kontakt mit Lebensmitteln oder MRGN E.coliTrägern bei Nichteinhaltung von Basishygienemaßnahmen.

Risikofaktoren: Mehrere Studien identifizierten eine vorangegangene Antibiotikatherapie als Risikofaktor für die Besiedlung mit ESBL-bildenden E. coli [39, 132, 145, 163, 164]. Klassische Risikofaktoren für den Erwerb multiresistenter Pathogene wie Immunsuppression nach Organtransplantation [39], langer Krankenhausaufenthalt [39] oder Fremdkörper (Dauerkatheter) $[164,165]$ wurden ebenfalls beschrieben. Risikofaktoren, die sich am ehesten durch den Konsum kontaminierter Nahrungsmittel ergeben, sind Auslandsreisen in Hochendemiegebiete wie z. B. nach Indien (acquisition rate $24 \%$ [166]) oder der Verzehr von Mahlzeiten außerhalb des eigenen Haushalts [162].

Als Risikofaktor für eine erhöhte Inzidenz nosokomialer Fälle mit Nachweis von ESBL-Bildnern fand sich eine Überbelegung für die Allgemeinstationen oder der Langzeitaufenthalt auf Intensivstationen [167].

Ebenso wurde der Aufenthalt in einem Hochendemiegebiet oder die Hospitalisierung in einem Krankenhaus außerhalb der Schweiz als Risikofaktor identifiziert [134]. Infektion oder Kolonisation mit NDM-Carbapenemase-bildenden E. coli (4MRGN) war eng mit Aufenthalten und medizinischen Maßnahmen in Indien oder Pakistan assoziiert $[44,45,168]$.

Ein Zusammenhang zwischen Besiedelungs- oder Infektionsort und dem Risiko einer Weiterverbreitung des Erregers wurde in keiner Untersuchung beschrieben.

Neben patienteneigenen Risikofaktoren sind die Aufnahme durch die Nahrung und eine Antibiotikatherapie die stärksten Risikofaktoren für den Erwerb eines $3 M R G N$ E. coli. $4 M R G N$ E. coli werden derzeit durch Aufenthalte in Endemiegebieten nach Deutschland importiert.

- Die Kommission empfiehlt:

- für 3MRGN E. coli in Risikobereichen, in denen Patienten mit erhöhter Infektionsgefahr gepflegt werden, Maßnahmen zur Prävention festzulegen und durchzuführen, die in erster Linie dem Schutz der nicht besiedelten Patienten dienen (Kat II).

- für 3MRGN E. coli in Bereichen, in denen kein erhöhtes Risiko für die Patienten besteht, eine Infektion zu erleiden, in der endemischen Situation keine über die Basishygienemaßnahmen hinausgehenden Maßnahmen durchzuführen (Kat II).

- für 4MRGN E. coli aufgrund der stark limitierten therapeutischen Möglichkeiten Maßnahmen zur Prävention für alle Krankenhausbereiche festzulegen und durchzuführen (Kat II).

\subsubsection{Klebsiella spp.}

Reproduktionsrate: Im Rahmen von Ausbrüchen, in denen Patienten als Reservoir angenommen wurden, waren 2 bis 3 Patienten pro Monat neu infiziert worden (www.outbreak-database.com, Zugang 02.11.2011), wobei die Gesamtzahl der suszeptiblen Patienten unbekannt ist. Einige der beschriebenen Ausbrüche betreffen jedoch auch große Zahlen von Patienten in kürzeren Zeiträumen [169-172], wobei zum Teil Punktquellen aus der Umgebung der Patienten die Ursache des Ausbruches waren $[169,170]$. In der endemischen Situation fanden Martins et al. eine Inzidenz der Besiedelung mit ESBL-produzierenden Klebsiella spp. von 5,8/1000 Patiententage, wobei keine Übertragung nachgewiesen wurde [173]. Willemsen und Mitarbeiter fanden in zwei Untersuchungen aus den Jahren 2008 und 2011 Reproduktionsraten für multiresistente gramnegative Stäbchen von 0,05 bzw. 0,07 (d.h. einen Sekundärfall auf 14 bis 20 Indexpatienten), wobei der Anteil von Klebsiellen an den Erregern nicht spezifiziert wurde $[135,174]$.

In einer deutschen Universitätsklinik wurden in einem 3-Jahreszeitraum zwei Übertragungen von $K$. pneumoniae bei 
40 Indexpatienten identifiziert (Reproduktionsrate 0,05) [139].

Die Reproduktionsrate von multiresistenten Klebsiella spp. ist in der Regel niedrig. Bestimmte Stämme können jedoch mit höheren Reproduktionsraten einhergehen und Ausbrüche verursachen.

Klinische Manifestationsrate: Der Anteil an Infektionen durch Carbapenemase-positive K. pneumoniae bezogen auf alle Patienten mit Nachweis einer Carbapenemase-positiven $K$. pneumoniae beträgt gemäß mehrerer Untersuchungen $70 \%$ [56], 76,9\% [175] oder 80,9\% [176]. In Studien, in denen systematische Surveillance-Kulturen erfolgen, war der Anteil an Infektionen geringer und lag bei $14 \%$ [54] oder 38,1\% [63].

Es wird allgemein angenommen, dass eine Kolonisation in den meisten Fällen einer Infektion vorausgeht. So konnte bei Bakteriämien durch Carbapenemase-tragende K. pneumoniae in einer Studie in der Hälfte der Fälle eine vorhergehende Kolonisation nachgewiesen werden [177].

In einem lebensmittelassozierten Ausbruch von ESBL-bildenden K. pneumoniae erlitten $22,4 \%$ der kolonisierten Personen eine Infektion (71 \% eine Harnweginfektion, und jeweils $14 \%$ Wundinfektionen und Sepsis) [169]. Während eines Ausbruchs auf einer Intensivstation erlitten 8,3 \% der besiedelten Patienten eine Infektion [178]. Sechzehn von 42 (38 \%) Patienten, die mit ESBL-bildenden $K$. pneumoniae besiedelte waren, entwickelten in einer Untersuchung von Kola et al. im endemischen Setting eine Infektion [139], wobei kein systematisches Aufnahmescreening durchgeführt wur de, so dass die Anzahl der asymptomatischen Träger vermutlich unterschätzt wurde.

Aus diesen Untersuchungen ergibt sich, dass in der endemischen Situation unter mit multiresistenten K. pneumoniae besiedelten Risikopatienten bis zu $40 \%$ im Krankenhaus eine Infektion erleiden können. Insgesamt muss davon ausgegangen werden, dass der Anteil kolonisierter Patienten, die nur durch Surveillance-Untersuchungen entdeckt werden können, sowohl für 3MRGN als auch für 4MRGN Klebsiellen hoch sein kann.

Mortalität: Für Bakteriämien mit ESBLproduzierenden Enterobakterien konnte in einer Meta-Analyse von 16 Studien, die auch 14 Studien mit ESBL-produzierenden K. pneumoniae einschloss, eine statistisch signifikant erhöhte Letalität mit einem relativen Risiko von 1,85 gezeigt werden [142]. Verschiedene Autoren kamen zu unterschiedlichen Resultaten bezüglich der zusätzlichen Mortalität durch Infektionen mit ESBL-bildenden Klebsiellen. Während zum Beispiel Demirdag [179] oder Wener [180] eine erhöhte Mortalität gegenüber Infektionen durch sensible Klebsiellen fanden, wurde dies von Mosqueda-Gómez [181] nicht festgestellt.

In einem Review zum klinischen Verlauf und Behandlungserfolg (Outcome) von Infektionen mit ESBL-Bildnern wiesen Ramphal und Ambrode [182] auf unterschiedliche Resultate verschiedener Untersuchungen hin, die durch zu kleine Untersuchungsgruppen, Einfluss der Grundkrankheit oder empirische Therapie bedingt sein könnten. Metaanalysen, die allein den klinischen Verlauf und Behandlungserfolg (Outcome) von ESBLbildenden Klebsiellen untersuchen, liegen bisher nicht vor. Es bleibt somit unklar, ob Infektionen durch ESBL-bildende Klebsiellen mit erhöhter Mortalität einhergehen.

Neun Studien aus den USA, Griechenland, Israel und Puerto Rico verglichen die Mortalität bei Patienten mit Infektionen durch Carbapenem-sensible und -resistente K. pneumoniae [183-189]. Sofern die Carbapenem-Resistenz näher untersucht wurde, handelte es sich dabei um Carbapenemase-bildende Stämme mit Carbapenemasen vom Typ KPC oder VIM. Vier der Studien untersuchten ausschließlich Patienten mit Bakteriämien. Die Mortalität der Patienten mit Carbapenem-resistenten Isolaten lag dabei zwischen $30,1 \%$ und $48 \%$. Nur eine einzige Studie [185] fand eine geringfügig niedrigere Letalität bei Patienten mit Carbapenem-resistenten Stämmen von $30,1 \%$ gegenüber $33,9 \%$ bei Patienten mit Carbapenem-sensiblen Stämmen, wobei dieser Unterschied nicht signifi- kant war. In einer weiteren Studie [187] war die Mortalität bei Patienten mit Infektionen durch Carbapenem-resistente Stämme gegenüber Carbapenem-sensiblen Stämmen zwar erhöht, jedoch nicht signifikant. Allerdings hatten in dieser Studie nur 5 von 39 Patienten eine Bakteriämie. Es ist denkbar, dass ein statistisch signifikanter Unterschied der Mortalität bei niedrigem Anteil an schweren Infektionen bei solch geringen Fallzahlen nur schwer zu finden ist. Alle anderen sieben Studien konnten bei Carbapenem-resistenten Stämmen eine signifikant erhöhte Mortalität nachweisen. Bei vier Studien war Carbapenem-Resistenz auch in einer multivariaten Analyse unter Einbeziehung der Krankheitsschwere ein signifikanter Risikofaktor für Mortalität [183, 186, 188, 189]. In einer weiteren Studie war Carbapenem-Resistenz bedingt durch KPC, nicht aber verursacht durch VIM, signifikant mit erhöhter Sterblichkeit assoziiert [188].

Für einen direkten Vergleich der Letalität durch ESBL-produzierende im Vergleich zu Carbapenem-resistenten K. pneumoniae ist die Datenlage dürftig. Eine Studie [183], die die Letalität von Bakteriämien durch $K$. pneumoniae untersuchte, fand bei den 85 Patienten mit sensiblen K. pneumoniae eine Letalität von $17 \%$, bei den 65 Patienten mit ESBL eine Letalität von $22 \%$ sowie bei den 42 Patienten mit Carbapenem-resistenten $K$. pneumoniae eine Letalität von $48 \%$. Im Gegensatz zur Carbapenem-Resistenz war in dieser Studie ESBL-Produktion nicht mit einem signifikant erhöhten Risiko für Letalität assoziiert. In einer weiteren Studie [190] lag die Letalität bei einer Bakteriämie durch ESBL mit 27,5 \% niedriger als bei einer Bakteriämie durch Carbapenem-resistente K. pneumoniae mit $47,4 \%$, jedoch war dieser Unterschied nicht statistisch signifikant.

Infektionen durch multiresistente K. pneumoniae sind mit einem schlechteren klinischen Verlauf und Behandlungserfolg (Outcome) assoziiert. Es wird derzeit davon ausgegangen, dass K. pneumoniae-Stämme mit Multiresistenz nicht virulenter sind als sensible K. pneumoni$a e$. Eine erhöhte Letalität bei Infektionen durch multiresistente K. pneumoniae- 
Stämme wird dennoch diskutiert und zurückgeführt (I) auf eine geringere Wahrscheinlichkeit, dass entsprechende $\mathrm{Pa}$ tienten initial kalkuliert mit einer resistenzgerechten Therapie behandelt werden oder (II) darauf, dass selbst für die gezielte Therapie nach Antibiogramm nur noch Substanzen mit geringerer Wirksamkeit oder erhöhten Nebenwirkungen zur Verfügung stehen.

Für $K$. pneumoniae mit ESBL (3MRGN) ist dabei der erste Faktor ausschlaggebend, da für die gezielte Therapie mit den Carbapenemen noch wirksame Antibiotika zur Verfügung stehen. Bei Carbapenem-resistenten K. pneumoniae sind beide Ursachen beteiligt.

Infektionen durch K. pneumoniae mit 4MRGN-Phänotyp haben aufgrund bisheriger Erkenntnisse einen ungünstigeren klinischen Verlauf und schlechteren Behandlungserfolg (Outcome) als Infektionen durch K. pneumoniae mit 3MRGN-Phänotyp.

Reservoire und Übertragungswege: Das natürliche Reservoir von K. pneumoniae ist die menschliche Darmflora.

Eine Abfrage der Outbreak-Datenbank ergab 168 Publikationen über Ausbrüche, die durch $K$. pneumoniae verursacht wurden (www.outbreak-database. com, Zugang 24.10.2011). In 76 Publikationen handelte es sich dabei um multiresistente $K$. pneumoniae mit ESBL, plasmidkodierten AmpC-Betalaktamasen oder Carbapenemasen, die in der Mehrzahl die Definition für 3MRGN oder 4MRGN erfüllen würden. Da nicht anzunehmen ist, dass sich Reservoir und Übertragungswege zwischen sensiblen und resistenteren K. pneumoniae-Stämmen prinzipiell unterscheiden, wurden für diese Auswertung die Daten aller in der Datenbank aufbereiteten Publikationen herangezogen.

Die Quelle von Ausbrüchen blieb bei 63,7 \% der Ausbruchsbeschreibungen unklar, in 18,5\% der Studien ließ sich der Ausbruch auf einen Indexpatienten zurückführen, Medizinprodukte waren in $8,9 \%$ verantwortliche Auslöser und Personal fand sich lediglich in 5,4 \% der Ausbruchsbeschreibungen als Quelle.
In $43,5 \%$ der Studien wurde eine Übertragung über Kontakt angegeben. In 36 Artikeln wurde eine Übertragung durch Personal oder die Hände des Personals für wahrscheinlich gehalten. Bei 48,2 \% der Ausbruchsbeschreibungen konnte kein gesicherter Übertragungsweg identifiziert werden. Es ist denkbar, dass sich darunter ebenfalls Übertragungen durch die Hände des Personals befinden, die sich aber nicht sicher verifizieren ließen. Übertragungen im Rahmen von invasiven Maßnahmen wurden in 10,7 \% der Ausbrüche beschrieben.

Aus diesen Daten kann abgeleitet werden, dass Klebsiellen in der großen Mehrzahl der Fälle direkt oder indirekt von Person $z u$ Person übertragen werden. Bei Häufung von Infektionen muss jedoch immer auch an eine Quelle aus der unbelebten Umgebung gedacht werden, wobei eher feuchte Habitate von Klebsiellen bevorzugt werden.

Risikofaktoren: Ob eine Vortherapie mit Antibiotika ein signifikanter Risikofaktor für das Auftreten von resistenten Bakterien ist, lässt sich in Fall-KontrollStudien nur dann untersuchen, wenn die Kontrollgruppe korrekt gewählt wurde [191]. In entsprechenden Studien konnte eine vorhergehende Antibiotikatherapie bei Infektionen durch K. pneumoniae mit ESBL $[192,193]$ oder CarbapenemResistenz $[189,194]$ als unabhängiger Risikofaktor identifiziert werden. Eine andere Studie konnte zwar nicht eine Antibiotikatherapie per se als signifikanten Risikofaktor für Carbapenem-resistente $K$. pneumoniae identifizieren, jedoch die Anzahl der vorher verabreichten Antibiotika [187].

Risikofaktoren für ESBL-produzierende $K$. pneumoniae sind neben der Antibiotikatherapie [179-181, 193, 195, 196], die Dauer des Krankenhausaufenthaltes [193], Pflege in Heimen, Hämodialyse [196], chirurgische Eingriffe [179] und Aufenthalt auf der Intensivstation [181].

Ein Zusammenhang zwischen Besiedelungs- oder Infektionsort und dem Risiko einer Weiterverbreitung des Erregers wurde in keiner der Untersuchungen beschrieben.
Neben Neugeborenen und Intensivtherapiepatienten waren auch Patienten der Hämatologie-Onkologie besonders von Infektionen durch ESBL-bildende Klebsiellen betroffen [197].

Zahlreiche unterschiedliche Risikofaktoren für Carbapenem-resistente K. pneumoniae sind beschrieben. Die Schwere der Grunderkrankung bzw. Komorbiditäten wurden in etlichen Studien als signifikante Risikofaktoren gefunden [183, 186, 188-190]. Daneben fanden sich eine kürzliche Organtransplantation [198], vorhergehende Operationen $[185,190]$ oder nicht operative Eingriffe [189], zentrale Gefäßzugänge $[183,187,189,198]$, mechanische Beatmung [185, 190, 198], Magensonden [187, 190], Harnwegskatheter [187, 189], Wunden [187], Aufenthalt auf Intensivstationen $[183,185,187,189,198]$, vorhergehende Hospitalisierung [189] und die Dauer des Krankenhausaufenthaltes $[183,187$, 190, 198] als signifikante Risikofaktoren.

Es gibt zahlreiche Studien, die beschreiben, dass Carbapenem-resistente K. pneumoniae aus dem Ausland nach Deutschland importiert wurden $[45,60$, 63, 199-202].

Der wichtigste Risikofaktor für Infektionen mit 3MRGN Klebsiellen ist, unabhängig von der betroffenen Population, die vorausgegangene Therapie mit Antibiotika. Neugeborene sind eine der am häufigsten von Klebsiellen-Infektionen betroffenen Populationen.

Für Infektionen mit 4MRGN Klebsiellen sind neben vorausgegangener Therapie mit Antibiotika, insbesondere Hospitalisierung und invasive Eingriffe Risikofaktoren. Der Aufenthalt in medizinischen Einrichtungen in Hochendemiegebieten ist ein besonderer Risikofaktor für 4MRGN Klebsiellen.

\section{- Die Kommission empfiehlt:}

- für 3MRGN Klebsiella spp. in Risikobereichen, in denen Patienten mit erhöhter Infektionsgefahr gepflegt werden, Maßnahmen zur Prävention festzulegen und durchzuführen, die in erster Linie dem Schutz der nicht besiedelten Patienten dienen (Kat II).

- für 4MRGN Klebsiella spp. aufgrund des krankenhausasoziierten Verbrei- 
tungsmodus und der stark limitierten therapeutischen Möglichkeiten Maßnahmen zur Prävention für alle Krankenhausbereiche festzulegen und durchzuführen (Kat II).

\subsubsection{Enterobacter spp.}

Reproduktionsrate: In einer niederländischen Studie mit 18 Krankenhäusern wurde der adjustierte Übertragungs-Index von multiresistenten gramnegativen Stäbchen mit 0,0 bis 0,2 angegeben [135]. Die Anzahl der Patienten pro Index-Fall, bei denen ein multiresistenter gramnegativer Erreger als Folge einer nosokomialen Übertragung nachgewiesen wurde, variierte von 0 bis 6 pro Krankenhaus. In 6 der 18 Krankenhäuser beobachtete man keine Übertragung. Bei dieser Studie waren Enterobacter spp. mit 76 Patienten die dritthäufigsten Erreger (nach $\mathrm{n}=305 \mathrm{E}$. coli und $\mathrm{n}=113$ Klebsiella spp.). In einer älteren Studie auf 22 schwedischen neonatologischen Stationen wurde ein epidemischer Index von 0 bis 0,012 für eine Darmkolonisation mit Enterobacter cloacae ermittelt [203]. Dieser Index lag deutlich niedriger als für Klebsiella spp., woraus die Autoren schlossen, dass Klebsiellen häufiger Cluster nosokomialer Übertragungen verursachen als E. cloacae (oder E. coli).

In einer deutschen Studie auf 16 Intensivstationen fand man bei $10 \%$ der Patienten 3. Generations-Cephalosporine resistente Enterobakterien - mit $71 \%$ am häufigsten Enterobacter spp. [204]. Bei dieser Studie lag auf pädiatrischen Intensivstationen der Anteil übertragener Stämme für Enterobacter sehr hoch bei $88 \%$, was ein Ausbruchsgeschehen wahrscheinlich macht. Auf pädiatrischen Allgemein stationen (kein Ausbruch) lag der Anteil übertragener Stämme immer noch deutlich höher (12,8 \%) als auf ErwachsenenIntensivstationen $(6,8 \%)$. Eine israelische Studie fand eine $8 \%$ ige Prävalenz mit ESBL-positiven Enterobakterien bei Aufnahme ins Krankenhaus (ein Viertel davon Enterobacter spp.); während des stationären Aufenthaltes erwarben $21 \%$ der Patienten einen ESBL-Bildner [163]. Die Erreger wurden allerdings nicht genotypisiert.
Hieraus lässt sich ableiten, dass eine Übertragung von besiedelten oder infizierten Patienten ausgehen kann, aber eher selten stattfindet (Reproduktionsrate $<1)$.

Klinische Manifestationsrate: In einer belgischen Studie, in der alle Patienten einer Intensivstation bei Aufnahme, wöchentlich und bei Entlassung auf Enterobacter gescreent wurden, entwickelten 25 $\%$ eine Infektion ( 8 von 32 kolonisierten Patienten) [205]. Im Rahmen eines Ausbruchs mit multiresistenten E. cloacae auf einer anderen belgischen Intensivstation kam es bei $44 \%$ der besiedelten Patienten (Rektalscreening 2x wöchentlich) zu einer Infektion [206]. In der bislang größten Studie mit 17.872 Patienten, die auf ESBL-Bildner gescreent wurden, entwickelten 8,5\% der kolonisierten $\mathrm{Pa}$ tienten eine Bakteriämie mit ESBL-Bildnern (dabei waren Enterobacter spp. nach E. coli und Klebsiella spp. der dritthäufigste ESBL) [140]. Auf 16 deutschen Intensivstationen entwickelten $10 \%$ der Patienten, die mit 3. Generations-Cephalosporin resistenten Enterobakterien besiedelt waren, eine Infektion (71 \% der Patienten waren mit Enterobacter spp. besiedelt) [204]. In einer kleineren Studie von 4 Intensivstationen in Deutschland erkrankten $25 \%$ der mit ESBL-positiven Erregern besiedelten Patienten an einer Infektion (Harnwegs- und Wundinfektionen, Pneumonie und Pleuraempyem) [207].

Es ist anzunehmen, dass ca. $10 \%$ bis $25 \%$ der mit multiresistenten Enterobacter spp. besiedelten Patienten im Rahmen ihres Krankenhausaufenthaltes eine Infektion bekommen.

Mortalität: Cosgrove et al. untersuchten in einer Fall-Kontroll-Studie bei 477 Patienten Mortalität und ökonomische Konsequenzen bei Patienten mit klinischen Isolaten 3. Generations-Cephalosporin sensibler und resistenter Enterobacter spp. [208]. Die Mortalität bei den Fall-Patienten, d.h. den Patienten, bei denen im Verlauf ein resistenter Enterobacter spp. nachgewiesen wurde, lag bei $26 \%$, bei den Kontroll-Patienten nur bei $13 \%(\mathrm{p}=0,06)$. In der multivariaten Ana- lyse zeigte sich allerdings, dass die Entwicklung einer 3. Generations-Cephalosporin-Resistenz signifikant mit einem 5 fach höheren Mortalitäts-Risiko einherging, ebenso mit 1,5fach verlängerter Verweildauer und 1,5fach höheren Kosten. Eine koreanische Studie zeigte ebenfalls, dass Resistenz gegenüber 3. Generations-Cephalosporinen bei Patienten mit einer Enterobacter-Bakteriämie ein signifikanter unabhängiger Risikofaktor war [209]: die 30 Tage Mortalität war um 3,7 höher als bei den Kontrollen ( $\mathrm{Pa}$ tienten mit 3. Generations-Cephalosporin sensibler Enterobacter-Bakteriämie).

Eine taiwanesische Studie fand bei 88 Patienten mit E. aerogenes Bakteriämie als unabhängigen Risikofaktor eine 9,2fach höhere Mortalität bei Patienten mit 3. Generations-Cephalosporin-Resistenz [210] Drei andere Studien konnten - zumindest in der multivariaten Analyse - allerdings nicht zeigen, dass Multiresistenz bei Enterobacter mit höherer Mortalität einhergeht. Ye et al. beschrieben bei 126 chinesischen Patienten mit Enterobacter Bakteriämie eine Mortalität von 32,5 \%.

Multiresistenz war jedoch kein unabhängiger Risikofaktor, im Gegensatz dazu war der nosokomiale Erwerb der Infektion ein unabhängiger Risikofaktor [211]. Gleichermaßen konnte in einer Kohortenstudie aus Singapur bei 675 Patienten mit Bakteriämie, verursacht durch multiresistente gramnegative Enterobakterien (ein Fünftel davon Enterobacter spp.) nicht gezeigt werden, dass Multiresistenz die 30 Tage Mortalität erhöhte [212]. Multiresistenz bei Enterobacter war jedoch mit signifikant verlängerter Verweildauer vergesellschaftet. Eine französische Gruppe untersuchte Patienten mit Beatmungspneumonie auf Intensivstationen [213]. Cephalosporin-Resistenz aufgrund von Überproduktion von AmpC ging bei Enterobacter spp. nicht mit einer höheren 28-Tage Mortalität einher.

Es ist auffallend, dass vor allem ältere Studien einen Unterschied in der Mortalität bei 3. Generations-Cephalosporin resistenten E. cloacae fanden, während neuere methodisch bessere Studien, diesen Unterschied nicht mehr nachweisen konnten.

Zur Mortalität bei Carbapenem-resistenten Enterobacter spp. gibt es bislang 
nur wenige Daten. In einer gematchten Fall-Kontroll-Studie von je 33 Patienten mit Imipenem-resistenten bzw. Imipe nem-sensiblen E. cloacae in Israel zeigte sich, dass das Risiko zu versterben, bei Patienten mit resistentem E. cloacae höher war (Odds Ratio 8,3) - statistisch signifikant in der multivariaten Analyse [80]. Auch in einer US-amerikanischen Studie konnte nachgewiesen werden, dass Besiedlung mit Carbapenem-resistenten Enterobakterien ( $74 \% \mathrm{~K}$. pneumoniae, 15 \% Enterobacter spp. u.a.) ein unabhängiger Risikofaktor in Bezug auf Mortalität war (OR 17,2) [214].

Für Infektionen mit 3MRGN Enterobacter spp. ist eine erhöhte Mortalität nicht sicher nachweisbar; für Infektionen mit Carbapenem-resistenten Enterobacter spp. (4MRGN) ist die Mortalität nach bisherigen Erkenntnissen erhöht.

\section{Reservoire und Übertragungswege:}

Die Gattung Enterobacter ist vielseitig und kommt im Gastrointestinaltrakt bei vielen Säugetieren, in Pflanzen und im Wasser vor und kann als Krankheitserreger bei Tieren und Pflanzen auftreten. Beim Menschen besiedeln sie meist ausgehend vom Darm andere Körperregionen und verursachen dort schwere Infektionen. Für eine Infektion durch Enterobacter, der zu 40-80\% in der normalen Darmflora von Erwachsenen vorkommt, ist das Zusammentreffen von bakteriellen Virulenzfaktoren und prädisponierenden Wirtsfaktoren notwen$\operatorname{dig}$ [215].

In einer niederländischen Studie wurde bei Neugeborenen die Darmbesiedlung mit Enterobacter spp. untersucht [216]. Bei 15 von 48 Neugeborenen fand sich Enterobacter spp. im Rachen- und Rektalabstrich. Drei Kinder blieben bis zur Entlassung mit demselben Genotyp besiedelt, nach 6 Monaten war bei den 13 Babys kein Enterobacter spp. mehr nach weisbar, nach 12 Monaten fand sich bei einigen der Kinder ein anderer Genotyp. In einer französischen Universitätsklinik waren $14,5 \%$ der aufgenommen Patienten (44 von 303) mit multiresistenten Enterobacter spp. (12 ESBL, 8 Carbapenemase positiv, 23 mit AmpC Hyperproduktion) rektal besiedelt [217].
Obwohl die meisten Infektionen endogener Natur sind, können Enterobacter spp. auch exogen übertragen werden. Vor allem wurden klonale Ausbrüche auf Neugeborenen-Intensivstationen, aber auch auf Erwachsenen-Intensivstationen, Verbrennungsstationen und in onkologischen Zentren beschrieben [218, 219]. Einzelne Krankheitsausbrüche konnten auf kontaminierte Flüssigkeiten zur intravenösen Verabreichung, Trockenmilch-Säuglingsnahrung (hier speziell Cronobacter (früher Enterobacter sakazakii)), auf Blutprodukte, destilliertes Wasser, kontaminierte Endoskope, Stethoskope, Thermometer, Betten und Hände von medizinischem Personal zurückgeführt werden [73].

Die Übertragung von Enterobacter spp. ist eher selten, erfolgt jedoch in der Regel über die Hände des Personals oder Gegenstände aus der direkten Umgebung der Patienten.

Risikofaktoren: Patienten, die längere Zeit im Krankenhaus behandelt wurden - insbesondere auf Intensivstationen haben ein höheres Risiko, an durch Enterobacter spp. verursachten Infektionen zu erkranken. Die Schwere der Grunderkrankung, Malignome und Verbrennungswunden erhöhen die Wahrscheinlichkeit einer Infektion mit Enterobacter spp. Prädisponierende Faktoren sind außerdem Frühgeburtlichkeit und ein Durchbrechen der natürlichen Barrieren, wie sie bei Erkrankungen des Gastrointestinaltrakts, Verbrennungen und invasiven Zugängen/-Katheter vorkommen [73]. Eine taiwanesische Studie verglich die Risikofaktoren bei Patienten, die mit Enterobacter-Bakteriämie versus Patienten, die mit einer E. coli-Bakteriämie stationär aufgenommen wurden [220]. In der multivariaten Analyse hatten Patienten mit Enterobacter-Bakteriämie signifikant häufiger eine Pneumonie, einen soliden Tumor, einen Katheter oder einen Nachweis der Infektion im Zusammenhang mit medizinischen Maßnahmen im Vergleich zu Patienten mit einer E. coli-Bakteriämie.

Risikofaktoren für Infektionen mit multiresistenten Enterobacter spp. wurden in einer multizentrischen US-ame- rikanischen Studie untersucht. Von 159 Patienten mit E. cloacae Bakteriämie hatten $10,1 \%$ der Patienten einen ESBL-produzierenden Enterobacter spp. [221]. Als unabhängige Risikofaktoren für Multiresistenz fanden sich die Aufnahme aus einem Altersheim, das Vorhandensein einer Magensonde und eine Transplantation in der Anamnese. Liu et al. veröffentlichten als unabhängige Risikofaktoren für eine Bakteriämie mit multiresistenten (Resistenz gegen 3. GenerationsCephalosporine und Aztreonam) versus nicht-multiresistenten E. cloacae folgende Faktoren: höheres Alter, gastrointestinaler Tumor, Beatmung und Aufenthalt auf einer Intensivstation [222].

Als Risikofaktor für die Entwicklung von Resistenzen unter Therapie wurde vor allem der Einsatz von Breitspektrum Cephalosporinen beschrieben [73]. Dies vor allem unter der Vorstellung, die intensive Verwendung von $\beta$-Laktam-Antibiotika fördere die Resistenzentwicklung durch Selektion von induzierten AmpC-Bildnern. Eine aktuelle niederländische Studie untersuchte den Zusammenhang von Antibiotikaeinsatz und Resistenzentwicklung bei Intensivpatienten, die bei Aufnahme mit Enterobacter spp. besiedelt waren (11\% von 1201 Patienten). Der Einsatz von Ceftriaxon und Ciprofloxacin war assoziiert mit Resistenzentwicklung; in der multivariaten Analyse zeigte sich jedoch kein statistisch signifikanter Zusammenhang [223]. Auch auf einer neonatologischen Abteilung beeinflusste die Gabe von 3. Generations-Cephalosporinen die Resistenzentwicklung nicht [224].

In einer spanischen Studie hatten $\mathrm{Pa}$ tienten mit Nierenversagen, Tracheotomie und vorausgegangenem Krankenhausaufenthalt ein höheres Risiko mit ESBL-Enterobacter infiziert oder kolonisiert zu sein. Ebenso war die Gabe von B-Laktamantibiotika in der Vorgeschichte ein Risikofaktor [79].

Risikofaktoren für Carbapenem-intermediär sensible oder Carbapenem-resistente Enterobakterien wurden in einer kanadischen Fall-Kontroll-Studie untersucht. Dazu wurden 85 Patienten mit Infektionen (davon $40 \%$ E. cloacae) mit zwei Kontrollgruppen verglichen: zum einen mit Patienten, die eine Infektion 
mit Carbapenem empfindlichen Enterobakterien hatten, zum anderen mit einer Patientengruppe ohne Infektion [225]. Der einzige unabhängige Risikofaktor für Infektionen mit intermediär sensiblen oder resistenten Enterobakterien war die kumulative vorausgegangene Antibiotikaexposition. Dies ist insbesondere deshalb interessant, weil nicht einige spezielle Antibiotikagruppen (z. B. Carbapeneme) als Risikofaktoren identifiziert wurden, sondern die Menge der verabreichten Antibiotika als solche.

Neben patienteneigenen Risikofaktoren ist eine vorausgegangene Antibiotikatherapie ein Risikofaktor für den Erwerb eines 3MRGN Enterobacter spp. Neugeborene sind vergleichsweise häufi ger von Infektionsausbrüchen betroffen. $4 M R G N$ Enterobacter spp. werden derzeit durch Aufenthalte in Endemiegebieten nach Deutschland importiert.

- Die Komission empfiehlt:

- für 3 MRGN Enterobacter spp. aufgrund der geringen Übertragungswahrscheinlichkeit und dem fehlenden Nachweis einer erhöhten Morbidität oder Mortalität von Infektionen mit 3MRGN Enterobacter spp. in der endemischen Situation keine über die Basishygienemaßnahmen hinausgehenden Maßnahmen durchzuführen (Kat II).

- für 4MRGN Enterobacter spp. aufgrund der stark limitierten therapeutischen Möglichkeiten Maßnahmen zur Prävention für alle Krankenhausbereiche festzulegen und durchzuführen (Kat II).

\subsubsection{Andere Enterobakterien}

Reproduktionsrate: In verschiedenen Untersuchungen zur Surveillance antibiotikaresistenter Enterobakterien konnte keine Übertragung von antibiotikaresistenten Proteus, Citrobacter oder Serratia nachgewiesen werden, wobei nur wenige Patienten überhaupt Träger solcher Isolate waren $[139,174,204]$.

\section{Eine Reproduktionsrate lässt sich aus den vorhandenen Daten nicht abschätzen.}

Klinische Manifestationsrate: Für Serratia spp. können Daten aus Ausbruchgeschehen abgeleitet werden. Bei den meisten Ausbrüchen war der Anteil der infizierten Patienten im Vergleich zur Gesamtzahl der Fälle (kolonisierte und oder infizierte Patienten) gering und lag bei etwa $10 \%$ - $20 \%$ der Betroffenen (www.outbreak-database.com, Zugriff 30.10.2011). Insbesondere unter Neu- und Frühgeborenen kann die Infektions- und Sterblichkeitsrate jedoch deutlich höher sein [226, 227]. Byrne et al. screenten Patienten einer Intensivstation, auf der S. marcescens prävalent war, bei Aufnahme. Von 40 Patienten waren 4 Träger von $S$. marcescens und keiner dieser Patienten entwickelte eine Infektion [228].

Für andere Enterobakterien sind nahezu keine Daten vorhanden. Ein Screening von Pflegeheimbewohnern auf Chinolon-resistente Enterobakterien ergab, dass nur wenige Bewohner mit Chinolon-resistenten Proteus besiedelt waren und keiner im Beobachtungszeitraum eine Infektion mit dem Erreger erlitt [229].

Das Verhältnis von kolonisierten $z u$ infizierten Personen ist aus den vorliegenden Daten nicht abzuschätzen. Neugeborene haben jedoch eine erhöhte Anfälligkeit für Infektionen durch Serratia spp.

Mortalität: Die häufigsten Serratia spp.Infektionen sind Infektionen des Respirationstraktes und die Keratokonjunktivitis [230]. Die Mortalität der Infektionen liegt bei etwa $4 \%$ [230]. In vulnerablen Populationen wie Neugeborenen liegt die Sterblichkeit an einer Serratia-Sepsis bei bis zu $24 \%$ und ist damit vergleichbar mit der Sterblichkeit aufgrund einer E. coli Sepsis [231]. Auch bei Erwachsenen findet sich eine Mortalität für eine durch Serratia spp. verursachte Sepsis von ca. $20 \%$ - $25 \%$ [232-234]. Als Risikofaktoren für Mortalität wurden dabei maligne oder schwere Grunderkrankungen identifiziert [234]. In einer Untersuchung wurde für ESBL-produzierende SerratiaInfektionen $(\mathrm{n}=15)$ eine Mortalität von $33 \%$ gefunden. Vergleichende Untersuchungen zur Mortalität von resistenten oder empfindlichen Infektionserregern [235] liegen für Serratia spp. nicht vor.
P. mirabilis führt in der Regel $\mathrm{zu}$ Harnwegsinfektionen, deren Verlauf und Sterblichkeit sich für antibiotikaresistente und antibiotikaempfindliche Isolate nicht signifikant unterscheidet [236]. Die Sepsis durch P. mirabilis ist ein eher seltenes Ereignis, einzelne Untersuchungsergebnisse wiesen jedoch darauf hin, dass die Sepsis durch ESBL-bildende $P$. mirabilis mit höherer Mortalität verbunden ist, als die durch empfindliche Erreger verursachte Sepsis [237].

Infektionen durch Citrobacter spp. sind in der Regel Harnwegsinfektionen, deren Mortalität eher niedrig ist [238]. Die selten auftretende Sepsis kann zu einer Mortalität von ca. 30 \% führen [239, 240]. In einer Untersuchung an $124 \mathrm{~Pa}$ tienten war Resistenz gegenüber 3 . Generations-Cephalosporinen ein unabhängiger Risikofaktor für Mortalität, wobei in der genannten Untersuchung nicht zwischen Sepsis durch Enterobacter spp. und Citrobacter spp. unterschieden wurde [241]. In einer anderen Untersuchung war eine Infektion mit 3. GenerationsCephalosporin-resistenten C. freundii nicht mit höherer Mortalität gegenüber Infektionen mit sensiblen Isolaten verbunden [239].

Eine durch $M$. morganii verursachte Sepsis ist in der Regel die Folge einer Harnwegsinfektion und mit einer Mortalität zwischen $20 \%$ und $38 \%$ verbunden $[239,242]$, wobei inadäquate Antibiotikatherapie ein unabhängiger Risikofaktor für Mortalität ist [242]. In der genannten Untersuchung an 73 Patienten waren allerdings nur $4 \%$ der Isolate Ceftazidim-resistent. Für Infektionen durch Carbapenem-resistente Isolate der genannten Spezies liegen bisher nur Einzelfallbeschreibungen vor, so dass keine belastbaren Daten zur Mortalität vorhanden sind [243-246]

$\mathrm{Zu}$ Morbidität und Mortalität seltenerer multiresistenter Enterobakterien liegen nur wenige Daten vor. Eine Erhöhung der Mortalität durch Antibiotikaresistenz bei den aufgeführten Spezies ist nicht nachgewiesen.

\section{Reservoire und Übertragungswege:} Serratia spp. gilt als ubiquitär vorkommendes Enterobakterium mit Nachwei- 
sen aus Staub, Wasser, Pflanzen und Tieren [247]. In Ausbrüchen nosokomialer Infektionen wurde es wiederholt aus Desinfektionsmitteln, Medikamenten oder Blutprodukten isoliert [247-250].

In einer populationsbasierten Untersuchung von Sepsisfällen zeigte sich, dass der Nachweis von Serratia spp. oder Citrobacter spp. mit einer stationären oder ambulanten medizinischen Betreuung verbunden war [251].

Als Reservoir für Citrobacter spp. und Proteus spp.-Infektionen wird der Darm angesehen [252, 253] mit einer anschließenden Verbreitung über die kontaminierten Hände des Personals. In einem größeren Ausbruch von P. mirabilisHarnwegsinfektionen in Großbritannien wurden Übertragungen innerhalb und außerhalb des Krankenhauses beobachtet, die auf direkte Übertragungen von Person zu Person schließen lassen [254]. Reservoire für die seltenen Häufungen von M. morganii konnten nicht identifiziert werden [255].

Während Serratia-Infektionen mit Quellen aus der unbelebten Umgebung assoziiert sein können, stehen für andere seltene Enterobakterien der Darm als Quelle und die Übertragung von Person zu Person im Vordergrund.

Risikofaktoren: Häufungen von Serratia-Infektionen treten vorwiegend auf neonatologischen Stationen auf [247, 256]. Risikofaktor für Infektionen mit 3. Generations-Cephalosporin-resistenten Serratia war die vorausgegangene Therapie mit Cephalosporinen der 2. und 3. Generation [232]. Eine Therapie mit Fluorchinolonen, Aminogylcosiden und $\beta$ Laktam-Antibiotika sowie ein Krankenhausaufenthalt sind Risikofaktoren für Infektionen mit Carbapenem-resistenten P. mirabilis [257].

Im Rahmen eines Risiko-Scores zur Identifikation von Patienten, die mit ESBL-produzierenden Mikroorganismen besiedelt sind, wurden vorausgegangener Krankenhausaufenthalt, CoMorbidität, vorausgegangene Therapie mit $\beta$-Laktam-Antibiotika oder Fluorchinolonen, vorausgegangene HarnwegKatheterisierung und ein Alter über 70 Jahre als signifikante Faktoren aufge- führt [258]. Infektionen mit 3. Generations-Cephalosporin-resistenten P. mirabilis ist signifikant häufiger eine Therapie mit Cephalosporinen oder Piperacillin/ Tazobactam vorausgegangen, als Infektionen mit 3. Generations-Cephalosporinen-empfindlichen P. mirabilis [236].

Auch für Infektionen mit $C$. freundii war die vorausgegangene antibiotische Therapie ein Risikofaktor für Infektionen mit antibiotikaresistenten Isolaten [259].

Risikofaktoren für Infektionen mit selteneren antibiotikaresistenten Enterobakterien sind vor allem vorausgegangene Therapien mit Antibiotika. Für Serratia spp. sind Neugeborene eine besonders anfällige Population.

\section{- Die Kommission empfiehlt:}

- für andere, seltener auftretende multiresistente Enterobakterien (z. B. Proteus spp., Serratia spp., M. morganii oder Citrobacter spp.) aufgrund der wenigen vorliegenden Daten und der Ähnlichkeit der genannten Spezies mit Enterobacter spp. bis zum Vorliegen weiterer Daten, ein Vorgehen in Anlehnung an Enterobacter spp. zu wählen.

- für andere 3MRGN Enterobakterien in der endemischen Situation keine über die Basishygienemaßnahmen hinausgehenden Maßnahmen durchzuführen, wobei jedoch aufgrund der erhöhten Anfälligkeit von Neugeborenen, insbesondere gegenüber Serratia spp., in der Neonatologie spezielle Maßnahmen durchgeführt werden sollten.

- für andere 4MRGN Enterobakterien aufgrund der stark limitierten therapeutischen Möglichkeiten Maßnahmen zur Prävention für alle Krankenhausbereiche festzulegen und durchzuführen.

\subsection{Nonfermenter}

\subsubsection{Pseudomonas aeruginosa}

Reproduktionsrate: In einer Untersuchung von Bonten et al. an Patienten einer Intensivstation waren bei Aufnahme $34 \%$ der Patienten mit P. aerugino$s a$ unterschiedlicher Antibiotikaresistenz kolonisiert. Drei Patienten erwarben eine Besiedelung mit $P$. aeruginosa während des Aufenthaltes (Reproduktionsrate 0,06) [260]. Thuong et al. publizierten demgegenüber bei einer niedrigeren Trägerrate bei Aufnahme (17 \%) eine deutlich höhere Übertragungsrate von 1,06 [261], wobei antibiotikasensible Stämme signifikant häufiger übertragen wurden. Auch Bergmans et al. zeigten in einer allerdings recht kleinen Untersuchungspopulation 8 Übertragungen ausgehend von 7 Patienten, die bei Aufnahme Träger sensibler Pseudomonas-Isolate waren (Reproduktionsrate 1,14) [262]. In einer Untersuchung zu Carbapenemresistenten $P$. aeruginosa fanden die Autoren eine Reproduktionsrate von 0,8 für einen epidemischen Stamm, während für die anderen Stämme keine Übertragung gefunden wurde [263]. Agodi et al. [264] untersuchten Patienten einer Intensivstation und wiesen nach, dass $60 \%$ aller $P$. aeruginosa-Besiedlungen bzw. -infektionen durch nosokomiale Übertragung verursacht waren, wobei Multiresistenz signifikant mit Übertragung einherging. Johnsen et al. werteten in einem ähnlichen Setting 30 \% aller Fälle als Folge einer nosokomialen Übertragung Imipenem-resistenter Pseudomonas-Stämme [265].

In einer weiteren Untersuchung an 473 Patienten zeigten Bertrand et al. [266], allerdings ohne Angaben zum Resistenzmuster der gefundenen Pseudomonas-Isolate zu machen, dass die Hälfte aller Fälle durch Übertragung entstanden war.

Nach bisherigen Erkenntnissen ist die Reproduktionsrate für P. aeruginosa von den Eigenschaften des einzelnen Stammes und der jeweiligen Umgebungssituation abhängig, kann jedoch deutlich über 1 liegen.

Klinische Manifestationsrate: Bei den bereits im vorangegangenen Abschnitt dargestellten Untersuchungen mit konsequentem Screening der Patienten erlitten $16 \%$ bis $25 \%$ der kolonisierten Patienten Infektionen mit $P$. aeruginosa [260-262]. In der Regel handelte es sich um Infektionen des Respirationstraktes. In einer Untersuchung von Lampati et al. ging $73 \%$ der beatmungsassoziierten Pneumonien eine nachweisbare trachea- 
le Besiedlung voraus und $85 \%$ der $\mathrm{Pa}$ tienten mit Nachweis von $P$. aeruginosa im Trachealsekret erlitten eine Pneumonie durch diesen Erreger [267]. 45 \% der Patienten mit endotrachealer Besiedlung durch multiresistente $P$. aeruginosa (definiert als Resistenz gegenüber mindestens drei der folgenden Substanzklassen: Cephalosporine/Monobactame, $\beta$-Laktamase Inhibitorkombinationen, Fluorchinolone, Aminoglykoside und Carbapeneme) entwickelten in einer anderen Untersuchung eine Pneumonie [268].

Daten zum Verhältnis infizierter $z u$ besiedelten Patienten außerhalb von Hochrisikopopulationen liegen nicht vor. In Risikopopulationen entwickeln bis zur Hälfte aller kolonisierten Patienten systemische Infektionen. In anderen Populationen ist davon auszugehen, dass ein höherer Anteil an Patienten asymptomatisch besiedelt bleibt.

Mortalität: Die Mortalitätsrate der durch $P$. aeruginosa verursachten Bakteriämien ist hoch, insbesondere bei $\mathrm{Pa}$ tienten mit inadäquater empirischer Therapie, und übersteigt die Mortalität der S. aureus-Sepsis [269]. Einige Studien konnten erhöhte Mortalitätsraten bei Patienten mit Infektionen durch multiresistente $P$. aeruginosa, verglichen mit Infektionen durch sensible $P$. aerugino$s a$, nachweisen $[89,270]$. In einer Übersicht fanden Orsi et al., dass sowohl die Bakteriämie als auch irgendeine Infektion durch multiresistente Pseudomonaden gegenüber Bakteriämie, bzw. Infektion mit sensiblen Isolaten mit erhöhter Mortalität einhergehen [271].

In einer retrospektiven Kohortenstudie kam Lye [212] zu dem Ergebnis, dass die Multiresistenz von $P$. aeruginosa per se nicht mit einer erhöhten Mortalität verbunden ist, wenn eine effektive antibiotische Therapie durchgeführt wird. In die Studie waren insgesamt 675 Patienten eingeschlossen, bei denen eine Bakteriämie und Sepsis mit multiresistenten $P$. aeruginosa $(\mathrm{n}=135)$ und/oder multiresistenten $A$. baumannii nachgewiesen war (Multiresistenz wurde definiert als Resistenz gegenüber mindesten drei der folgenden Antibiotikagruppen: $\beta$-Laktam/ $\beta$-Laktamase-Inhibitor-Kombinationen,
Cephalosporine, Fluorchinolone, Aminoglykoside, Carbapeneme oder Polymyxine). Die 30-Tage Mortalität lag bei Patienten mit Bakteriämie mit multiresistenten Isolaten und nicht adäquater Antibiotikatherapie bei $26,7 \%$; bei Patienten mit adäquater Antibiotikatherapie bei 22,6 \%. Gasink [272] konnte in einem multivarianten Modell zeigen, dass nur eine Imipenemresistenz signifikant mit einer erhöhten Mortalität assoziiert war. Auch Eagye [273] und Joo [274] konnten zeigen, dass eine Ceftazidim- oder Imipenemresistenz signifikant mit einer erhöhten Mortalität einhergeht. Andererseits konnten Suárez et al. dies in einer Kohorte von 121 Fällen (33 mit Sepsis durch Carbapenem-resistente $P$. aeruginosa) nicht bestätigen $[275,276]$. In einer chinesischen Untersuchung zeigte sich, dass insbesondere eine Veränderung des Resistenzmusters multiresistenter Pseudomonaden zu einem schlechteren klinischen Verlauf und Behandlungsergebnis (Outcome) führten, mit einer OR von 26,5 gegenüber Infektionen durch multiresistente Pseudomonaden mit stabilen Resistenzmustern [277].

Hirsch und Tam stellten in einer Übersicht verschiedene Arbeiten zur Morbidität zusammen, die trotz eingeschränkter methodischer Vergleichbarkeit zeigten, dass Infektionen durch multiresistente $P$. aeruginosa mit einer höheren Morbidität einhergehen [89]. Die Besiedelung mit einem multiresistenten $P$. aeruginosa hatte in einer anderen Untersuchung im Rahmen eines Ausbruches jedoch keinen Einfluss auf die Mortalität [278].

Auch wenn ein Vergleich der publizierten Studien bei unterschiedlichem Studiendesign und Resistenzdefinitionen schwierig ist, ist ein Zusammenhang zwischen Infektionen mit resistentem P. aeruginosa und einer erhöhten Morbidität und Mortalität offensichtlich. Unterschiede in der Mortalität zwischen 3MRGN und 4MRGN können aus den vorliegenden Daten nicht abgeleitet werden.

\section{Reservoire und Übertragungswege:}

$P$. aeruginosa ist ein ubiquitär vorkommender Keim, dessen natürlicher Standort die Umwelt ist, der aber auch auf
Lebensmitteln sowie vor allem in den Nass- und Feuchtbereichen des Krankenhauses zu finden ist. $P$. aeruginosa verursacht häufig nosokomiale Infektionen, insbesondere bei kritisch kranken oder immunkompromittierten Patienten. Besonders gefährdet durch eine Besiedelung mit $P$. aeruginosa sind Mukoviszidose-Patienten, bei denen sich eine Pseudomonas-Infektion statistisch lebensverkürzend auswirkt. Eine Erregerübertragung von Mensch zu Mensch erfolgt praktisch nur im Krankenhaus. Dabei spielen kontaminierte Wasserauslässe auf Intensivstationen [279-281] oder invasive Maßnahmen mit kontaminierten Geräten wie z. B. Bronchoskopen [282, 283] eine entscheidende Rolle. So berichtet Hota über einen Ausbruch mit einem multiresistenten $P$. aeruginosa auf einer Intensivstation mit 36 infizierten Patienten, von denen 17 innerhalb von 3 Monaten verstarben. Als Quelle konnten kontaminierte Abflussrohre der Waschbecken identifiziert werden [279]. Auch das Überleben gramnegativer Keime auf unbelebten Oberflächen kann eine Übertragungsquelle sein. So konnte Kramer [284] nachweisen, dass $P$. aeruginosa bei unsachgemäßer Oberflächendesinfektion für Monate überleben kann.

In Einzelfällen sind auch Träger unter dem Personal mit dem Ausbruchstamm assoziiert worden [285, 286].

Das Verhältnis von endogener und exogener Infektion im endemischen Setting wurde für $P$. aeruginosa mehrfach untersucht [260-263, 265]. Hier wurde wiederholt ein größerer Anteil an Patienten gefunden, der bereits bei Aufnahme kolonisiert war, und deren Stämme eine große Heterogenität aufwiesen. Hieraus wurde geschlossen, dass im endemischen Setting die Infektionen in der Regel endogener Natur sind.

Hieraus kann gefolgert werden, dass für Pseudomonaden sowohl die endogene Infektion als auch die Übertragung von Person zu Person und Umgebungsreservoire bedeutsame Infektionswege darstellen.

Risikofaktoren: In einer populationsbasierten Studie identifizierten Parkins et al. [287] die folgenden Personengrup- 
pen mit erhöhtem Risiko für Pseudomonas-bedingte Sepsis: Senioren, Hämodialyse-Patienten, Organtransplantierte, Patienten mit Malignomen, Herzkranke, HIV-Infizierte, Diabetiker und COPDPatienten.

Da die Prävalenz von multiresistentem $P$. aeruginosa in den letzten Jahren deutlich zugenommen hat, fokussierten sich einige Studien auf die speziellen Risikofaktoren im Zusammenhang mit dem Nachweis multiresistenter Isolate. In fallkontrollierten Studien konnten der Einsatz von Antibiotika, vorbestehende Kolonisation oder Infektion mit $P$. aeruginosa, maschinelle Beatmung, Sinusitis, maligne Grunderkrankung, Dauer des Krankenhaus-und/oder Intensivaufenthaltes und Komorbidität z. B. COPD als Risikofaktoren nachgewiesen werden $[89,288]$. In einer fallkontrollierten Studie [277] wurde gezeigt, dass eine vorausgegangene antibiotische Therapie mit Imipenem/Meropenem sowie eine maschinelle Beatmung unabhängige Risikofaktoren für eine Infektion mit multiresistenten Pseudomonaden waren. Ohmagari [289] konnte bei Patienten mit maligner Grunderkrankung zeigen, dass eine Infektion mit multiresistentem $P . a e$ ruginosa signifikant mit einer Carbapenem-Therapie über 7 Tage, einer vorausgegangenen Infektion mit $P$. aeruginosa und einer COPD als Risikofaktoren verbunden war. In einer Untersuchung von Ong et al. [223] war eine vorausgegangene Therapie mit Ciprofloxacin, Ceftazidim oder Meropenem signifikant mit neu auftretender Resistenz bei $P$. aeruginosa verbunden.

Weitere Risikofaktoren wie enterale Ernährung via Magensonde identifizierte Defez [290] in einer fallkontrollierten Studie. In einer japanischen Studie [291] konnten eine antimykotische Behandlung und der Patiententransfer aus anderen Krankenhäusern als Risikofaktor für Bakteriämien mit Imipenem-resistentem $P$. aeruginosa nachgewiesen werden.

Untersuchungen zu Risikofaktoren für eine Besiedelung mit $P$. aerugino$s a$ ergaben, dass eine vorausgegangene Therapie mit Antibiotika, obwohl diese nicht gegen $P$. aeruginosa wirksam waren, dennoch das Risiko für eine Besiedlung mit $P$. aeruginosa erhöhen [261]. Eine vo- rausgegangene Therapie mit Carbapenemen oder Fluorchinolonen sowie schwere Grunderkrankungen erhöhen das Risiko für eine Besiedelung mit Carbapenem-resistenten $P$. aeruginosa [263].

Neben patienteneigenen Risikofaktoren und invasiven Maßnahmen ist eine vorausgegangene Antibiotikatherapie Risikofaktor für den Erwerb von $3 M R G N$ oder 4MRGN P. aeruginosa. Besonders häufig sind Patienten der Intensivstation betroffen.

\section{- Die Kommission empfiehlt:}

- trotz der bisher nicht in allen Aspekten erforschten Epidemiologie von multiresistenten $P$. aeruginosa, Maßnahmen in der Klinik zu ergreifen, die sich zur einfacheren Umsetzbarkeit an den Maßnahmen für andere multiresistente gramnegative Stäbchen orientieren.

- für 3MRGN P. aeruginosa in Risikobereichen, in denen Patienten mit erhöhter Infektionsgefahr gepflegt werden, Maßnahmen zur Prävention festzulegen und durchzuführen, die in erster Linie dem Schutz der nicht besiedelten Patienten dienen (Kat II).

- für 4MRGN P. aeruginosa aufgrund der extrem limitierten therapeutischen Möglichkeiten Maßnahmen zur Prävention für alle Krankenhausbereiche festzulegen und durchzuführen (Kat II).

\subsubsection{Acinetobacter baumannii}

Reproduktionsrate: Es gibt nur wenige Daten zur Übertragungswahrscheinlichkeit von A. baumannii. Eine Analyse von 69 publizierten Ausbrüchen von A. baumannii, die zwischen 1999 und 2009 beobachtet wurden, ergab auf Basis der Outbreak Database (www.outbreakdatabase.com, Zugang 15.04.2011), dass im Rahmen dieser Ausbrüche im Mittel 5 Patienten pro Monat neu mit dem Erreger besiedelt oder infiziert wurden (Min 0,3 ; Max 21).

Hierbei ist jedoch die Grundgesamtheit der suszeptiblen Patienten nicht bekannt. Untersuchungen zur Transmission von Acinetobacter spp. zeigten, dass in endemischen Situationen 3 Fälle pro 100 Neuaufnahmen auftraten, von denen 2/3 nosokomial erworben waren [292].
Hieraus lässt sich grob abschätzen, dass jeder mit multiresistentem A. baumannii besiedelte oder infizierte Patient unter unkontrollierten Bedingungen für ca. 2 bis 3 weitere Patienten eine Quelle darstellen kann.

Klinische Manifestationsrate: Im Rahmen der bereits oben beschriebenen Ausbrüche waren zwischen 0 und $80 \%$ der betroffenen Patienten (Mittelwert $20 \%$ bei 32 Ausbrüchen mit insgesamt 948 Fällen) mit $A$. baumannii infiziert. Im endemischen Setting eines spanischen Krankenhauses der Maximalversorgung waren $55 \%$ der Patienten $(602$ von 1090 Patienten) infiziert, wobei respiratorische Infekte (35\%), gefolgt von Harnwegsinfektionen (18\%), Haut- und Weichteilinfektionen (18\%) und primärer Sepsis (17 \%) die häufigsten Infektionen waren [293]. Auch in anderen Untersuchungen waren respiratorische Infekte, Haut- und Weichteil-Infektionen und Harnwegsinfektionen die häufigsten Infektionsarten [130, 292, 294]. Da bisher nur wenige Untersuchungen vorliegen, in denen ein kontinuierliches systematisches Screening der Patienten vorgenommen wurde, und das Infektionsrisiko in Abhängigkeit der individuellen Risikofaktoren als unterschiedlich einzuschätzen ist, kann nicht sicher abgeschätzt werden, wie hoch der Anteil an klinischsymptomatischen Patienten bzw. der Anteil unauffälliger Träger ist. Apisarnthanarak et al. fanden während eines Ausbruches heraus, dass ca. $20 \%$ der kolonisierten Patienten Infektionen erlitten [295].

Es ist davon auszugehen, dass nur ein Teil besiedelter Patienten im Rahmen des stationären Aufenthaltes eine Infektion erleidet und dass ein erheblicher Anteil der Patienten asymptomatisch besiedelt ist.

Mortalität: In einem systematischen Review gingen Falagas et al. der Frage nach, ob Besiedelung oder Infektion mit A. baumannii Ursache für eine erhöhte Mortalität sein könnte. Auf Basis der Analyse von 9 Fall-Kontroll-Studien kamen die Autoren zu dem Schluss, dass A. baumannii-Infektionen mit einer 
beträchtlichen Morbidität und Mortalität einhergehen [296]. Der Effekt auf die Mortalität konnte jedoch nicht in allen Studien dargestellt werden [297]. Allerdings findet sich in nahezu allen Untersuchungen ein verlängerter Krankenhausaufenthalt als Konsequenz der Infektion [297-299]. Im Rahmen des Surveillance and Control of Pathogens of Epidemiologic Importance (SCOPE) Projektes wurden nosokomiale Septikämien untersucht und die Mortalität der A. baumannii Sepsis mit der durch andere gramnegative Erreger verursachten Sepsis verglichen. Mit $31 \%$ war die Mortalität der A. baumanni-Sepsis vergleichbar mit der Mortalität der durch andere gramnegative Erreger verursachten Sepsis $(27 \%)$ [300]. Eine kürzlich erschienene Meta-Analyse ergab, dass die Infektion mit $A$. baumannii ein unabhängiger Risikofaktor für die Mortalität der beatmungsassoziierten Pneumonie ist (OR, 1,74; 95 \% CI, 1,02-2,96) [301].

In neueren Untersuchungen wurde der Frage nachgegangen, ob die Infektion durch antibiotikaresistente $A$. baumannii eine höhere Mortalität aufweist als vergleichbare Infektionen mit sensiblen Isolaten. Während einige Autoren eine signifikant höhere Mortalität von Infektionen mit multiresistenten A. baumannii nachwiesen [302, 303], waren bei anderen Untersuchungen die vorhandenen Unterschiede nicht signifikant [304-306]. Mit Ausnahme einer einzelnen Studie [305] zeigten alle Untersuchungen, dass eine Infektion durch einen multiresistenten $A$. baumannii mit einem verlängerten Krankenhausaufenthalt verbunden ist. Problematisch ist der Vergleich der Ergebnisse jedoch aufgrund der Verwendung unterschiedlichster Definitionen für Multiresistenz. So wird z. B. in der Untersuchung von Lambert et al. die Antibiotikaresistenz als Resistenz lediglich gegen Ceftazidim definiert. In dieser Untersuchung konnte nahezu kein Einfluss der Resistenz auf den klinischen Verlauf und den Behandlungserfolg (Outcome) nachgewiesen werden [305]. Sunenshine et al. verwendeten eine Definition, die mit 3MRGN vergleichbar ist, und fanden eine Mortalität bei Infektionen durch multiresistente Isolate von
$26 \%$, verglichen mit $18 \%$ bei empfindlichen Erregern (Relatives Risiko 2,6; 95 $\%$ CI 0,3-26,1).

In zwei weiteren Studien wurde der Einfluss der Carbapenem-Resistenz (entspricht 4MRGN) auf den klinischen Verlauf und Behandlungserfolg (Outcome) untersucht. Während Sheng et al. eine höhere Mortalität bei Carbapenem-resistenten A. baumannii-Septikämien nachwiesen (46\% bei Carbapenem-resistenten A. baumannii ( $\mathrm{n}=121)$ vs. $28,3 \%$ bei Carbapenem-empfindlichen A. baumannii $(\mathrm{n}=127, \mathrm{p}=0,04)$ [307] fanden Routsi et al. [308] in einer allerdings kleineren Studie keinen Unterschied in der Mortalität der Septikämie (43,3 \% Carbapenem-resistenter $A$. baumannii $(\mathrm{n}=30)$ vs. 46,9 \% Carbapenem-empfindlicher $A$. baumannii $(\mathrm{n}=66), \mathrm{p}=0,74)$. Lautenbach et al. zeigten, dass Patienten mit Carbapenem-resistenten A. baumannii einen längeren Krankenhausaufenthalt mit höheren Kosten nach Detektion der Infektion oder Kolonisation hatten. Nachdem statistisch für andere Faktoren kontrolliert wurde, war der Unterschied jedoch nicht mehr signifikant. Allerdings zeigte die Analyse der Subgruppe mit positiven Blutkulturen eine signifikante Assoziation der Sterblichkeit mit Carbapenem-resistenten A. baumannii [309].

Derzeit kann somit nicht sicher festgestellt werden, ob die Infektion mit einem 3MRGN A. baumannii mit einer erhöhten Mortalität einhergeht. Im Vergleich $z u$ Infektionen durch antibiotikaempfindliche Isolate besteht jedoch eine erhöhte Morbidität mit signifikant verlängerter Krankenhausaufenthaltsdauer. Infektionen durch 4MRGN A. baumannii haben gemäß dem gegenwärtigen Wissensstand gegenüber Infektionen mit sensiblen Isolaten eine höhere Mortalität.

\section{Reservoire und Übertragungswege:}

Bisher ist wenig zu den natürlichen Habitaten von A. baumannii im Krankenhaus bekannt. In mehreren Studien an Krankenhauspatienten konnte A. baumannii häufig in respiratorischen Materialien und auf der Haut nachgewiesen werden [294]. Demgegenüber fanden Seifert et al. nur in $1 \%$ der Patien- ten eine Besiedelung der Haut mit $A$. baumannii [310]. Die Rolle der Besiedelung des Gastrointestinaltrakts mit A. baumannii wird ebenfalls kontrovers diskutiert [311]. Corbella et al. zeigten, dass $41 \%$ der Patienten einer Intensivstation im Laufe ihres Aufenthaltes gastrointestinal mit A. baumannii besiedelt waren, wobei bei $10 \%$ der Patienten die Besiedelung bereits bei Aufnahme bestand [312].

A. baumannii gilt als Ausnahme unter den gramnegativen Stäbchen mit einer ausgesprochen hohen Umweltresistenz [284, 313]. In einer Reihe von Ausbrüchen wurden entsprechende Reservoire in der unbelebten Umgebung als Quelle identifiziert [118, 314-323]. Neben der Umwelt wurden Reservoire in medizinischen Geräten [324-326] beschrieben. Als weitere Quelle wurden Patienten und in einigen Fällen auch Personal identifiziert, wobei Personal als Vektor bei unzureichender Händehygiene wirkte $[327,328]$. Eine Streuung ausgehend von asymptomatischen Trägern unter dem Personal wurde in einer Untersuchung als Ursache der Verbreitung von A. baumannii angesehen, wobei in keinem Fall eine längerfristige Kolonisation mit wiederholt positiven Proben nachgewiesen werden konnte [329]. Dagegen wurde in einer prospektiven Untersuchung kein Zusammenhang zwischen kolonisiertem Personal und dem Nachweis von A. baumannii bei Patienten gefunden [330].

Die Übertragung von A. baumannii erfolgte in der Regel durch direkten oder indirekten Kontakt. Eine aerogene Übertragung wurde wiederholt diskutiert, da eine Reihe von Ausbrüchen mit Beatmungszubehör assoziiert war [321, 331-333]. Bernards et al. fanden zudem in einer retrospektiven Analyse verschiedener Ausbrüche, dass reine Barrieremaßnahmen (Unterbringung in einem Einzelzimmer und Pflege mit Handschuh, Kittel und Mund-Nasen-Schutz) allein zur Prävention der Übertragung nicht ausreichend waren, während die Unterbringung in einem speziell belüfteten Zimmer gemeinsam mit Barrieremaßnahmen zur Vermeidung der Übertragung von A. baumannii führte [334]. Eine aerogene Übertragung wird jedoch 
nicht als führender Übertragungsweg angesehen [311,335].

\section{Zusammenfassend erfolgt die Übertra- gung von A. baumannii durch direkten oder indirekten Kontakt zu Quellen aus der belebten und in nennenswerten Um- fang auch der unbelebten Umgebung des Patienten.}

Risikofaktoren: Zu den Risikofaktoren für eine Infektion oder Kolonisation mit antibiotikaresistentem A. baumannii gehören längerer Krankenhausaufenthalt, Aufenthalt auf Intensivstation, Beatmung, antibiotische Vorbehandlung, vorausgehende Operationen, invasive Maßnahmen und das Vorliegen schwerer Grunderkrankungen [129, 294, 298]. Risikofaktoren für Kolonisation oder Infektion mit Carbapenem-resistenten A. baumannii waren im Wesentlichen identisch. [299, 336].

Fournier et al. analysierten 45 Ausbrüche, von denen mit großem Abstand die meisten Intensivstationen betrafen (51 \%), gefolgt von Ausbrüchen auf Verbrennungsstationen und neonatologischen Intensivstationen [294]. Ausbrüche, die sich abteilungs- und stationsübergreifend [337, 338] und zum Teil auch krankenhausübergreifend ausbreiten, sind ebenfalls beschrieben $[339,340]$.

Obgleich Patienten auf Intensivstationen gemäß der vorliegenden Publikationen häufiger von Infektion oder Kolonisation mit multiresistenten A. baumannii betroffen sind, können Infektionen und Übertragungen in allen Bereichen des Krankenhauses vorkommen.

\section{- Die Kommission empfiehlt:}

- aufgrund der eingeschränkten therapeutischen Möglichkeiten bei Infektionen mit 3MRGN A. baumannii mit erhöhter Morbidität in Risikobereichen, in denen Patienten mit erhöhter Infektionsgefahr gepflegt werden, Maßnahmen zur Prävention festzulegen und durchzuführen, die in erster Linie dem Schutz der nicht besiedelten Patienten dienen (Kat II).

- für 4MRGN A. baumannii aufgrund der krankenhausassoziierten Verbreitung und der stark limitierten thera- peutischen Möglichkeiten Maßnahmen zur Prävention für alle Krankenhausbereiche festzulegen und durchzuführen (Kat II).

\subsection{Zusammenfassung der rationalen Ableitung}

Die Rationale zur Durchführung krankenhaushygienischer Maßnahmen ergibt sich zum einen aus der Epidemiologie, der Morbidität und Mortalität, der durch die Erreger ausgelösten Erkrankung (• Tab. 4). Zum anderen ist eine Assoziation mit der Verbreitung im Krankenhaus oder Einrichtungen zur ambulanten oder pflegerischen Betreuung von Patienten von Bedeutung. Letzterem kann durch Maßnahmen in allen Bereichen eines Krankenhauses entgegengewirkt werden. Insbesondere für hochresistente gramnegative Stäbchen ist eine klonale Verbreitung beschrieben [341]. Bei erhöhter Mortalität sind entsprechende Risikopopulationen vor Übertragungen zu schützen.

\section{Präventionsmaßnahmen}

\subsection{Enterobakterien}

\subsubsection{Escherichia coli}

Willemsen et al. fanden keinen statistisch signifikanten Zusammenhang zwischen dem Transmissions-Index für multiresistente gramnegative Erreger und der Größe des Krankenhauses, Größe und Ausstattung der Intensivstation mit Isolierzimmern, unterschiedlichem Hygienemanagement, Screeningstrategien sowie dem lokalen Antibiotikaverbrauch [135]. Warren et al. führten Einzelzimmerisolierung für ESBL E. coli-positive Patienten in den Kliniken in Shropshire, Großbritannien ein. Dies hatte keinerlei Effekt auf die Inzidenz und Ausbreitung der Erreger in mehr als 50 Stationen in 7 Krankenhäusern. Erst die Einführung einer Isolierstation zur Kohortenisolierung führte zu einem Rückgang der Inzidenz [342]. Auch Eveillard et al. führten in einem französischen Krankenhaus Barrieremaßnahmen, bestehend aus Händehygiene, Kitteln und Handschuhen, für Patienten mit multiresistenten Mikroorganismen ein [343]. 84 \% der Patienten wurden zudem in Einzelzimmern oder in Kohortenisolierung untergebracht. Die Inzidenz von ESBL-Bildnern fiel daraufhin um $54,9 \%$, wobei nur $3 \%$ der ESBLBildner E. coli waren. In Ausbruchsituationen war die Unterbringung in Einzelzimmern, zusammen mit weiteren Maßnahmen (Schulung, Aufnahmescreening) wirksam, um weitere Übertragungen zu verhindern [158].

Cheng et al. [344] beobachteten auf ihrer Intensivstation den Verlauf nosokomialer Infektionen verursacht durch MRSA (untergebracht in Einzelzimmern) bzw. ESBL-Bildnern (Basishygiene, keine Isolierung). Die MRSA-Infektionen gingen zurück, während Infektionen durch ESBL-Bildner anstiegen. Letzteres wurde jedoch auf einen zunehmenden Import von ESBL-Bildnern aus dem ambulanten Bereich auf die Intensivstation zurückgeführt.

Kola et al. [139] beobachteten über einen Zeitraum von 2 Jahren 123 ESBLPatienten (E. coli, K. pneumoniae und $P$. mirabilis), von denen $80 \%$ in Einzelzimmern isoliert wurden. 98 ESBL-Bildnerpositive Patienten hatten einen Zimmernachbarn, der untersucht werden konnte, es kam jedoch nur in 7 Fällen (8\%) zu einer Übertragung. Ob die Isolierung effektiv weitere Fälle verhindert hat, ist der Publikation nicht zu entnehmen.

Gardam et al. propagieren, dass aufgrund der polyklonalen Erregercharakteristik für ihre Transplantationspatienten eine Isolierung beim Nachweis antibiotikaresistenter E. coli in der Endemiesituation nicht notwendig sei.

In einer kanadischen Untersuchung versuchten die Autoren festzustellen, ob niedrige Raten von antibiotikaresistenten Erregern in den Krankenhäusern auf die strikte Einhaltung von Hygienemaßnahmen zurückgeführt werden können [345]. $4 \%$ der Einrichtungen führten ein regelmäßiges Prävalenzscreening auf ESBL-/AmpC-Bildner durch, 46,2 \% markierten ESBL- und 15,4 \% markierten AmpC-Patienten und $50 \%$ führten Barrieremaßnahmen (Kittel und Handschuhe) bei Patienten mit ESBL-Bildnern durch. Korrelationen zur Prävalenz von ESBL-/AmpC-Bildner wurde nicht dargestellt. 


\begin{tabular}{|c|c|c|c|c|c|c|}
\hline & $\begin{array}{l}\text { Verbreitung } \\
\text { überwiegend } \\
\text { klonal }\end{array}$ & $\begin{array}{l}\text { Reproduktion im } \\
\text { Krankenhaus }\end{array}$ & $\begin{array}{l}\text { Krankenhaus- } \\
\text { assoziierte } \\
\text { Verbreitung in } \\
\text { Deutschland }\end{array}$ & Infektionsrate & $\begin{array}{l}\text { Gegenüber sen- } \\
\text { siblen Isolaten } \\
\text { erhöhte Mortali- } \\
\text { tät }\end{array}$ & $\begin{array}{l}\text { Über Standard- } \\
\text { hygiene hinausge- } \\
\text { hende Maßnahmen }\end{array}$ \\
\hline 3MRGN E. coli & Nein & $<1$ & Nein & $30 \%$ & $\mathrm{Ja}$ & Ja (Risikobereiche) \\
\hline 4MRGN E. coli & $\mathrm{Ja}$ & $\begin{array}{l}\text { Ungenügende } \\
\text { Daten }\end{array}$ & $\mathrm{Ja}$ & Keine Daten & $\mathrm{Ja}^{1}$ & Ja (alle Bereiche) \\
\hline $\begin{array}{l}\text { 3MRGN Klebsiella } \\
\text { spp. }\end{array}$ & ungeklärt & $<1$ & $\begin{array}{l}\text { Ungenügende } \\
\text { Daten }\end{array}$ & 10 bis $20 \%$ & $\mathrm{Ja}$ & $\begin{array}{l}\text { Ja (mindestens Risi- } \\
\text { kobereiche) }\end{array}$ \\
\hline 4MRGN Klebsiella spp. & $\mathrm{Ja}$ & Oft $>1$ & $\mathrm{Ja}$ & 40 bis $80 \%$ & $\mathrm{Ja}$ & Ja (alle Bereiche) \\
\hline $\begin{array}{l}\text { 3MRGN } \\
\text { Enterobacter spp. }\end{array}$ & Nein & $<1$ & Nein & $10-20 \%$ & Nein & Nein \\
\hline $\begin{array}{l}\text { 4MRGN } \\
\text { Enterobacter spp. }\end{array}$ & $\mathrm{Ja}$ & $\begin{array}{l}\text { Ungenügende } \\
\text { Daten }\end{array}$ & $\mathrm{Ja}$ & Keine Daten & $\mathrm{Ja}$ & Ja (alle Bereiche) \\
\hline $\begin{array}{l}\text { andere 3MRGN } \\
\text { Enterobakterien }\end{array}$ & $\begin{array}{l}\text { Nein (Ausnahme } \\
\text { Serratia spp.) }\end{array}$ & $\begin{array}{l}\text { Ungenügende } \\
\text { Daten }\end{array}$ & Nein & Keine Daten & $\begin{array}{l}\text { Ungenügende } \\
\text { Daten }\end{array}$ & Nein \\
\hline $\begin{array}{l}\text { andere 4MRGN } \\
\text { Enterobakterien }\end{array}$ & $\begin{array}{l}\text { Ungenügende } \\
\text { Daten }\end{array}$ & $\begin{array}{l}\text { Ungenügende } \\
\text { Daten }\end{array}$ & $\begin{array}{l}\text { Ungenügende } \\
\text { Daten }\end{array}$ & $\begin{array}{l}\text { Ungenügende } \\
\text { Daten }\end{array}$ & $\begin{array}{l}\text { Ungenügende } \\
\text { Daten }\end{array}$ & Ja (alle Bereiche) ${ }^{2}$ \\
\hline $\begin{array}{l}\text { 3MRGN } \\
\text { P. aeruginosa }\end{array}$ & $\begin{array}{l}\text { Klonale und nicht- } \\
\text { klonale Verbrei- } \\
\text { tung beschrieben }\end{array}$ & $\begin{array}{l}\text { Nach Stamm, } \\
\text { sowohl }<1 \text { als } \\
\text { auch }>1\end{array}$ & Einige Stämme & 15 bis $25 \%$ & $\mathrm{Ja}$ & Ja (Risikobereiche) \\
\hline $\begin{array}{l}\text { 4MRGN } \\
\text { P. aeruginosa }\end{array}$ & $\begin{array}{l}\text { Klonale und nicht- } \\
\text { klonale Verbrei- } \\
\text { tung beschrieben }\end{array}$ & $\begin{array}{l}\text { Nach Stamm, } \\
\text { sowohl }<1 \text { als } \\
\text { auch }>1\end{array}$ & Einige Stämme & 15 bis $25 \%$ & $\mathrm{Ja}$ & Ja (alle Bereiche) \\
\hline 3MRGN A. baumannii & $\mathrm{Ja}$ & Oft $>1$ & $\begin{array}{l}\text { Ungenügende } \\
\text { Daten }\end{array}$ & Сa. $20 \%$ & $\begin{array}{l}\text { Ungenügende } \\
\text { Daten }\end{array}$ & $\begin{array}{l}\text { Ja (mindestens Risi- } \\
\text { kobereiche) }\end{array}$ \\
\hline 4MRGN A. baumannii & $\mathrm{Ja}$ & Meist $>1$ & $\mathrm{Ja}$ & Ca. $20 \%$ & $\mathrm{Ja}$ & Ja (alle Bereiche) \\
\hline \multicolumn{7}{|c|}{$\begin{array}{l}{ }^{1} \text { Analogieschluss aus Daten für 3MRGN E. coli bei derzeit noch ungenügenden Daten } \\
{ }^{2} \text { Die Empfehlung ergibt sich aus einem Analogieschluss zu Enterobacter spp. } \\
{ }^{3} \text { Die publizierten Daten erlauben derzeit keine Unterscheidung zwischen 3MRGN P. aeruginosa und 4MRGN P. aeruginosa. Die Eingruppierung erfolgt daher in Analogie } \\
\text { zu den anderen Erregern und aufgrund der extrem eingeschränkten therapeutischen Möglichkeiten bei 4MRGN P. aeruginosa. }\end{array}$} \\
\hline
\end{tabular}

Woerther et al. propagieren in einer populationsepidemiologischen Studie an Wayampi-Indianern den restriktiven Einsatz von Antibiotika als wichtigste Maßnahme, um eine intestinale Kolonisation und die konsekutive Transmission von ESBLE. coli zu verhindern [346].

Im Rahmen einer Risikoanalyse des ECDC zur Verbreitung Carbapenem-resistenter Enterobakterien wurden auch Empfehlungen zur Prävention herausgegeben [347]. Hier wird empfohlen alle Patienten, die aus internationalen Krankenhäusern (unabhängig davon aus welchem Land) verlegt werden, zu screenen und bis zum Vorliegen des Befundes $\mathrm{zu}$ isolieren. Auf Basis einiger Berichte zur Bekämpfung von Ausbrüchen wurde empfohlen, dass die Pflege von Risikopatienten oder positiven Patienten durch speziell zugeordnetes Personal er- folgen sollte. Insgesamt wurde die Datenlage jedoch als gering eingeschätzt und eine Evidenz-Kategorisierung der Empfehlung nicht gegeben.

Der Nutzen einer Unterbringung in Einzelzimmern lässt sich für $3 M R G N \mathrm{E}$. coli in der Endemiesituation nicht generell belegen. In Ausbruch-Situationen war die Einzelzimmerunterbringung in Kombination mit weiteren Maßnahmen effektiv.

- Die Kommission empfiehlt:

- Patienten mit Besiedelung oder Infektion durch 3MRGN E. coli in Risikobereichen ${ }^{\star}$, Patienten mit Besiedelung oder Infektion durch 4MRGN E. coli in allen Krankenhausbereichen $\mathrm{zu}$ isolieren (Kat II).

- Risikobereiche nach individueller Risikoabwägung, z. B. auf Basis des Patien- tengutes und baulich-struktureller Gegebenheiten festzulegen, wobei Intensivstationen, inklusive der Neonatologie und hämatologisch-onkologische Stationen als Bereiche mit besonders gefährdeten Patienten gelten.

- Es ist eine offene Frage, ob in der endemischen Situation Patienten, die aufgrund des Verdachtes der Besiedelung, einer nachgewiesenen Besiedelung oder Infektion mit 4MRGN E. co$l i$ isoliert werden, durch speziell zugeordnetes Personal gepflegt werden sollen (Kat III).

${ }^{*}$ Als Risikobereiche gelten solche, in denen Patienten mit einer erhöhten Infektionsgefahr gepflegt werden. 


\section{Screeningprogramme}

Screeningmethode: Am häufigsten werden Rektalabstriche zum Screening auf ESBL-Bildner eingesetzt. Im Rahmen des Ausbruchsmanagements ist diese Methode etabliert.

Der Nachweis von ESBL-produzierenden Bakterien beruht klassischerweise auf einem Suchtest, mit dem verdächtige Enterobakterien identifiziert werden, und einem Bestätigungstest, mit dem die ESBL-Produktion bestätigt oder ausgeschlossen wird [348]. Hinsichtlich des geeigneten Screeningverfahrens sind viele Fragen ungeklärt. So sind der Einfluss des verwendeten Abstrichtupfers oder der Qualität der verwendeten Untersuchungsmedien noch unzureichend untersucht.

In Anreicherungsexperimenten mit gespikten Stuhlproben ließen sich ESBLbildende E. coli bis zu einer Verdünnung von 7 Logstufen wiederfinden [349]. Die gleiche Arbeitsgruppe untersuchte 500 Surveillance-Abstriche aus Rachen und Rektum von 88 Beatmungspatienten mit und ohne Anreicherungskultur in Trypton-Soja-Bouillon. Neun Patienten waren mit ESBL-Bildnern kolonisiert, davon 5 mit ESBL-bildenden E. coli. Die Anreicherungskultur entdeckte signifikant mehr $(\mathrm{p}=0,006)$ ESBL-Bildner und dies auch etwa 1 Woche früher.

March et al. [160] berichteten über die Nachweishäufigkeit von ESBL-Bildnern (allgemein) bei insgesamt 225 Personen (Heimbewohner, Mitarbeitern und ger iatrische Patienten). Die höchste Sensitivität hatte der Rektalabstrich mit $96 \%$ gefolgt vom Inguinalabstrich mit $73 \%$, wobei der Goldstandard aus der Summe der Personen errechnet wurde, die in einem der entnommenen Abstriche positiv waren, und daher nicht als unabhängiger Maßstab angesehen werden kann. Bühlmann et al. [350] fanden bei der Untersuchung von Trägern ESBLbildender Enterobakterien eine Sensitivität von $70 \%$ für Perianal-Abstriche, 63 $\%$ für Inguinal-Abstriche und $72 \%$ für die Untersuchung von Urin. Andere Autoren berichten von niedriger Sensitivität des rektalen oder perirektalen Screenings, bei dem nur 40 bis $50 \%$ der Träger erkannt wurden $[139,351]$. In keiner der klinischen Untersuchungen wurden Anreicherungskulturen durchgeführt.

Effektivität von aktiver Surveillance:

In der endemischen Situation wird bisher ein Aufnahmescreening auf ESBLbildende E. coli nur bei Patienten mit bestimmtem Risikoprofil empfohlen. Eine retrospektive Studie von Thouverez et al. [351] an 2883 Patienten empfiehlt aufgrund der niedrigen Prävalenz (0,45\%) und der geringen Aussagekraft der Screeninguntersuchung ( 9 von 19 Fällen nicht erkannt) kein Aufnahmescreening in einer endemischen Situation. Gardam et al. zeigten, dass ein Screening auf multiresistente Enterobakterien bei Aufnahme für Patienten mit Organtransplantation in Kanada in der Endemiesituation nicht kosteneffektiv war [38].

Meyer et al. screenten Patienten bei Aufnahme auf eine Intensivstation und fanden ESBL-Bildner bei $3 \%$ bis $9 \%$ der Patienten. Sie empfahlen ein Screeningprogramm für Patienten mit erhöhtem Infektionsrisiko als Grundlage für eine empirische Therapie bei Infektionen [207].

Für ein risikobasiertes Aufnahmescreening gelten als Risikopatienten Personen, die aus anderen Einrichtungen des Gesundheitswesens übernommen werden [342] oder aus Hochendemiegebieten verlegt werden. US-amerikanische militärisch-medizinische Einrichtungen (MEDCENs = military medical centers) führen seit 2008 ein standardisiertes Eingangsscreening auf multiresistente Erreger bei verwundeten Militärangehörigen durch. Da das Screening vorrangig auf multiresistente Acinetobacter spp. abzielt, wird anstelle eines Rektalabstrichs ein beidseitiger Leistenabstrich entnommen [352]. Allerdings lag die Sensitivität dieser Maßnahme in einer anderen Untersuchung nur bei $63 \%$ [350].

Kola et al. screenten im endemischen Setting Kontaktpatienten zu Trägern von ESBL-Bildnern und fanden $11 \%$ positive Kontaktpatienten, die wiederum isoliert wurden [139]. Es konnte jedoch nicht abgeschätzt werden, ob dieses Vorgehen effektiv war hinsichtlich der Prävention weiterer Fälle.

Im Rahmen einer Risiko-Analyse des ECDC zur Verbreitung Carbapenem-re- sistenter Enterobakterien wurden auch Empfehlungen zur Prävention herausgegeben [347]. Hier wird empfohlen alle Patienten, die aus internationalen Krankenhäusern (unabhängig davon aus welchem Land) verlegt werden, zu screenen und bis zum Vorliegen des Befundes zu isolieren. Zu dieser Empfehlung wird jedoch keine Evidenz-Kategorie gegeben. Um die Maßnahme auf Patienten mit erhöhten Risiko zielgerichtet durchzuführen, ist es sinnvoll auf Basis der individuellen Zuweiserstruktur und regionalen Epidemiologie eigene Richtlinien für das Krankenhaus zu erstellen, welche $\mathrm{Pa}$ tienten einem Screening unterzogen werden sollen. Informationen aus der ARSDatenbank des RKI, europäische Daten (EARSS) und die internationale Literatur sollten dabei berücksichtigt werden (https://ars.rki.de/CommonReports/Resistenzuebersicht.aspx).

\section{- Die Kommission empfiehlt:}

- alle Patienten mit Risiko für eine Besiedelung oder Infektion mit 4MRGN E. coli zu screenen und bis zum Vorliegen der Ergebnisse zu isolieren. Als Risikopatienten gelten Patienten mit kürzlichem Kontakt zum Gesundheitssystem in Ländern mit endemischem Auftreten und Patienten, die zu 4MRGN E. coli-positiven Patienten Kontakt hatten, d. h. im gleichen Zimmer gepflegt wurden (Kat. II).

- Screening-Richtlinien auf Basis der Patientenstruktur festzulegen und regelmäßig auf Basis aktueller Informationen zu aktualisieren.

- als Screeningproben Rektalabstriche und ggf. zusätzlich Urin und chronische Wunden zu wählen (Kat II). Bei bisher nicht standardisierten Untersuchungsmethoden kann die Sensitivität ggf. durch Einsatz von Anreicherungsmedien erhöht werden (Kat II).

- aktives Screening auf 3MRGN E. coli in der endemischen Situation zur Prävention der weiteren Verbreitung nicht durchzuführen, da es sich nicht als effektiv erwiesen hat (Kat II). Screening aus anderen Gründen, z. B. als Grundlage für kalkulierte empirische Antibiotika-Therapien in der Neonatologie bleibt davon unberührt. 
Sanierungsmöglichkeiten: Patienten, die mit ESBL-bildenden E. coli kolonisiert sind, bleiben dies häufig über mehrere Monate. Alsterlund et al. [353] untersuchte 42 Patienten mit ESBL-bildenden E. coli. Von diesen waren 5 dauerhaft besiedelt (mediane Beobachtungsdauer 58 Monate). 16 Patienten waren nach einer medianen Beobachtungsdauer von 9 Monaten verstorben, 18 hatten mehrere negative Abstriche nach 7,5 Monaten.

Es wurden nur wenige Studien $\mathrm{zu}$ Eradikation von ESBL-bildenden E. co$l i$ durchgeführt, die keine überzeugenden Erfolgsraten zeigten. Buehlmann et al. [354] beschreiben mehrere unterschiedliche Eradikationsversuche, teilweise parallel zu systemisch verabreichten Antibiotikagaben, bei 100 mit ESBLBildnern besiedelten Patienten, davon 71 Patienten mit ESBL-bildenden E. coli. In einer Übersichtstabelle dekolonisierter ESBL-Patienten $(\mathrm{n}=35)$ werden 30 ESBL-bildende E. coli-besiedelte $\mathrm{Pa}$ tienten genannt, so dass die Autoren von einer Eradikation von $42 \%$ der ESBL-bildenden E. coli-Träger nach einem durchschnittlichen Beobachtungszeitraum von 24,5 Monaten ausgehen.

In einer französischen Untersuchung wurde die selektive Darmdekontamination zur Eradikation von ESBL-Bildnern (ohne Angaben zur Speziesverteilung) angewandt. Die Behandlung bestand aus zwei der folgenden Antibiotika: Polymyxin E (1,5 Millionen Einheiten), Neomycin (500 mg) oder Erythromycin (500 mg) 4x/Tag. Nur 17 von 37 Patienten ( $46 \%$ ) hatten 2 negative Kontrolluntersuchung jeweils unter der Behandlung und galten damit als eradiziert. Nachuntersuchungen wurden nicht erwähnt [355].

\section{- Die Kommission empfiehlt:}

- solange keine nachvollziehbaren erfolgreichen Sanierungskonzepte für 3MRGN oder 4MRGN E. coli vorliegen, Sanierungsmaßnahmen für mit 3MRGN oder 4MRGN E. coli besiedelte Patienten nicht durchzuführen (Kat II).

\subsubsection{Klebsiella spp.}

Aussagen zur Effektivität einzelner Maßnahmen zur Prävention der Übertragung von antibiotikaresistenten $K$. pneumoniae sind nicht sicher möglich, da in den veröffentlichten Studien immer mehrere Interventionen gleichzeitig vorgenommen wurden, und die Compliance mit der Basishygiene vor der Intervention unklar bleibt.

Im Rahmen der Intervention bei Ausbrüchen von ESBL-bildenden Klebsiellen wurden Surveillance-Kulturen, Isolierung und Kohortierung der Patienten, zum Teil in gesonderten Bereichen, und Kohortierung des Pflegepersonals eingesetzt $[171,356]$.

Für das endemische Setting beschreiben Lipworth et al. [357] einen Versuch, die Zunahme von ESBL-bildenden E. co$l i$ und Klebsiellen in zwei Krankenhäusern durch Veränderung des Antibiotikaregimes zu beeinflussen. Bei einem Rückgang der Verwendung von Ceftriaxon- um 86 \% bzw. $95 \%$ und des Ceftazidim-Verbrauchs um 95 \% bzw. $97 \%$ ging die Prävalenz der ESBL-BildnerNachweise um 45 \% bzw. $22 \%$ zurück. Eine geringere Reduktion der Nachweise von ESBL-Bildnern wurde in einem Haus mit hohem Anteil an Heimbewohnern und chronisch kranken Patienten erreicht. Auch Lee et al. [358] konnten eine Reduktion der Inzidenz von ESBLNachweisen im Trachealsekret nach Reduktion des Verbrauches von 3. Generations-Cephalosporinen nachweisen.

Im Rahmen eines Programmes, welches zur Prävention von MRSA eingeführt wurde (u. a. Einführung von Händedesinfektion und Umgebungsdesinfektion mit einem „Kulturwechsel“ hin $\mathrm{zu}$ verbesserten Hygienemaßnahmen), ging der Nachweis von ESBL-bildenden gramnegativen Stäbchen signifikant zurück [359].

In fünf französischen Kinderkliniken wurde ein Programm zur Prävention mit den Komponenten Screening, Barrieremaßnahmen und Einzelunterbringung durchgeführt. Die mittlere Inzidenz von ESBL-bildenden K. pneumoniae sank innerhalb von 5 Jahren von 0,71 auf 0,12 pro 1000 Patiententage [360].

Für Carbapenemase-produzierende K. pneumoniae wurde in Studien aus Is- rael eine sinkende Inzidenz im Zusammenhang mit bestimmten kombinierten Interventionsmaßnahmen gezeigt.

Landesweit fand sich eine sinkende Inzidenz, nachdem eine nationale Taskforce etabliert wurde, die die Einhaltung der Empfehlung zur aktiven Surveillance und zur Kohortenisolierung mit Betreuung durch spezielles Pflegepersonal überwachte [361]. In einem Krankenhaus war die Einzelzimmerisolierung nicht erfolgreich bei der Prävention weiterer Übertragungen. Erst die Kohortierung der Patienten mit Betreuung durch zugeordnetes Pflegepersonal in Kombination mit aktiver Surveillance konnte die Inzidenz neuer Infektionen bzw. Kolonisationen senken [362]. In einem weiteren Krankenhaus in Israel wurden nicht näher spezifizierte Barrieremaßnahmen bei Patienten mit Kolonisation oder Infektion durch Carbapenem-resistente K. pneumoniae in Kombination mit aktiver Surveillance umgesetzt. Wiederum konnte eine sinkende Inzidenz von Neuinfektionen beobachtet werden [363].

Auf einer Intensivstation in New York konnte die Inzidenz neuer kultureller Nachweise von Carbapenem-resistenten $K$. pneumoniae gesenkt werden, nachdem eine Kohortenisolierung der Patienten mit Carbapenem-resistenten $K$. pneumoniae erfolgte, kombiniert mit einer Betreuung durch zugeordnetes Pflegepersonal, Maßnahmen zur Erhöhung der Compliance der Händehygiene sowie einer aktiven Surveillance [364].

Neben diesen Studien aus Endemiegebieten gibt es auch Beschreibungen erfolgreich terminierter Ausbrüche, bei denen ebenfalls Einzelzimmerisolierung oder Kohortenisolierung, Maßnahmen zur Verbesserung der Compliance mit der Händehygiene sowie aktive Surveillance eingesetzt wurden $[69,187,365$ 368].

Im Rahmen einer Risikoanalyse des ECDC zur der Verbreitung Carbapenem-resistenter Enterobakterien wurden auch Empfehlungen zur Prävention herausgegeben [347]. Hier wird empfohlen alle Patienten, die aus internationalen Krankenhäusern (unabhängig davon aus welchem Land) verlegt werden, zu screenen und bis zum Vorliegen des Befundes 
zu isolieren. Die Pflege von Risikopatienten oder positiven Patienten soll durch eigens zugeordnetes Personal erfolgen.

\section{- Die Kommission empfiehlt:}

- Patienten mit Besiedelung oder Infektion durch 3MRGN Klebsiella spp. in Risikobereichen, Patienten mit Besiedelung oder Infektion durch 4MRGN Klebsiella spp. in allen Krankenhausbereichen zu isolieren (Kat II).

- Risikobereiche* nach individueller Risikoabwägung, z. B. auf Basis des Patientengutes und baulich struktureller Gegebenheiten festzulegen, wobei Intensivstationen, inklusive der Neonatologie und hämatologisch-onkologische Stationen als Bereiche mit besonders gefährdeten Patienten gelten.

- Es ist eine offene Frage, ob in der endemischen Situation Patienten, die aufgrund des Verdachts der Besiedelung, einer nachgewiesenen Besiedelung oder Infektion mit 4MRGN Klebsiella spp. isoliert werden, durch speziell zugeordnetes Personal gepflegt werden sollen (Kat III).

${ }^{*}$ Risikobereiche sind solche, in denen Patienten mit einer erhöhten Infektionsgefahr gepflegt werden.

\section{Screeningprogramme}

Screeningmethode: $\mathrm{Da}$ in der Regel gleichzeitig auf E. coli und Klebsiellen gescreent wird, sind kombinierte Daten für ESBL-Screening heranzuziehen. Bei der Untersuchung von 500 Surveillance-Abstrichen aus Rachen und Rektum von 88 Beatmungspatienten mit und ohne Anreicherungskultur in Trypton-Soja-Bouillon fanden Murk et al. [349] eine höhere Sensitivität bei der Verwendung einer Anreicherungskultur. March et al. fanden bei der Untersuchung von Heimbewohnern, Mitarbeitern und geriatrischen Patienten (225 Personen) die höchste Sensitivität im Rektalabstrich mit $96 \%$ gefolgt vom Inguinalabstrich mit $73 \%$, wobei kein geeigneter Goldstandard verwendet wurde. Andere Autoren berichten von niedriger Sensitivität des rektalen oder perirektalen Screenings, bei dem nur 40 bis $50 \%$ der Träger erkannt wurden [139, 351]. In keiner der klinischen Untersuchungen wurden Anreichungskulturen durchgeführt.

Bühlmann et al. [350] fanden bei der Untersuchung von Trägern ESBL-bildender Enterobakterien eine Sensitivität von $70 \%$ für Perianal-Abstriche, $63 \%$ für Inguinal-Abstriche und $72 \%$ für die Untersuchung von Urin.

Für den Nachweis Carbapenem-resistenter Klebsiellen hat die Untersuchung von Rektal-Abstrichen eine Sensitivität von $94 \%$ ergeben [369]. Perianal-Abstriche haben eine Sensitivität von $53 \%$ [370].

Auch für Carbapenem-resistente Klebsiellen konnte die Sensitivität des Nachweises durch selektive Anreicherungs-Bouillons erhöht werden [371].

Bei Verlaufsuntersuchungen von $\mathrm{Pa}$ tienten mit bereits nachgewiesenen multiresistenten Erregern kann zusätzlich zu den oben genannten Probenlokalisationen auch noch eine Lokalisation gewählt werden, die sich am Ort des Erstnachweises oder der weiteren klinischen Situation des Patienten orientiert. Mögliche Materialien für solche Untersuchungen können Urin, Wundabstriche oder Trachealsekrete sein.

Die weitere Untersuchung auf K. pneumoniae mit Bildung von ESBL oder Carbapenemasen kann durch Verwendung von Screening-Agarplatten erfolgen [372].

\section{Effektivität von aktiver Surveillance:}

Für Carbapenem-resistente Klebsiellen ist aktive Surveillance im Sinne einer Untersuchung von Kontaktpatienten oder regelmäßigen Untersuchungen aller Patienten in bestimmten Bereichen wie z. B. der Intensivstation nahezu immer Bestandteil der Interventionen bei erfolgreich kontrollierten Ausbrüchen oder der Verringerung der Inzidenz von Übertragungen in der endemischen Situation [187, 364-368].

Von acht Patienten mit Nachweis von Carbapenem-resistenten $K$. $p$ neumoniae sowohl aus einem klinischen Material bei Infektion als auch in der Surveillance-Kultur ging in einer Studie bei drei Patienten die positive Surveillance-Kultur dem Nachweis aus einem klinischen Material im Mittel 7
Tage voraus [364]. In einer anderen Studie fand sich bei $26 \%$ aller Patienten mit positiver Surveillance-Kultur im weiteren Verlauf eine positive mikrobiologische Probe und zwar im Median neun Tage nach der Surveillance-Kultur [183].

Für ESBL-bildende Klebsiellen liegen nur Ergebnisse zu genereller Surveillance auf ESBL-Bildner vor. Thouverez et al. [351] empfehlen aufgrund der niedrigen Prävalenz $(0,45 \%)$ und der geringen Aussagekraft der Screeninguntersuchung kein Aufnahmescreening in der endemischen Situation. Auch Gardam et al. fanden, dass ein Screening auf multiresistente Enterobakterien bei Aufnahme für Patienten mit Organtransplantation in $\mathrm{Ka}$ nada in der Endemiesituation nicht kosteneffektiv war [38].

Meyer et al. empfahlen ein Screeningprogramm für Patienten mit erhöhtem Infektionsrisiko als Grundlage für eine empirische Therapie bei Infektionen [207] nachdem $3 \%$ bis $9 \%$ der Patienten bei einem Aufnahme-Screening auf Intensivstation positiv waren.

Das Screening von Kontaktpatienten wurde von Kola et al. untersucht. Die Arbeitsgruppe screente im endemischen Setting Kontaktpatienten von ESBL-kolonisierten Patienten und fand $11 \%$ positive Kontaktpatienten, die wiederum isoliert wurden [139]. Es konnte jedoch nicht abgeschätzt werden, ob dieses Vorgehen effektiv war hinsichtlich der Prävention weiterer Fälle.

Im Rahmen einer Risiko-Analyse des ECDC zur Prävention der Verbreitung Carbapenem-resistenter Enterobakterien wurden Empfehlungen zur Prävention herausgegeben [347]. Hier wird empfohlen alle Patienten, die aus internationalen Krankenhäusern (unabhängig davon aus welchem Land) verlegt werden, zu screenen und bis zum Vorliegen des Befundes zu isolieren.

\section{- Die Kommission empfiehlt:}

- alle Patienten mit Risiko für eine Besiedelung oder Infektion mit 4MRGN Klebsiella spp. zu screenen und bis zum Vorliegen der Ergebnisse zu isolieren. Als Risikopatienten gelten Patienten mit kürzlichem Kontakt zum Gesundheitssystem in Ländern mit endemischem Auftreten und Patienten, die zu 
4MRGN Klebsiella spp.-positiven Patienten Kontakt hatten, d. h. im gleichen Zimmer gepflegt wurden (Kat II).

- Screening-Richtlinien auf Basis der Patientenstruktur festzulegen und regelmäßig auf Basis aktueller Informationen zu aktualisieren.

- als Screeningproben Rektalabstriche und ggf. zusätzlich Urin und chronische Wunden zu wählen (Kat II). Bei bisher nicht standardisierten Untersuchungsmethoden kann die Sensitivität ggf. durch Einsatz von Anreicherungsmedien erhöht werden (Kat II).

- aktives Screening auf 3MRGN Klebsiella spp. in der endemischen Situation zur Prävention der weiteren Verbreitung nicht durchzuführen, da es sich nicht als effektiv erwiesen hat (Kat II). Screening aus anderen Gründen, z. B. als Grundlage für kalkulierte empirische Antibiotika-Therapien in der Neonatologie bleibt davon unberührt.

Sanierungsmöglichkeiten: Es ist davon auszugehen, dass sich - mindestens bei einem Teil der Patienten - die Kolonisation nach Monaten ohne gezielte weitere Maßnahmen verliert. In einer Untersuchung zur ESBL-Epidemiologie war bei nur $6,8 \%$ der Patienten keine Besiedelung mehr nachweisbar [139].

Gut validierte medizinische Maßnahmen zur Sanierung einer Kolonisation mit multiresistenten gramnegativen Bakterien stehen nicht zur Verfügung.

Buehlmann et al. [354] beschreiben mehrere unterschiedliche Eradikationsversuche, teilweise parallel zu systemisch verabreichten Antibiotikagaben, bei 100 mit ESBL-Bildnern besiedelten Patienten, davon 25 Patienten mit ESBL-bildender K. pneumoniae. In einer Übersichtstabelle dekolonisierter ESBL-Patienten $(\mathrm{n}=35)$ werden $5 \mathrm{mit}$ ESBL-bildender K. pneumoniae besiedelte Patienten genannt, so dass von einer Eradikation bei $14 \%$ der ESBL-bildenden K. pneumoniae-Träger nach einem durchschnittlichen Beobachtungszeitraum von 24,5 Monaten ausgegangen werden kann.

Bei Anwendung selektiver Darmdekontamination (2 der folgenden Antibiotika: Polymyxin E (1,5 Millionen Einheiten), Neomycin (500 mg) oder Erythro- mycin (500 mg) 4x/Tag) zur Eradikation von ESBL-Bildnern (ohne Angaben zur Speziesverteilung) wurden nur $46 \%$ der Patienten negativ unter der Behandlung und galten damit als eradiziert. Nachuntersuchungen wurden nicht erwähnt [355].

Zuckermann et al. behandelten 15 Knochenmarkstransplantationspatienten mit Gentamycin und erreichten eine Eradikation unter Therapie bei 10 Patienten [373].

Der Versuch einer Dekolonisierung mit systemischen oder topischen Antibiotika kann jedoch aufgrund der Resistenzselektion gefährlich sein und sollte nur im Rahmen von Studien erfolgen.

\section{- Die Kommission empfiehlt:}

- solange keine nachvollziehbaren erfolgreichen Sanierungskonzepte für 3MRGN oder 4MRGN Klebsiella spp. vorliegen, Sanierungsmaßnahmen für mit 3MRGN oder 4MRGN Klebsiella spp. besiedelte Patienten nicht durchzuführen (Kat II).

\subsubsection{Enterobacter spp.}

Im Rahmen von Ausbrüchen mit Enterobacter spp. wurden die entsprechenden Hygienemaßnahmen etabliert, wenn die Quelle identifiziert werden konnte, z. B. Desinfektion von kontaminierten Thermometern oder sachgerechter Umgang mit Mehrdosisbehältnissen [218, 219]. In vielen Fällen, in denen keine Quelle nachweisbar war und von einer Übertragung durch das medizinische Personal ausgegangen werden konnte, wurden Basishygienemaßnahmen (Händehygiene) forciert, Patienten kohortiert, ein Aufnahmescreening eingeführt, Neuzugänge auf Station begrenzt und die empirische Antibiotikatherapie modifiziert [218]. Bei einem Enterobacter-Ausbruch auf einer niederländischen neonatologischen Station wurden zunächst alle $\mathrm{Pa}$ tienten mit Enterobacter spp. (unabhängig von der Resistenz) mit Barrieremaßnahmen (Kittel, Handschuhe) gepflegt [216]. Nach Beendigung des Ausbruchs wurden diese Maßnahmen für sensible Enterobacter aufgehoben. Dies führte nicht zu einer vermehrten Kolonisation der Neugeborenen. Die Autoren schlussfolgern, dass Barrieremaßnahmen bei sensiblen Enterobacter nicht notwendig sind.

In zwei Studien kam es nicht zu einer Verminderung der Transmission nach Einführung von strikteren Hygienemaßnahmen. In einem spanischen Krankenhaus konnten Einzelzimmerisolierung neben Standard- und Kontaktisolierungs-Maßnahmen die Übertragung auf insgesamt 38 Patienten mit ESBL-produzierenden E. cloacae (nur noch empfindlich auf Carbapeneme, Tigecyclin-resistent) nicht stoppen [79]. In einer belgischen Studie führten die frühe Implementierung von Kohortenpflege und intensivierte Sterilisationsfrequenz von Beatmungsmaterial nicht dazu, dass die Übertragung von multiresistenten E. aerogenes (nur noch empfindlich auf Imipenem und Gentamycin) gestoppt wurde [206]. Der Nachweis von E. aerogenes gelang in 5,7\% der untersuchten Umgebungsproben; auf den Händen von Mitarbeitern $(n=50)$ war er jedoch nicht nachweisbar.

Eine Umgebungskontamination durch Enterobacter spp. konnte bei einem Ausbruch auf zwei neonatologischen Stationen nur im Waschbecken (allerdings nicht der Ausbruchsstamm) und auf Thermometern (Quelle) nachgewiesen werden [374]. In einer französischen Studie wurde die Umgebungskontamination auf einer chirurgischen Intensivstation mit ESBL-positiven Enterobakterien untersucht [375]. 1,7 \% der 2038 aufgenommen Patienten waren mit ESBL-Bildnern infiziert oder kolonisiert. In 176 Umgebungsuntersuchungen (Bettumgebung, Computer, Arbeitsplatte u.a.) wuchsen in $26 \%$ ESBL-Bildner (davon waren 12 Stämme E. cloacae). Die 12 Stämme hatten insgesamt 4 PFGE-Muster; ein Stamm war identisch bei $4 \mathrm{~Pa}$ tienten, die keinen überlappenden Aufenthalt hatten. Im Vergleich zu K. oxytoca (37 Umgebungsstämme) und identischen Stämmen bei 14 Patienten war die Übereinstimmung jedoch deutlich geringer, was möglicherweise ein Hinweis darauf ist, dass die Umgebungskontamination bei Klebsiella spp. eine größere Rolle spielt. Auf zwei US-Amerikanischen Intensivstationen wurden 185 Patienten mit E. aerogenes aufgenommen und über ein Jahr 6-mal pro Jahr diverse Umgebungs- 
und Händeuntersuchungen des medizinischen Personals vorgenommen [376]. Dabei wurden Enterobacter spp. nur in 10 Umgebungsisolaten nachgewiesen. Bei einem Ausbruch mit 46 Neugeborenen fand sich der Ausbruchsstamm auf den Händen von zwei Krankenschwestern [377].

Im Rahmen einer Risiko-Analyse des ECDC zur Verbreitung Carbapenem-resistenter Enterobakterien wurden auch Empfehlungen zur Prävention herausgegeben [347]. Hier wird empfohlen alle Patienten, die aus internationalen Krankenhäusern (unabhängig davon aus welchem Land) verlegt werden, zu screenen und bis zum Vorliegen des Befundes zu isolieren. Die Pflege von Risikopatienten oder positiven Patienten soll durch eigens zugeordnetes Personal erfolgen.

\section{- Die Kommission empfiehlt:}

- zur Prävention der Übertragung von 3MRGN Enterobacter spp. die Maßnahmen der Basishygiene in allen Krankenhausbereichen durchzuführen (Kat II). Darüber hinausgehende Maßnahmen sind in der endemischen Situation nicht erforderlich.

- Patienten mit Besiedelung oder Infektion durch 4MRGN Enterobacter spp. in allen Krankenhausbereichen zu isolieren (Kat II).

- Es ist eine offene Frage, ob in der endemischen Situation Patienten, die aufgrund des Verdachtes der Besiedelung, einer nachgewiesenen Besiedelung oder Infektion mit 4MRGN Enterobacter spp. isoliert werden, durch speziell zugeordnetes Personal gepflegt werden sollen (Kat III).

\section{Screeningprogramme}

Screeningmethode: Im Rahmen von Ausbruchsuntersuchungen bzw. bei steigender ESBL-Prävalenz bei Enterobakterien wurde oft ein Aufnahmescreening und/oder regelmäßige Screeninguntersuchungen durchgeführt. Dieses umfasste in der Regel Rektal- bzw. Perinealabstriche, um eine gastrointestinale Kolonisation festzustellen, sowie mitunter zusätzlich Rachenabstriche und Screening von Urin und Sekreten aus dem Respirationstrakt. Naesens et al. berichten, dass
$80 \%$ aller Patienten, die mit ESBL-positiven Enterobakterien besiedelt waren, einen Nachweis im Perineal-Abstrich hatten, 33 \% im Urin, 40 \% im Respirationstrakt und $31 \%$ im Rachenabstrich [378]. In einer spanischen Studie war ein multiresistenter E. cloacae bei $22(58 \%)$ von 38 Patienten an mindestens einer weiteren Lokalisation (rektal, tracheal, Wunde, axillär) zusätzlich zum Nachweisort des primären klinischen Isolates nachweisbar [79]. Es gibt bis dato jedoch keine Untersuchung, die systematisch untersucht hat, wo und wie häufig Enterobacter spp. bei kolonisierten oder infizierten Patienten nachgewiesen werden kann.

Der phänotypische Nachweis einer ESBL-Produktion bei Enterobacter spp. ist komplex. In einer niederländischen Studie konnte mittels Screening mit Cefepim im Vitek 2, gefolgt von einem Cefepim/Cefepim-Clavulansäure E-Test, die ESBL-Produktion bei EnterobacterIsolaten sicher erkannt werden (positiver Vorhersagewert $100 \%$; negativer Vorhersagewert $99 \%$ ) [379]. Selektive chromogene Medien werden seit kurzem auch für die Detektion von ESBL-produzierenden Enterobacter spp. angeboten. Die Sensitivität liegt bei über $96 \%$, die Spezifität allerdings nur zwischen $44 \%$ und $78 \%$ [372].

Leverstein-van Hall et al. weisen darauf hin, dass es bei der Surveillance von multiresistenten Enterobacter spp. zu Verzögerungen beim Erkennen eines Ausbruchs kommen kann, wenn die computergestützte Erfassung auf dem Abgleich von Antibiogrammen basiert [380]. Im Fall von Enterobacter spp. sind Antibiogramme sehr variabel (horizontaler Gentransfer); deshalb schlagen die Autoren vor, auf bestimmte Resistenzmarker zu fokussieren bzw. einen speziellen Algorithmus zu etablieren.

\section{Effektivität von aktiver Surveillance:} Routine-Screening der Haut bei Frühgeborenen zur Sepsis-Früherkennung hatte nur einen positiven prädiktiven Wert von $<2 \%$ für Enterobacter spp. bezogen auf positive Blutkulturen, d. h. die Maßnahme war nicht hilfreich [381]. Auch Rektal- und NasopharyngealScreeningabstriche hatten keinen kli- nisch nutzbaren Vorhersagewert für das spätere Auftreten einer Sepsis verursacht durch Enterobacter spp. bei 278 Neugeborenen [382].

Die Kosteneffektivität eines routinemäßigen Aufnahmescreenings auf multiresistente Enterobakterien wurde in einem kanadischen Krankenhaus in der endemischen Situation untersucht [38]. Alle Patienten, die für eine Organtransplantation anstanden, wurden rektal gescreent (bei Aufnahme und im Verlauf). Kolonisierte Patienten wurden nicht isoliert. Von den 287 Patienten waren 69 (24\%) kolonisiert, davon 36 mit Enterobacter spp., $9 \%$ entwickelten eine klinische Infektion. 66 der 69 kolonisierenden Stämme waren Einzelisolate. Die Übertragungen (ein Citrobacter und ein E. coli) führten nicht zu einer Infektion. Die Autoren schlussfolgern, dass routinemäßiges Screening, Kontakt- und Einzelzimmerunterbringung (veranschlagt mit einem finanziellen Aufwand von 1.130.184,44 kanadischen \$) nicht kosteneffektiv sei - zumindest nicht, wenn kein klonaler Ausbruch vorliege. Im Rahmen einer Risiko-Analyse des ECDC zur Verbreitung Carbapenem-resistenter Enterobakterien wurden auch Empfehlungen zur Prävention herausgegeben [347]. Hier wird empfohlen alle Patienten, die aus internationalen Krankenhäusern (unabhängig davon aus welchem Land) verlegt werden, zu screenen und bis zum Vorliegen des Befundes zu isolieren.

\section{- Die Kommission empfiehlt:}

- alle Patienten mit Risiko für eine Besiedelung oder Infektion mit 4MRGN Enterobacter spp. zu screenen und bis zum Vorliegen der Ergebnisse zu isolieren. Als Risikopatienten gelten $\mathrm{Pa}$ tienten mit kürzlichem Kontakt zum Gesundheitssystem in Ländern mit endemischem Auftreten und Patienten, die zu 4MRGN Enterobacter spp.positiven Patienten Kontakt hatten, d. h. im gleichen Zimmer gepflegt wurden (Kat II).

- Screening-Richtlinien auf Basis der Patientenstruktur festzulegen und regelmäßig auf Basis aktueller Informationen zu aktualisieren.

- als Screeningproben Rektalabstriche zu wählen (Kat II). 
- aktives Screening auf 3MRGN Enterobacter spp. in der endemischen Situation zur Prävention der weiteren Verbreitung nicht durchzuführen, da es sich nicht als effektiv erwiesen hat (Kat II). Screening aus anderen Gründen, z. B. als Grundlage für kalkulierte empirische Antibiotika-Therapien in der Neonatologie bleibt davon unberührt.

Sanierungsmöglichkeiten: Enterobacter spp. gehören zur normalen Darmflora. Eine Sanierung des Gastrointestinaltraktes ist schwierig. Abecasis et al. [383] untersuchten in einem englischen Krankenhaus den Einfluss einer selektiven Darmdekontamination (parenteral Cefotaxim und oral Polymyxin E/ Tobramycin) bei Kindern mit ESBL-Bildnern [383]. Die Kinder wurden 2x wöchentlich über 12 Monate gescreent. 39 der 1001 Kinder waren positiv, davon 28 kolonisiert, 11 infiziert ( 8 hatten einen ESBL-positiven Enterobacter spp.). Bei 21 Patienten (54 \%) war die Dekolonisierung erfolgreich. Eine Schweizer Studie zur Dekolonisierung von ESBL-Patienten mit Chlorhexidin 0,2 \% Mundspülung, Paromomycin oral und parenteralen Antibiotika bei Nachweis im Urin berichtete über eine Erfolgsrate von 83 \% (15/18 Patienten) [354]. Zum Stellenwert einer antiseptischen Ganzkörperwaschung, um Enterobacter spp. zu eradizieren, gibt es keine Daten.

\section{- Die Kommission empfiehlt:}

- solange keine nachvollziehbaren erfolgreichen Sanierungskonzepte für 3MRGN oder 4MRGN Enterobacter spp. vorliegen, Sanierungsmaßnahmen für mit 3MRGN oder 4MRGN Enterobacter spp. besiedelte Patienten nicht durchzuführen (Kat II).

\subsubsection{Andere Enterobakterien}

Maßnahmen zur Prävention der Verbreitung seltenerer Enterobakterien wurden in Kombinationen zur Beendigung von Ausbrüchen durchgeführt. Spezielle Maßnahmen im endemischen Setting wurden für die Einzelerreger nicht untersucht. Empfehlungen erfolgen daher in Anlehnung an die Empfehlungen zu Enterobacter spp. und werden daher nicht kategorisiert.
- Die Kommission empfiehlt:

- zur Prävention der Übertragung von anderen Enterobakterien vom 3MRGN-Phänotyp die Maßnahmen der Basishygiene in allen Krankenhausbereichen durchzuführen. Darüber hinausgehende Maßnahmen sind in der endemischen Situation nicht erforderlich.

- Patienten mit Besiedelung oder Infektion durch andere Enterobakterien vom 4MRGN-Phänotyp in allen Krankenhausbereichen $\mathrm{zu}$ isolieren.

- Es ist eine offene Frage, ob in der endemischen Situation Patienten, die Aufgrund des Verdachtes der Besiedelung, einer nachgewiesenen Besiedelung oder Infektion mit anderen Enterobakterien vom 4MRGN-Phänotyp isoliert werden, durch speziell zugeordnetes Personal gepflegt werden sollen.

\section{Screeningprogramme}

Screeningmethode: Für die selteneren Enterobakterien ist das wichtigste Reservoir der Darm. Für S. marcescens fanden Giles et al. [384] eine Sensitivität von 78 \% für die Untersuchung von Proben des Gastrointestinaltraktes und von 61 \% für Proben des Respirationstraktes. Die Sensitivität der Untersuchung konnte durch Verwenden eines Anreicherungsmediums verbessert werden. Spezielle Untersuchungen für andere seltene multiresistente Enterobakterien liegen nicht vor.

Bemerkenswert ist, dass die Spezifität von selektiven Screeningagars für den Nachweis seltenerer multiresistenter Enterobakterien schlechter ist als für den Nachweis ESBL-bildender Klebsiellen oder E. coli mit Werten zwischen 40 und $80 \%$ [372].

Effektivität von aktiver Surveillance: Da keine speziellen Surveillance-Programme für seltene multiresistente Enterobakterien untersucht wurden, liegen hier keine Daten vor.

Empfehlungen erfolgen daher in Anlehnung an die Empfehlungen zu Enterobacter spp. und werden daher nicht kategorisiert.
- Die Kommission empfiehlt:

- alle Patienten mit Risiko für eine Besiedelung oder Infektion mit anderen Enterobakterien vom 4MRGN-Phänotyp zu screenen und bis zum Vorliegen der Ergebnisse zu isolieren. Als Risikopatienten gelten Patienten mit kürzlichem Kontakt zum Gesundheitssystem in Ländern mit endemischem Auftreten und Patienten, die zu Patienten mit Nachweis von anderen Enterobakterien vom 4MRGN-Phänotyp Kontakt hatten, d. h. im gleichen Zimmer gepflegt wurden.

- Screening-Richtlinien auf Basis der Patientenstruktur festzulegen und regelmäßig auf Basis aktueller Informationen zu aktualisieren.

- als Screeningproben Rektalabstriche zu wählen.

- aktives Screening auf anderen Enterobakterien vom 3MRGN-Phänotyp in der endemischen Situation zur Prävention der weiteren Verbreitung nicht durchzuführen, da es sich nicht als effektiv erwiesen hat. Screening aus anderen Gründen, z. B. als Grundlage für kalkulierte empirische AntibiotikaTherapien in der Neonatologie bleibt davon unberührt.

Sanierung: Die Besiedelung mit antibiotikaresistenten Erregern ist in der Regel lange persistierend. In einer Untersuchung an Bewohnern eines Pflegeheimes fanden O'Fallon et al. [385] eine Clearance Rate von 8,3/1000 Tage für Citrobacter spp., 5,9/1000 Tage für M. morganii, 6,1/1000 Tage für P. stuartii und $0,4 / 1000$ Tage für $P$. mirabilis. Die Besiedelung mit $P$. mirabilis persistierte signifikant häufiger als Besiedelung mit anderen Spezies (mittlere Beobachtungsdauer der Besiedelung 144 Tage).

Im Rahmen von Ausbrüchen wurden Eradikationsversuche, in der Regel mit systemischen Antibiotika, vorgenommen, die jedoch nicht effektiv waren $[386,387]$.

\section{- Die Kommission empfiehlt:}

- keine Sanierungsmaßnahmen für mit anderen Enterobakterien vom 3MRGN- oder 4MRGN-Phänotyp besiedelte Patienten anzuwenden, da bisher keine nachvollziehbaren erfolgrei- 
chen Sanierungskonzepte für 3 MRGN oder 4MRGN Enterobacter spp. vorliegen (Kat II).

\subsection{Nonfermenter}

\subsubsection{Pseudomonas aeruginosa}

Eine Reihe von kombinierten Maßnahmen wurden bei der Bekämpfung von Ausbrüchen untersucht. Im Rahmen eines persistierenden Ausbruchs eines multiresistenten $P$. aeruginosa-Stammes (4MRGN) wurden Barriere-Pflege (Kittel und Handschuhe), intensivierte Umgebungsdesinfektion, Einzelzimmerunterbringung auf Intensivstationen und Einschränkung der Carbapenem-Anwendung eingesetzt [388]. Obgleich die Maßnahmen jeweils zu einer Reduktion der Inzidenz von multiresistenten $P$. aeruginosa führten, konnte der Ausbruch durch die Maßnahmen nicht beendet werden.

Furtado et al. implementierten ein Programm, bei dem alle Patienten mit klinischen Nachweisen von Carbapenem-resistenten $P$. aeruginosa oder Carbapenem-resistenten A. baumannii kohortiert und mit Barrieremaßnahmen gepflegt wurden. Kontaktpatienten wurden ebenfalls gescreent und ggf. isoliert [389]. Dieses Programm führte zur Reduktion der Nachweise von Carbapenem-resistenten $A$. baumannii, nicht jedoch zur Reduktion der Nachweise Carbapenem-resistenter Pseudomonaden.

Die Unwirksamkeit von Barrieremaßnahmen zur Prävention von Pseudomonas-Infektionen wurde darauf zurückgeführt, dass es sich in vielen Fällen um endogene Infektionen handeln könnte [390]. Hingegen fanden Pereira et al. [391] heraus, dass die Einführung von Einzelzimmer-Isolierung, die Durchführung von Barrieremaßnahmen (Kittel und Handschuhe) sowie Schulung und Training des Personals zur signifikanten Reduktion von Infektionen mit $P$. aeruginosa führten. Auch Petignat et al. [392] zeigten, dass die Verbesserung der Compliance mit Händehygiene und Einführung der alkoholischen Händedesinfektion zur Reduktion der Übertragung von $P$. aeruginosa führten.

Die Kontrolle von Umgebungsquellen (Leitungswasser) erwies sich auch im en- demischen Setting als erfolgreiche Maßnahme in der Kontrolle von $P$. aeruginosa-Infektionen [392, 393].

In einer aktuelleren klinischen Studie fanden Forrestier et al. eine Reduktion der respiratorischen Besiedelung mit $P$. aeruginosa nach Verabreichung von Probiotika. Inwiefern dies zu einer Reduktion der Verbreitung führen kann, bleibt jedoch unklar [394].

Zusammenfassend ist die Effektivität von Einzelzimmerunterbringung oder Barrieremaßnahmen zur Prävention der Verbreitung von 3MRGN oder 4MRGN P. aeruginosa ungeklärt. Daher hat sich die Kommission entschlossen, Maßnahmen in Analogie zu den Maßnahmen bei Enterobakterien mit erhöhter Mortalität der Infektion (E. coli und Klebsiella spp.) zu empfehlen. Dies dient einer nachvollziehbaren Systematik. Eine Kategorisierung der Empfehlung wird dabei nicht vorgenommen.

\section{- Die Kommission empfiehlt:}

- Patienten mit Besiedelung oder Infektion durch 3MRGN $P$. aeruginosa in Risikobereichen, Patienten mit Besiedelung oder Infektion durch 4MRGN $P$. aeruginosa in allen Krankenhausbereichen zu isolieren.

- Risikobereiche* nach individueller Risikoabwägung, z. B. auf Basis des Patientengutes und baulich-struktureller Gegebenheiten festzulegen, wobei Intensivstationen, inklusive der Neonatologie und hämatologisch-onkologische Stationen als Bereiche mit besonders gefährdeten Patienten gelten.

- Es ist eine offene Frage, ob in der endemischen Situation Patienten, die Aufgrund des Verdachtes der Besiedelung, einer nachgewiesenen Besiedelung oder Infektion mit 4MRGN P. aeruginosa isoliert werden, durch speziell zugeordnetes Personal gepflegt werden sollen.

- bei Auftreten von 3 MRGN oder 4MRGN $P$. aeruginosa mögliche Umgebungsquellen zu untersuchen und ggf. zu beseitigen (Kat II).

${ }^{*}$ Risikobereiche sind solche, in denen Patienten mit einer erhöhten Infektionsgefahr gepflegt werden,
Screeningmethode: Für das Screening zum Nachweis einer Besiedelung mit $P$. aeruginosa wurden vorwiegend $\mathrm{Ab}$ striche aus dem Respirationstrakt und/ oder Gastrointestinaltrakt verwendet. Bonten et al. [260] fanden eine Sensitivität von $83 \%$ für rektale Abstriche sowie $96 \%$ für Abstriche aus dem Oropharynx. Dalben et al. zeigten eine schlechte Sensitivität für Abstriche verschiedener Lokalisationen (Oropharynx $38 \%$, Axilla $34 \%$ und Rektum $47 \%$ ). Die Kombination verschiedener Screeninglokalisationen erhöhte die Sensitivität auf 63 \% für Oropharynx plus Axilla und jeweils $78 \%$ für Rektum plus Axilla und Rektum plus Oropharynx [395].

PCR-Verfahren für den direkten Nachweis von Metallo-B-laktamase-bildenden $P$. aeruginosa wurden evaluiert, diese Methode ist aber bisher nur bei der Diagnostik für Mukoviszidose-Patienten etabliert [396].

\section{Effektivität von aktiver Surveillance:}

Suarez et al. etablierten in einer prolongierten Ausbruchssituation ein rektales Screening mit anschließender Einführung von Barrieremaßnahmen und Isolierung. Die Maßnahmen reduzierten die Inzidenz der Neuinfektionen, beendeten den Ausbruch jedoch nicht [388].

Im Rahmen eines Programmes, welches zur Reduktion der Inzidenz Carbapenem-resistenter Klebsiellen auf einer Intensivstation eingeführt wurde (Screening und als Konsequenz Pflege mit Kittel und Handschuhen (Barrieremaßnahmen), Kohortierung in bestimmten Bereichen, Kohortierung des Pflegepersonals) untersuchten Kochar et al. [364] auch den Einfluss auf die Rate von Patienten mit Nachweisen von Carbapenem-resistenten $P$. aeruginosa. Während die Rate für Carbapenem-resistente Klebsiellen zurückging, fand sich kein Einfluss auf die Rate von Patienten mit Nachweisen von Carbapenem-resistenten $P$. aeruginosa.

Vonberg et al. [397] führten im endemischen Setting Surveillance-Kulturen von Kontaktpatienten zu Patienten mit multiresistenten gramnegativen Stäbchen durch und identifizierten 4,7 \% positive Kontaktpatienten. $40 \%$ der Indexpatienten waren mit multiresisten- 
ten $P$. aeruginosa besiedelt oder infiziert, die Rate der Übertragung für $P$. aeruginosa wird jedoch nicht explizit angegeben. Aus den Daten kann nicht entnommen werden, ob das Programm im endemischen Setting hinsichtlich der Prävention effektiv war. Furtado et al. [389] beurteilten das Screening von Kontaktpatienten als wirksamen Bestandteil eines Programmes zur Reduktion von $P$. aeru ginosa Kolonisationen oder Infektionen.

\section{- Die Kommission empfiehlt:}

- alle Patienten mit Risiko für eine Besiedelung oder Infektion mit 4MRGN $P$. aeruginosa zu screenen und bis zum Vorliegen der Ergebnisse zu isolieren. Als Risikopatienten gelten Patienten mit kürzlichem Kontakt zum Gesundheitssystem in Ländern mit endemischem Auftreten und Patienten, die zu 4MRGN $P$. aeruginosa-positiven Patienten Kontakt hatten, d. h. im gleichen Zimmer gepflegt wurden (Kat II).

- Sceening-Richtlinien auf Basis der Patientenstruktur festzulegen und regelmäßig auf Basis aktueller Informationen zu aktualisieren.

- als Screeningproben Rektal- und Rachenabstriche und ggf. chronische Wunden zu wählen (Kat II).

- aktives Screening auf 3MRGN P. aeruginosa in der endemischen Situation zur Prävention der weiteren Verbreitung nicht durchzuführen, da es sich nicht als effektiv erwiesen hat (Kat II). Screening aus anderen Gründen, z.B. als Grundlage für kalkulierte empirische Antibiotikatherapien in der Hämatologie-Onkologie bleibt davon unberührt.

Sanierungsmöglichkeiten: Maßnahmen zur Eradikation von $P$. aeruginosa wurden bisher für Mukoviszidose-Patienten beschrieben und umfassen lokale und systemische Antibiotikatherapien [398-400].

Eradikationsmaßnahmen bei NichtMukoviszidose-Patienten zur Prävention der Verbreitung antibiotikaresistenter Stämme sind nicht beschrieben. Der mögliche Nutzen zur Prävention der weiteren Verbreitung erscheint jedoch gering im Vergleich zur Gefahr der weiteren Resistenzentwicklung.
- Die Kommission empfiehlt:

- außerhalb der Mukoviszidose-Patientengruppe keine Sanierungsmaßnahmen für mit 3MRGN oder $4 \mathrm{MRGN}$ $P$. aeruginosa besiedelte Patienten anzuwenden, da hierdurch eine Resistenzentwicklung für die wenigen noch wirksamen Antibiotika gefördert wird.

\subsubsection{Acinetobacter baumannii}

Isolierungs- und Barrieremaßnahmen bis hin zur Schließung von Stationen für Neuaufnahmen wurden in der Regel zusammen mit anderen Maßnahmen im Rahmen von Ausbrüchen als Präventionsmaßnahmen eingesetzt. Ausbrüche durch A. baumannii führen signifikant häufiger als andere bakterielle Infektionen dazu, dass Stationen für Neuaufnahmen geschlossen wurden [401]. Zudem wird bei A. baumannii-Ausbrüchen besonders häufig der Einsatz erweiterter Reinigungs- und Desinfektionsmaßnahmen beschrieben [114, 402-404]. Wilks et al. berichten von einem Ausbruch, der allein durch verbesserte Reinigungsmaßnahmen und Prävention der Umgebungskontamination ohne Isolierungsmaßnahme beendet werden konnte. Allerdings hielt der Ausbruch nach Einführung der Maßnahmen noch für nahezu ein halbes Jahr lang an [323].

Der hohe Stellenwert der Umgebungskontamination ist ein Hinweis darauf, dass eine Begrenzung der Umgebungskontamination durch eine Isolierung des Patienten ein bedeutender Bestandteil einer Präventionsstrategie ist.

Furtado et al. [389] zeigten, dass die Isolierung (Kohortierung, Tragen von Schutzkitteln und Handschuhen) von Patienten mit klinischen Nachweisen von Carbapenem-resistenten A. baumannii, sowie Screening der Kontaktpatienten und ggf. deren Isolierung zur Reduktion der Nachweise von Carbapenem-resistenten A. baumannii führte.

Es ist zu beachten, dass sich in einer französischen Untersuchung die Vorbelegung eines Patientenzimmers mit einem Patienten mit A. baumanniiNachweis als ein unabhängiger Risikofaktor für den nosokomialen Erwerb von A. baumannii erwiesen hat [157]. Der Patientenbereich selbst soll daher gemäß Empfehlung der Kommission für Kran- kenhaushygiene und Infektionsprävention beim Robert Koch-Institut zur Anforderungen an die Hygiene bei der Reinigung und Desinfektion von Flächen [9] als „Bereich mit Patienten, die Erreger so in oder an sich tragen, dass im Einzelfall die Gefahr einer Weiterverbreitung besteht" eingestuft werden. Dies bedeutet, dass neben Flächen mit häufigem Hand-/ Hautkontakt auch Fußböden täglich desinfiziert werden müssen.

In einer Umfrage unter spanischen Krankenhäusern zeigte sich, dass Häuser mit einem schriftlich fixierten Kontrollprogramm niedrigere Infektions- und Kolonisationsraten hatten [405].

\section{- Die Kommission empfiehlt:}

- Patienten mit Besiedelung oder Infektion durch 3MRGN A. baumannii in Risikobereichen*, Patienten mit Besiedelung oder Infektion durch 4MRGN A. baumannii in allen Krankenhausbereichen $\mathrm{zu}$ isolieren.

- Risikobereiche nach individueller Risikoabwägung, z. B. auf Basis des Patientengutes und baulich-struktureller Gegebenheiten festzulegen, wobei Intensivstationen, inklusive der Neonatologie und hämatologisch-onkologische Stationen als Bereiche mit besonders gefährdeten Patienten gelten.

- Es ist eine offene Frage, ob in der endemischen Situation Patienten, die Aufgrund des Verdachtes der Besiedelung, einer nachgewiesenen Besiedelung oder Infektion mit 4MRGN A. baumannii isoliert werden, durch speziell zugeordnetes Personal gepflegt werden sollen.

- Flächen in der Patientenumgebung mit häufigem Hände- und/oder Hautkontakt und Fußböden täglich zu desinfizieren (Kat II).

${ }^{*}$ Risikobereiche sind solche, in denen $\mathrm{Pa}$ tienten mit einer erhöhten Infektionsgefahr gepflegt werden.

\section{Screeningprogramme}

Screeningmethode: Es sind nur wenige Daten zum Screening auf A. baumannii publiziert. Marchaim et al. untersuchten die Sensitivität des Screenings, indem sie 22 Patienten, von denen innerhalb der 
10 vorangegangenen Tage A. baumannii aus einem klinischen Material isoliert worden war, mittels Tupferabstrichen untersuchten. Nur 12 Patienten (55\%) waren im Screening positiv, wobei einzelne Screening-Orte die folgende Positivrate aufwiesen: Nase $18 \%$, Pharynx $23 \%$, Haut 13,5\% und Rektum $14 \%$. Sofern vorhanden, waren Wunden in $22 \%$ positiv, Trachealsekret beatmeter Patienten war in $29 \%$ positiv [406]. Im Rahmen eines Aufnahmescreenings wurden $90 \%$ der kolonisierten Patienten mit rektalen und/oder Rachenabstrichen identifiziert, $10 \%$ durch perianale Abstriche [293]. In dieser Untersuchung wurden keine weiteren Hautabstriche untersucht.

Doi et al. untersuchten, ob sich die Sensitivität der Screeninguntersuchung durch die Probenahmetechnik beeinflussen lässt. Sie verwendeten Schwämmchen zur Entnahme von Screeningproben von der Haut, reicherten über Nacht in einer Bouillon an und impften die Bouillon auf einem Selektivagar aus. Mit dieser Methode konnten sie eine Sensitivität von $85 \%$ für die Hüftregion, von $81 \%$ für den Oberarm und $72 \%$ für die Stirn erzielen. Tupferabstriche, die ebenfalls angereichert und auf Selektivmedien ausgeimpft wurden, wiesen eine deutlich geringere Sensitivität auf. Lediglich mit Abstrichen von der Wangenschleimhaut konnte eine annähernd mit den Schwämmchenproben vergleichbare Sensitivität von $72 \%$ erreicht werden [407].

Seit kurzem werden selektive chromogene Medien für die Detektion von Acinetobacter spp. angeboten. Diese $\mathrm{Me}$ dien scheinen im Vergleich zu anderen Medien eine hohe Sensitivität für den Nachweis von Acinetobacter spp. zu besitzen, jedoch sind sie nicht spezifisch für A. baumannii. Für die Selektion resistenter Isolate müssen zusätzliche Supplemente verwendet werden [408-410].

\section{Effektivität von aktiver Surveillance:}

Aktives Screening, z. B. bei Aufnahme, wurde in verschiedenen Ausbrüchen als eine von mehreren Interventionen durchgeführt [293, 295, 411-413]. Daher ist der Nutzen eines generellen Aufnahmescreenings in der endemischen Situation derzeit nicht beurteilbar. Um den präventiven und ökonomischen Wert eines Aufnahmescreenings abzuschätzen, müssen verschiedene Daten vorliegen, die derzeit nur geschätzt werden können [414]. Unter Abwägung verschiedener Parameter kommen Lee et al. in einem mathematischen Modell zu dem Schluss, dass ein Screening unter Verwendung einer sensitiven Screeningmethode dann effektiv ist, wenn die Prävalenz über $1 \%$ liegt und die Infektionswahrscheinlichkeit über $30 \%$ [415].

In einer Studie, in der Kontaktpatienten gescreent und wie Indexpatienten isoliert wurden, konnte eine Reduktion der Nachweise Carbapenem-resistenter Stämme erreicht werden [389].

\section{- Die Kommission empfiehlt:}

- alle Patienten mit Risiko für eine Besiedelung oder Infektion mit 4MRGN A. baumannii $z u$ screenen und bis zum Vorliegen der Ergebnisse zu isolieren. Als Risikopatienten gelten Patienten mit kürzlichem Kontakt zum Gesundheitssystem in Ländern mit endemischem Auftreten und Patienten die zu 4MRGN A. baumannii-positiven Patienten Kontakt hatten, d. h. im gleichen Zimmer gepflegt wurden (Kat II).

- Screening-Richtlinien auf Basis der Patientenstruktur festzulegen und regelmäßig auf Basis aktueller Informationen zu aktualisieren.

- als Screeningproben in Absprache mit dem Labor eine möglichst sensitive Screeningmethode festzulegen, die neben Abstrichen aus dem Mund-Rachen-Raum möglichst großflächige Proben der Haut einschließt (Kat II).

- aktives Screening auf 3MRGN A. baumannii in der endemischen Situation zur Prävention der weiteren Verbreitung nicht durchzuführen, da es sich nicht als effektiv erwiesen hat (Kat II). Screening aus anderen Gründen, z. B. als Grundlage für kalkulierte empirische Antibiotika-Therapien in der Intensivmedizin bleibt davon unberührt.

Sanierungsmöglichkeiten: $D a$ das eigentliche Habitat von A. baumannii bei Krankenhauspatienten nicht geklärt ist, befindet sich die Konzeption von Sanierungsstrategien noch in Entwicklung. Da die Haut jedoch ein häufiges Reservoir mit erheblichem Streuungspotential darstellt, liegt es nahe antiseptische Hautbehandlungen durchzuführen. Borer et al. verglichen die Inzidenz des nosokomialen A. baumannii-Erwerbs und der Rate von A. baumannii-Bakteriämien in einer retrospektiven Kohortenstudie vor und nach Einführung einer Ganzkörperwaschung mit Chlorhexidin. Sie fanden eine signifikante Reduktion der SepsisRate durch A. baumannii und der Inzidenz nosokomialer A. baumannii-Nachweise. $80 \%$ der kolonisierten Patienten waren bei Kontroll-Untersuchungen (Abstrich von Leisten und Axillen mit einem Tupfer), die unter laufender Behandlung entnommen wurden, negativ [416]. Weitere Bestätigungen der Effektivität der Maßnahmen stehen noch aus.

Eine weitere Arbeitsgruppe untersuchte die Effektivität einer selektiven Darmdekontamination mit oraler Gabe von Polymyxin und Tobramycin auf Kolonisation und Infektion mit $A$. baumannii. Es traten signifikant weniger Infektionen unter selektiver Darmdekontamination als in der Kontroll-Gruppe auf. In der SDD-Gruppe war zwar die Rate der pharyngealen und fäkalen Besiedelung in der 3. Woche des Intensivstationsaufenthaltes signifikant niedriger als in der Kontrollgruppe, die Rate der Hautbesiedlung war jedoch nicht verändert [417].

\section{- Die Kommission empfiehlt:}

- keine selektive Darmdekontamination zur Sanierung der A. baumannii-Besiedelung durchzuführen (Kat II).

- Es ist eine offene Frage, ob eine antiseptische Ganzkörperwaschung zur Eradikation von A. baumannii effektiv ist (Kat III). 


\section{Umsetzung im Krankenhaus}

Programme zur Prävention der Verbreitung multiresistenter gramnegativer Stäbchen müssen verschiedene Komponenten enthalten, um erfolgreich zu sein [3, 271]. Folgende Komponenten gehören dazu und sind in erfolgreichen Programmen eingesetzt worden, bzw. ergeben sich aus den zuvor dargestellten Daten.

\section{Risikoanalyse und schriftliche Festlegung der Maßnahmen im Hygieneplan}

Die Einzelmaßnahmen des Programmes müssen nach Analyse der lokalen Epidemiologie, dem Risiko für die behandelten Patienten und der Umsetzbarkeit der Maßnahmen hinsichtlich der räumlichen Gegebenheiten festgelegt werden [405]. Grundlage hierzu sind die unter Kapitel 3 und 4 und in $\bullet$ Tabelle 5 zusammengefassten Empfehlungen.

Für Isolierungsmaßnahmen in der Neonatologie sollen dabei die Empfehlung zur Prävention nosokomialer Infektionen bei neonatologischen Intensivpflegepatienten mit einem Geburtsgewicht unter $1500 \mathrm{~g}$ [10] und die Ergänzung zur Prävention nosokomialer Infektionen bei neonatologischen Intensivpflegepatienten [418] herangezogen werden.

Es ist zu berücksichtigen, dass Resistenzprofile sich während eines stationären Aufenthaltes verändern können. Wird im Rahmen klinischer Untersuchungen erkannt, dass ein 3MRGN-Erreger weitere Resistenzen entwickelt, so dass es als 4MRGN eingestuft werden muss, kann eine Anpassung der Hygienemaßnahmen erforderlich werden.

Da Fluorchinolone nicht zur Primärtherapie bei Frühgeborenen oder Schwangeren zugelassen sind, sollte in entsprechenden Risikobereichen bereits eine alleinige Resistenz gegenüber 3. Generations-Cephalosporinen bei bestimmten Erregern (wie zum Beispiel K. pneumoniae, E. cloacae, S. marcescens, P. aeruginosa, Acinetobacter spp., C. koseri) interdisziplinäre Überlegungen zur Notwendigkeit einer krankenhaushygienischen Intervention nach sich ziehen. Die entsprechenden Maßnahmen sind mit dem zuständigen Krankenhaushygieniker abzustimmen.

\section{Maßnahmen zur Verbesserung der Compliance der Mitarbeiter wie Schulung, Information und Surveillance der Compliance}

In einer Übersicht zu Kontrollmaßnahmen für die Verbreitung antibiotikaresistenter Mikroorgansimen berichten Siegel et al. [3], dass in $63 \%$ aller Originalarbeiten zur Prävention der Verbreitung von MRGN Schulung des Personals eine Komponente war. Robert et al. konnten die Compliance mit den eingeführten Maßnahmen durch Flyer für die Mitarbeiter, die mit den Befunden mitgegeben wurden, verbessern [419].

Computer-Alarme bei Aufnahme oder Verlegung bekannter Träger multiresistenter Erreger [420] waren weitere Maßnahmen zur Verbesserung des Informationsflusses.

Beobachtungen zur Compliance mit empfohlenen Maßnahmen und Rückmeldung der Beobachtungsergebnisse an die Mitarbeiter tragen wesentlich zur Verbesserung der Compliance bei [3].

\section{Surveillance}

Die Erfassung und Bewertung der Epidemiologie von MRGN aus Routinekulturen ist eine einfache und kostengünstige Maßnahme, die durch entsprechende Regelungen im Infektionsschutzgesetz ( $\$ 4$ Abs. $2 \mathrm{Nr} 2 \mathrm{~b}$ IfSG in Verbindung mit $\$ 23$ Abs. 4 IfSG) in Deutschland vorgeschrieben ist.

Insbesondere für 3MRGN, für die kein aktives Aufnahmescreening empfohlen wird, empfiehlt es sich, alle klinischen Befunde bei einer verantwortlichen Person (z. B. Hygienefachkraft) zusammenzuführen und engmaschig zu bewerten. Schon bei Auftreten eines zweiten Falles eines MRGN, für den eine Ausbruchsneigung bekannt ist ( $\mathrm{z}$. B. K. pneumoniae, S. marcescens, E. cloacae speziell in der Neonatologie, A. baumannii), sollten in zeitlichem und örtlichem Zusammenhang Maßnahmen entsprechend eines Ausbruchsverdachtes durchgeführt werden [7].
Darüber hinaus sollen gezielte Screeningprogramme für Risikopatienten etabliert werden [3, 271, 347]. Das Vorgehen für das Screening auf 4MRGN von Patienten mit kürzlichem Kontakt zum Gesundheitssystem in Ländern mit endemischem Auftreten und für Kontaktpatienten muss festgelegt werden. Hierzu gehören Algorithmen zur schnellstmöglichen Identifizierung der Risikopatienten, Festlegung der Verantwortung für die Durchführung des Screenings und die fachkundige Wahl einer optimalen Methodik für ein Screening.

Je nach Art der Einrichtung muss geprüft werden, ob weitere Screeningverfahren sinvoll sind. Dazu können Wiederaufnahmescreenings in Bereichen oder Einrichtungen mit regelmäßigen oder häufigen Wiederaufnahmen der Patienten gehören. Regelmäßige Folgescreenings können in Bereichen sinnvoll sein, in denen für Patienten ein besonders hohes Infektionsrisiko besteht als Basis für eine empirische Antibiotikatherapie, z. B. in der Neonatologie oder in der Hämatologie-Onkologie. Es empfiehlt sich, solche Programme in Zusammenarbeit zwischen Kliniker, Krankenhaushygieniker, Mikrobiologen und ggf. Infektiologen festzulegen.

\section{Durchführung von Isolierungs- maßnahmen}

International sind unter dem Begriff „Kontakt-Isolierung“ (Contact precaution) sowohl Barrieremaßnahmen (Verwendung von Schutzkitteln und Handschuhen), als auch Isolierungen (Einzelzimmerunterbringung) beschrieben, so dass die Maßnahmen oft nicht vergleichbar sind. Bei einer hohen Anzahl von Kontrollprogrammen wurden solche Kontakt-Isolierungen durchgeführt [3, 421]. Die Effektivität von Barrieremaßnahmen oder Isolierungen ist als Einzelmaßnahme für die Prävention von MRGN-Transmissionen nicht untersucht. Es gibt jedoch Hinweise, dass Barrieremaßnahmen oder Isolierung für einige Erreger bzw. für einige Settings effektiv sind. Ein Vorschlag zur Festlegung von Maßnahmen im Umgang mit Patienten, die mit MRGN besiedelt sind, findet sich im Anhang der Empfehlung. Die 


\begin{tabular}{|c|c|c|c|c|}
\hline & \multirow{2}{*}{$\begin{array}{l}\text { Aktives Screening und Isolierung bis } \\
\text { zum Befund }^{1}\end{array}$} & \multicolumn{2}{|c|}{ Prävention der Übertragung } & \multirow[t]{2}{*}{ Sanierung } \\
\hline & & Normalbereiche & $\begin{array}{l}\text { Risikoberei- } \\
\text { che }^{1,2}\end{array}$ & \\
\hline 3MRGN E. coli & Nein & Basishygiene & Isolierung & Nicht empfohlen \\
\hline 4MRGN E. coli & $\begin{array}{l}\text { Risikopopulation }{ }^{4} \\
\text { (Rektal, ggf. Wunden, Urin) }\end{array}$ & Isolierung & Isolierung & Nicht empfohlen \\
\hline 3MRGN Klebsiella spp. & Nein & Basishygiene & Isolierung & Nicht empfohlen \\
\hline 4MRGN Klebsiella spp. & $\begin{array}{l}\text { Risikopopulation } \\
\text { (Rektal, ggf. Wunden, Urin) }\end{array}$ & Isolierung & Isolierung & Nicht empfohlen \\
\hline 3MRGN Enterobacter spp. & Nein & Basishygiene & Basishygiene & Nicht empfohlen \\
\hline 4MRGN Enterobacter spp. & Risikopopulation (Rektal) & Isolierung & Isolierung & Nicht empfohlen \\
\hline $\begin{array}{l}\text { andere 3MRGN Enterobak- } \\
\text { terien }\end{array}$ & Nein & Basishygiene & Basishygiene & Nicht empfohlen \\
\hline $\begin{array}{l}\text { andere 4MRGN Enterobak- } \\
\text { terien }\end{array}$ & Risikopopulation ${ }^{4}$ (Rektal) & Isolierung & Isolierung & Nicht empfohlen \\
\hline 3MRGN P. aeruginosa & Nein & Basishygiene & Isolierung & Nicht empfohlen \\
\hline 4MRGN P. aeruginosa & $\begin{array}{l}\text { Risikopopulation } \\
\text { (Rektal, Rachen) }\end{array}$ & Isolierung & Isolierung & Nicht empfohlen \\
\hline 3MRGN A. baumannii & Nein & Basishygiene & Isolierung & ungeklärt \\
\hline 4MRGN A. baumannii & $\begin{array}{l}\text { Risikopopulation } \\
\text { (Mund-Rachen-Raum, Haut) }\end{array}$ & Isolierung & Isolierung & ungeklärt \\
\hline \multicolumn{5}{|c|}{$\begin{array}{l}1 \text { Risikobereiche sind nach individueller Risikoabwägung, z. B. auf Basis des Patientengutes und baulich-struktureller Gegebenheiten festzulegen, wobei Intensivstationen, } \\
\text { inklusive der Neonatologie und hämatologisch-onkologische Stationen als Bereiche mit besonders gefährdeten Patienten gelten. } \\
2 \text { In der Neonatologie kann bereits eine alleinige Resistenz gegenüber 3. Generations-Cephalosporinen bei bestimmten Erregern (wie zum Beispiel K. pneumoniae, E. cloacae, } \\
\text { S. marcescens, P. aeruginosa, Acinetobacter spp., C. koseri) interdisziplinäre Überlegungen zur Notwendigkeit einer krankenhaushygienischen Intervention nach sich ziehen } \\
{ }^{3} \text { Eine gemeinsame Isolierung (Kohorten-Isolierung) kann nur für Patienten mit einem MRGN derselben Spezies mit gleichem Resistenzmuster erfolgen. } \\
{ }^{4} \text { Als Risikopatienten gelten Patienten mit kürzlichem Kontakt zum Gesundheitssystem in Ländern mit endemischem Auftreten und Patienten die zu 4MRGN-positiven Pa- } \\
\text { tienten Kontakt hatten, d. h. im gleichen Zimmer gepflegt wurden }\end{array}$} \\
\hline
\end{tabular}

Zuordnung verschiedener Maßnahmen ergibt sich aus $\bullet$ Tabelle 5.

Da bisher keine effektiven Sanierungsmaßnahmen verfügbar sind, müssen entsprechende Maßnahmen in der Regel für den gesamten Krankenhausaufenthalt beibehalten werden. Für Langzeitpatienten und Patienten mit wiederholten Krankenhausaufenthalten können in Zusammenarbeit mit Krankenhaushygieniker, Mikrobiologen und Infektiologen Kriterien zur Aufhebung der Maßnahmen festgelegt werden. Hierbei ist $\mathrm{zu}$ berücksichtigen, dass die Sensitivität einzelner Kontrollabstriche eingeschränkt ist. Daher sollten immer mehrere Kontrollen in nicht zu kurzen $\mathrm{Ab}$ ständen entnommen werden. Wenn keine Faktoren vorlagen, die die Sensitivität beeinträchtigen (z. B. laufende Antibiotikatherapie), können die Isolierungsmaßnahmen nach 3 negativen Kontrollen aufgehoben werden.

\section{Sanierungsmaßnahmen}

Sanierungsmaßnahmen für MRGN sind derzeit nicht evaluiert und können daher nicht als Bestandteil von Kontrollprogrammen für MRGN empfohlen werden.

\section{Informationsweitergabe}

Die aufgeführten Maßnahmen können nur dann zeitnah und effizient durchgeführt werden, wenn Informationen unverzüglich an alle relevanten Stellen weitergegeben werden. So muss durch geeignete Mittel sichergestellt werden, dass Informationen aus dem Labor krankenhausintern an behandelnde Ärzte und das Hygienefachpersonal weitergegeben werden. Innerhalb des Hauses müssen bei Verlegungen und in diagnostischen und therapeutischen Abteilungen die notwendigen Informationen vor Ankunft des Patienten vorliegen. Bei Verlegung in andere Krankenhäuser, nachsorgende Einrichtungen oder Heime soll die Information über die Besiedelung weitergegeben werden, wobei Hinweise auf die Konsequenz des Befundes mitgegeben werden sollen. So hat die Besiedlung mit 4MRGN in allen medizinischen und pflegerischen Einrichtungen Konsequenzen, während die Besiedelung mit 3MRGN nur in Risikobereichen zu Konsequenzen führt.

\section{Antibiotikamanagement}

Ein angemessener Umgang mit Antibiotika führt zur Reduktion des Selektionsdruckes und trägt somit entscheidend zur Prävention der Verbreitung von MRGN bei. Hier sei auf entsprechende Leitlinien und Empfehlungen [422] verwiesen (http://www.awmf.org/leitlinien/ detail/anmeldung/1/ll/092-001.html).

\section{- Die Kommission empfiehlt:}

- ein Programm zur Prävention der Verbreitung multiresistenter gramnegativer Stäbchen im Krankenhaus zu implentieren (Kat II, Kat IV), welches die folgenden Komponenten enthält: 
- Risikoanalyse und schriftliche Festlegung der Maßnahmen im Hygieneplan;

- Maßnahmen zur Verbesserung der Compliance der Mitarbeiter wie Schulung, Information und Surveillance der Compliance;

- Surveillance und Screeningmaßnahmen;

- Durchführung von Isolierungsmaßnahmen;

- Festlegungen zur Informationsweitergabe;

- Antibiotikamanagement.

\section{Informativer Anhang ohne Empfehlungscharakter}

Maßnahmen im Umgang mit Patienten, die mit multiresistenten gramnegativen Mikroorganismen besiedelt oder infiziert sind, zur Berücksichtigung bei Erstellung eines Hygieneplans

1. Maßnahmen für ALLE Patienten, da eine Besiedelung unerkannt vorliegen kann (Basishygiene).

- Händedesinfektion vor und nach direktem Kontakt mit dem Patienten, vor aseptischen Tätigkeiten, nach Kontamination (Kontakt mit Blut, Sekreten oder Exkreten), nach Kontakt mit der Patientenumgebung, sowie nach Ablegen der Handschuhe

- Handschuhe tragen, wenn die Wahrscheinlichkeit des Kontaktes mit Blut, Sekreten, Exkreten oder sichtbar kontaminierten Flächen besteht

- Tragen von Mund-Nasen-Schutz und Schutzbrille, wenn Verspritzen von oder Tröpfchenbildung aus Blut, Sekreten oder Exkreten möglich ist

- Tragen einer Schürze, um Dienstkleidung bei Eingriffen oder Pflegemaßnahmen vor Blut, Sekreten oder Exkreten zu schützen

- Einzelzimmer für Patienten, denen adäquates hygienisches Verhalten nicht möglich ist

- Behandlung von Ausrüstung und Geräten (Medizinprodukten), Oberflächen und Einrichtung, Bettwäsche und Abfall so, dass keine Übertragungsgefahr davon ausgeht

- Desinfektion und Reinigung (Flächen: Routinemaßnahmen gemäß Reinigungs- und Desinfektionsplan, Instrumente: Aufbereitung aller zur Wiederverwendung bestimmter Instrumente mit geeignetem Verfahren, Geschirr: Desinfizierende Reinigung, Wäsche: Desinfizierende Waschverfahren für Krankenhauswäsche)

- Abfallentsorgung gemäß Abfallentsorgungsplan
2. Zusatzmaßnahmen bei Isolierung. Zusätzlich zu den Maßnahmen der Basishygiene werden folgende Maßnahmen durchgeführt:

> Unterbringung im Einzelzimmer mit eigener Nasszelle oder Kohortierung mit Patienten mit gleicher Spezies und gleichem Resistenzphänotyp

- Tragen eines langärmeligen Schutzkittels bei allen direkten Patientenkontakten (für 4MRGN A. baumannii: Anlegen des Schutzkittels vor Betreten des Zimmers)

- Handschuhe tragen schon bei möglichem Kontakt zu Blut, Sekreten, Exkreten oder kontaminierten Oberflächen; Wechsel der Handschuhe und hygienische Händedesinfektion zwischen unreinen und reinen Arbeiten am Patienten und hygienische Händedesinfektion nach Ausziehen der Handschuhe

- Zuordnung von unkritischen Geräten/Instrumenten zum Patienten während der Dauer des Aufenthaltes

- Desinfektion und Reinigung von Flächen (Routinemaßnahmen gemäß Reinigungs- und Desinfektionsplan für Bereiche mit Patienten, die Erreger so in oder an sich tragen, dass im Einzelfall die Gefahr einer Weiterverbreitung besteht)

- Benachrichtigung der durchführenden oder aufnehmenden Abteilung bei Durchführung von diagnostischen oder therapeutischen Maßnahmen oder Verlegung des Patienten

- Schlussdesinfektion des Zimmers mit der Nasszelle nach Entlassung oder Verlegung

Die Empfehlungen wurden ehrenamtlich und ohne Einflussnahme kommerzieller Interessengruppen im Auftrag der Kommission für Krankenhaushygiene und Infektionsprävention bearbeitet von Prof. Dr. Constanze Wendt, Heidelberg (Leiterin der Arbeitsgruppe); Prof. Dr. Heike von Baum, Ulm; Dr. Martin Kaase, Bochum; PD Dr. Elisabeth Meyer, Berlin; Prof. Dr. Heidemarie Suger-Wiedeck, Ulm; Dr. Claudia Ruscher, Berlin (für das RKI). 


\section{Literatur}

1. Guidance for control of infections with carbapenem-resistant or carbapenemase-producing Enterobacteriaceae in acute care facilities. MMWR Morb Mortal Wkly Rep, 2009. 58(10): p. 256-60.

2. Kluytmans-Vandenbergh, M.F., J.A. Kluytmans, and A. Voss, Dutch guideline for preventing nosocomial transmission of highly resistant microorganisms (HRMO). Infection, 2005. 33(5-6): p. 30913.

3. Siegel, J.D., et al., Management of multidrug-resistant organisms in health care settings, 2006. Am J Infect Control, 2007. 35(10 Suppl 2): p. S165-93.

4. von Baum, H., et al., Konsensusempfehlung Baden-Württemberg: Umgang mit Patienten mit hochresistenten Enterobakterien inklusive ESBLBildnern. Hyg Med, 2010. 35: p. 40-45.

5. Mattner, F., et al., Preventing the spread of multidrug-resistant gram-negative pathogens: recommendations of an expert panel of the German Society For Hygiene and Microbiology. Dtsch Arztebl Int, 2012. 109(3): p. 39-45.

6. Kommission für Krankenhaushygiene und Infektionsprävention, Infektionsprävention in Heimen. Bundesgesundheitsbl - Gesundheitsforsch - Gesundheitsschutz, 2005. 48: p. 1061-1080.

7. Kommission für Krankenhaushygiene und Infektionsprävention, Ausbruchsmanagement und struktuiertes Vorgehen bei gehäuftem Auftreten nosokomialer Infektionen. Bundesgesundheitsbl - Gesundheitsforsch - Gesundheitsschutz, 2002. 45: p. $180-186$

8. Kommission für Krankenhaushygiene und Infektionsprävention, Empfehlungen zur Händehygiene. Bundesgesundheitsbl-Gesundheitsforsch Gesundheitsschutz, 2000. 43: p. 230-233.

9. Kommission für Krankenhaushygiene und Infektionsprävention, Anforderungen an die Hygiene bei der Reinigung und Desinfektion von Flächen. Bundesgesundheitsbl - Gesundheitsforsch - Gesundheitsschutz, 2004. 47: p. 51-61.

10. Kommission für Krankenhaushygiene und Infektionsprävention, Empfehlung zur Prävention nosokomialer Infektionen bei neonatologischen Intensivpflegepatienten mit einem Geburtsgewicht unter $1500 \mathrm{~g}$. Bundesgesundheitsbl - Gesundheitsforsch - Gesundheitsschutz, 2007. 50: p. 1265-1303.

11. NN, Surveillance nosokomialer Infektionen sowie die Erfassung von Erregern mit speziellen Resistenzen und Multiresistenzen $\S 6$ Abs. 3 und $\S$ 23 Abs. 1 und 2 in Verbindung mit $\S 4$ Abs. 2 Nr. $2 \mathrm{~b}$ IfSG. Rechtliche Voraussetzungen und Umsetzungsempfehlungen. Bundesgesundheitsbl-Gesundheitsforsch - Gesundheitsschutz, 2000. 43: p. 887-890.

12. Kommission für Krankenhaushygiene und Infektionsprävention, Die Kategorien der Richtlinie für Krankenhaushygiene und Infektionsprävention Aktualisierung der Definitionen. Bundesgesundheitsbl - Gesundheitsforsch - Gesundheitsschutz, 2010. 53: p. 754-756.

13. Bush, K., G.A. Jacoby, and A.A. Medeiros, A functional classification scheme for beta-lactamases and its correlation with molecular structure. Antimicrob Agents Chemother, 1995. 39(6): p. 1211 33.
14. Knothe, H., et al., Transferable resistance to cefotaxime, cefoxitin, cefamandole and cefuroxime in clinical isolates of Klebsiella pneumoniae and Serratia marcescens. Infection, 1983. 11(6): p. 315-7.

15. Ambler, R.P., The structure of beta-lactamases. Philos Trans R Soc Lond B Biol Sci, 1980. 289(1036): p. 321-31.

16. Queenan, A.M. and K. Bush, Carbapenemases: the versatile beta-lactamases. Clin Microbiol Rev, 2007. 20(3): p. 440-58, table of contents.

17. Pop-Vicas, A.E. and E.M. D'Agata, The rising influx of multidrug-resistant gram-negative bacilli into a tertiary care hospital. Clin Infect Dis, 2005. 40(12): p. 1792-8.

18. vonberg, R.P., et al., Surveillance von Patienten mit multiresistenten gramnegativen Erregern an einem Universitätsklinikum. Hyg Med, 2005. 30: p. 186-188.

19. Magiorakos, A.P., et al., Multidrug-resistant, extensively drug-resistant and pandrug-resistant bacteria: an international expert proposal for interim standard definitions for acquired resistance. Clin Microbiol Infect, 2011.

20. Muder, R.R., et al., Bacteremia due to Stenotrophomonas (Xanthomonas) maltophilia: a prospec tive, multicenter study of 91 episodes. Clin Infect Dis, 1996. 22(3): p. 508-12

21. Ansari, S.R., et al., Risk factors for infections with multidrug-resistant Stenotrophomonas maltophilia in patients with cancer. Cancer, 2007. 109(12): p. 2615-22.

22. Looney, W.J., Role of Stenotrophomonas maltophilia in hospital-acquired infection. Br J Biomed Sci, 2005. 62(3): p. 145-54; quiz 1 p following 154.

23. Paez, J.I. and S.F. Costa, Risk factors associated with mortality of infections caused by Stenotrophomonas maltophilia: a systematic review. J Hosp Infect, 2008. 70(2): p. 101-8.

24. Safdar, A. and K.V. Rolston, Stenotrophomonas maltophilia: changing spectrum of a serious bac terial pathogen in patients with cancer. Clin Infect Dis, 2007. 45(12): p. 1602-9.

25. Falagas, M.E., et al., Attributable mortality of Stenotrophomonas maltophilia infections: a systematic review of the literature. Future Microbiol, 2009. 4(9): p. 1103-9.

26. Valdezate, S., et al., High genetic diversity among Stenotrophomonas maltophilia strains despite their originating at a single hospital. J Clin Microbiol, 2004. 42(2): p. 693-9.

27. Sanyal, S.C. and E.M. Mokaddas, The increase in carbapenem use and emergence of Stenotrophomonas maltophilia as an important nosocomial pathogen. J Chemother, 1999. 11(1): p. 28-33.

28. Simon, A., et al., Anforderungen an die Hygiene bei der medizinischen Versorgung von Patienten mit Cystischer Fibrose (Mukoviszidose). www.rki. de -> Infektionsschutz -> Krankenhaushygiene $\rightarrow$ Empfehlungen der Kommission für Krankenhaushygiene und Infektionsprävention, 2012.

29. Pardos de la Gandara, M., et al., Prevalence and characterization of extended-spectrum beta-lactamases-producing Salmonella enterica isolates in Saragossa, Spain (2001-2008). Microb Drug Resist, 2011. 17(2): p. 207-13.

30. Matar, G.M., et al., First detection and sequence analysis of the bla-CTX-M-15 gene in Lebanese isolates of extended-spectrum-beta-lactamaseproducing Shigella sonnei. Ann Trop Med Parasitol, 2007. 101(6): p. 511-7.
31. Sharma, S., P. Ramnani, and J.S. Virdi, Detection and assay of beta-lactamases in clinical and nonclinical strains of Yersinia enterocolitica biovar $1 \mathrm{~A}$. J Antimicrob Chemother, 2004. 54(2): p. 401-5.

32. Miriagou, V., et al., Imipenem resistance in a Salmonella clinical strain due to plasmid-mediated class A carbapenemase KPC-2. Antimicrob Agents Chemother, 2003. 47(4): p. 1297-300.

33. Coque, T.M., F. Baquero, and R. Canton, Increasing prevalence of ESBL-producing Enterobacteriaceae in Europe. Euro Surveill, 2008. 13(47).

34. Katsandri, A., et al., Risk factors for coexistence of fluoroquinolone resistance and ESBL production among Enterobacteriaceae in a Greek university hospital. J Chemother, 2008. 20(4): p. 452-7.

35. Meier, S., et al., Extended-spectrum beta-lactamase-producing Gram-negative pathogens in community-acquired urinary tract infections: an increasing challenge for antimicrobial therapy. Infection, 2011. 39(4): p. 333-40.

36. Walsh, F. and T.R. Rogers, Comparison of plasmidmediated quinolone resistance and extendedspectrum beta-lactamases in third-generation cephalosporin-resistant Enterobacteriaceae from four Irish hospitals. J Med Microbiol, 2012. 61(Pt 1): p. 142-7.

37. Meyer, E., et al., Dramatic increase of third-generation cephalosporin-resistant E. coli in German intensive care units: secular trends in antibiotic drug use and bacterial resistance, 2001 to 2008. Crit Care, 2010. 14(3): p. R113.

38. Gardam, M.A., et al., Is surveillance for multidrugresistant enterobacteriaceae an effective infection control strategy in the absence of an outbreak? J Infect Dis, 2002. 186(12): p. 1754-60.

39. Rodriguez-Bano, J., et al., Risk factors and prognosis of nosocomial bloodstream infections caused by extended-spectrum-beta-lactamase-producing Escherichia coli. J Clin Microbiol, 2010. 48(5): p. 1726-31.

40. Mendonca, N., et al., Spread of extended-spectrum beta-lactamase CTX-M-producing escherichia coli clinical isolates in community and nosocomial environments in Portugal. Antimicrob Agents Chemother, 2007. 51(6): p. 1946-55.

41. Valverde, A., et al., Dramatic increase in prevalence of fecal carriage of extended-spectrum betalactamase-producing Enterobacteriaceae during nonoutbreak situations in Spain. J Clin Microbiol, 2004. 42(10): p. 4769-75.

42. Rogers, B.A., H.E. Sidjabat, and D.L. Paterson, Escherichia coli 025b-ST131: a pandemic, multiresistant, community-associated strain. J Antimicrob Chemother, 2011. 66(1): p. 1-14.

43. Kaase, M., Nachweis von Carbapenemasen im Jahr 2010 - Bericht des NRZ für gramnegative Krankenhauserreger. Epidemiologische Bulletin, 2011. 32: p. 301-304.

44. Pfeifer, Y., et al., NDM-1-producing Escherichia coli in Germany. Antimicrob Agents Chemother, 2011. 55(3): p. 1318-9.

45. Kumarasamy, K.K., et al., Emergence of a new antibiotic resistance mechanism in India, Pakistan, and the UK: a molecular, biological, and epidemiological study. Lancet Infect Dis, 2010. 10(9): p. 597-602.

46. Walsh, T.R., et al., Dissemination of NDM-1 positive bacteria in the New Delhi environment and its implications for human health: an environmental point prevalence study. Lancet Infect Dis, 2011. 11(5): p. 355-62. 
47. Askar, M., et al., Update on the ongoing outbreak of haemolytic uraemic syndrome due to Shiga toxin-producing Escherichia coli (STEC) serotype 0104, Germany, May 2011. Euro Surveill, 2011. 16(22).

48. Hauri, A., et al., Secondary transmissions during the outbreak of Shiga toxin-producing Escherichia coli 0104 in Hesse, Germany, 2011. Euro Surveill, 2011. 16(31).

49. Kumar, A., et al., Duration of hypotension before initiation of effective antimicrobial therapy is the critical determinant of survival in human septic shock. Crit Care Med, 2006. 34(6): p. 1589-96.

50. Jones, R.N., Microbial etiologies of hospital-acquired bacterial pneumonia and ventilator-associated bacterial pneumonia. Clin Infect Dis, 2010. 51 Suppl 1: p. S81-7.

51. Castanheira, M., et al., Trends in carbapenemase-producing Escherichia coli and Klebsiella spp. from Europe and the Americas: report from the SENTRY antimicrobial surveillance programme (2007-09). J Antimicrob Chemother, 2011. 66(6): p. 1409-11.

52. Nordmann, P., et al., Emergence of an Autochthonous and Community-Acquired NDM-1-Producing Klebsiella pneumoniae in Europe. Clin Infect Dis, 2011.

53. Sidjabat, H., et al., Carbapenem resistance in Klebsiella pneumoniae due to the New Delhi Metallo-beta-lactamase. Clin Infect Dis, 2011. 52(4): p. 481-4.

54. Bratu, S., et al., Rapid spread of carbapenem-resistant Klebsiella pneumoniae in New York City: a new threat to our antibiotic armamentarium. Arch Intern Med, 2005. 165(12): p. 1430-5.

55. Cagnacci, S., et al., Bloodstream infections caused by multidrug-resistant Klebsiella pneumoniae producing the carbapenem-hydrolysing VIM1 metallo-beta-lactamase: first Italian outbreak. J Antimicrob Chemother, 2008. 61(2): p. 296-300.

56. Cuzon, G., et al., Outbreak of OXA-48-positive carbapenem-resistant Klebsiella pneumoniae isolates in France. Antimicrob Agents Chemother, 2011. 55(5): p. 2420-3.

57. Endimiani, A., et al., Emergence of blaKPC-containing Klebsiella pneumoniae in a long-term acute care hospital: a new challenge to our healthcare system. J Antimicrob Chemother, 2009. 64(5): p. 1102-10.

58. Giakoupi, P., et al., KPC-2-producing Klebsiella pneumoniae infections in Greek hospitals are mainly due to a hyperepidemic clone. Euro Surveill, 2009. 14(21).

59. Goldfarb, D., et al., Detection of plasmid-mediated KPC-producing Klebsiella pneumoniae in Ottawa, Canada: evidence of intrahospital transmission. J Clin Microbiol, 2009. 47(6): p. 1920-2.

60. Kassis-Chikhani, N., et al., First outbreak of multidrug-resistant Klebsiella pneumoniae carrying blaVIM-1 and blaSHV-5 in a French university hospital. J Antimicrob Chemother, 2006. 57(1): p. $142-5$.

61. Kontopoulou, K., et al., Hospital outbreak caused by Klebsiella pneumoniae producing KPC-2 beta-lactamase resistant to colistin. J Hosp Infect, 2010. 76(1): p. 70-3.

62. Leavitt, A., et al., Molecular epidemiology, sequence types, and plasmid analyses of KPC-producing Klebsiella pneumoniae strains in Israel. Antimicrob Agents Chemother, 2010. 54(7): p. 3002-6.
63. Lopez, J.A., et al., Intercontinental spread from Israel to Colombia of a KPC-3-producing Klebsiella pneumoniae strain. Clin Microbiol Infect, 2011. 17(1): p. 52-6.

64. Mezzatesta, M.L., et al., Outbreak of KPC-3-producing, and colistin-resistant, Klebsiella pneumoniae infections in two Sicilian hospitals. Clin Microbiol Infect, 2011. 17(9): p. 1444-7.

65. Naas, T., et al., Endoscopy-associated transmission of carbapenem-resistant Klebsiella pneumoniae producing KPC-2 beta-lactamase. J Antimicrob Chemother, 2010. 65(6): p. 1305-6.

66. Psichogiou, M., et al., Ongoing epidemic of blaVIM-1-positive Klebsiella pneumoniae in Athens, Greece: a prospective survey. J Antimicrob Chemother, 2008. 61(1): p. 59-63.

67. Souli, M., et al., An outbreak of infection due to beta-Lactamase Klebsiella pneumoniae Carbapenemase 2-producing K. pneumoniae in a Greek University Hospital: molecular characterization, epidemiology, and outcomes. Clin Infect Dis, 2010. 50(3): p. 364-73.

68. Tokatlidou, D., et al., Outbreak caused by a multidrug-resistant Klebsiella pneumoniae clone carrying blaVIM-12 in a university hospital. J Clin Microbiol, 2008. 46(3): p. 1005-8.

69. Wendt, C., et al., First outbreak of Klebsiella pneumoniae carbapenemase (KPC)-producing $\mathrm{K}$. pneumoniae in Germany. Eur J Clin Microbiol Infect Dis, 2010. 29(5): p. 563-70.

70. Cuzon, G., et al., Worldwide diversity of Klebsiella pneumoniae that produce beta-lactamase blaKPC-2 gene. Emerg Infect Dis, 2010. 16(9): p. 1349-56.

71. Fraser, S., Enterobacter Infections. http://emedicine.medscape.com/article/216845-overview, 2010.

72. Nationales Referenzzentrum für Surveillance von nosokomialen Infektionen, KISS KrankenhausInfektions-Surveillance-System, Modul ITS-KISS. www.nrz-hygiene.de, 2011.

73. Sanders, W.E., Jr. and C.C. Sanders, Enterobacter spp.: pathogens poised to flourish at the turn of the century. Clin Microbiol Rev, 1997. 10(2): p. 220-41.

74. Gaston, M.A., Enterobacter: an emerging nosoco mial pathogen. J Hosp Infect, 1988. 11(3): p. 197 208.

75. Oteo, J., et al., Outbreak of vim-1-carbapenemase-producing Enterobacter cloacae in a pediatric intensive care unit. Pediatr Infect Dis J, 2010. 29(12): p. 1144-6.

76. Hoffmann, H., et al., Prevalence of extendedspectrum beta-lactamases in isolates of the Enterobacter cloacae complex from German hospitals. Clin Microbiol Infect, 2006. 12(4): p. 322-30.

77. Hoffmann, H. and A. Roggenkamp, Population genetics of the nomenspecies Enterobacter cloacae. Appl Environ Microbiol, 2003. 69(9): p. 530618.

78. Stumpf, A.N., A. Roggenkamp, and H. Hoffmann, Specificity of enterobacterial repetitive intergenic consensus and repetitive extragenic palindromic polymerase chain reaction for the detection of clonality within the Enterobacter cloacae complex. Diagn Microbiol Infect Dis, 2005. 53(1): p. 9-16.

79. Fernandez, A., et al., Emergence in Spain of a multidrug-resistant Enterobacter cloacae clinical isolate producing SFO-1 extended-spectrum beta-lactamase. J Clin Microbiol, 2011. 49(3): p. 8228.
80. Marchaim, D., et al., Isolation of imipenem-resistant Enterobacter species: emergence of KPC-2 carbapenemase, molecular characterization, epidemiology, and outcomes. Antimicrob Agents Chemother, 2008. 52(4): p. 1413-8.

81. Marcos, M., et al., Changing epidemiology of central venous catheter-related bloodstream infections: increasing prevalence of Gram-negative pathogens. J Antimicrob Chemother, 2011. 66(9): p. 2119-25.

82. Lockhart, S.R., et al., Antimicrobial resistance among Gram-negative bacilli causing infections in intensive care unit patients in the United States between 1993 and 2004. J Clin Microbiol, 2007. 45(10): p. 3352-9.

83. Hejazi, A., H.M. Aucken, and F.R. Falkiner, Epidemiology and susceptibility of serratia marcescens in a large general hospital over an 8-year period. J Hosp Infect, 2000. 45(1): p. 42-6.

84. D'Agata, E., et al., Molecular epidemiology of acquisition of ceftazidime-resistant gram-negative bacilli in a nonoutbreak setting. J Clin Microbiol, 1997. 35(10): p. 2602-5.

85. Kanayama, A., et al., Rapidly spreading CTX-M-type beta-lactamase-producing Proteus mirabilis in Japan. Int J Antimicrob Agents, 2010. 36(4): p. 340-2.

86. Kiratisin, P. and A. Henprasert, Resistance phenotype-genotype correlation and molecular epidemiology of Citrobacter, Enterobacter, Proteus, Providencia, Salmonella and Serratia that carry extended-spectrum beta-lactamases with or without plasmid-mediated AmpC beta-lactamase genes in Thailand. Trans R Soc Trop Med Hyg, 2011. 105(1): p. 46-51.

87. Deshpande, L.M., et al., Occurrence and characterization of carbapenemase-producing Enterobacteriaceae: report from the SENTRY Antimicrobial Surveillance Program (2000-2004). Microb Drug Resist, 2006. 12(4): p. 223-30.

88. National Nosocomial Infections Surveillance (NNIS) System Report, data summary from January 1992 through June 2004, issued October 2004. Am J Infect Control, 2004. 32(8): p. 470-85.

89. Hirsch, E.B. and V.H. Tam, Impact of multidrug-resistant Pseudomonas aeruginosa infection on patient outcomes. Expert Rev Pharmacoecon Outcomes Res, 2010. 10(4): p. 441-51.

90. Obritsch, M.D., et al., National surveillance of antimicrobial resistance in Pseudomonas aeruginosa isolates obtained from intensive care unit patients from 1993 to 2002. Antimicrob Agents Chemother, 2004. 48(12): p. 4606-10.

91. Biedenbach, D.J., G.J. Moet, and R.N. Jones, Occurrence and antimicrobial resistance pattern comparisons among bloodstream infection isolates from the SENTRY Antimicrobial Surveillance Program (1997-2002). Diagn Microbiol Infect Dis, 2004. 50(1): p. 59-69.

92. Souli, M., I. Galani, and H. Giamarellou, Emergence of extensively drug-resistant and pandrug-resistant Gram-negative bacilli in Europe. Euro Surveill, 2008. 13(47).

93. Pirnay, J.P., et al., Pseudomonas aeruginosa displays an epidemic population structure. Environ Microbiol, 2002. 4(12): p. 898-911.

94. Fonseca, E.L., S. Freitas Fdos, and A.C. Vicente, The colistin-only-sensitive Brazilian Pseudomonas aeruginosa clone SP (sequence type 277 ) is spread worldwide. Antimicrob Agents Chemother, 2010. 54(6): p. 2743. 
95. Giske, C.G., et al., Establishing clonal relationships between VIM-1-like metallo-beta-lactamase-producing Pseudomonas aeruginosa strains from four European countries by multilocus sequence typing. J Clin Microbiol, 2006. 44(12): p. 4309-15.

96. Santella, G., et al., Intercontinental dissemination of IMP-13-producing Pseudomonas aeruginosa belonging in sequence type 621. J Clin Microbiol, 2010. 48(11): p. 4342-3.

97. Cholley, P., et al., Molecular epidemiology of multidrug-resistant Pseudomonas aeruginosa in a French university hospital. J Hosp Infect, 2010. 76(4): p. 316-9.

98. Kouda, S., et al., Increased prevalence and clonal dissemination of multidrug-resistant Pseudomonas aeruginosa with the blalMP-1 gene cassette in Hiroshima. J Antimicrob Chemother, 2009. 64(1): p. 46-51.

99. Vettoretti, L., et al., Emergence of extensive-drugresistant Pseudomonas aeruginosa in a French university hospital. Eur J Clin Microbiol Infect Dis, 2009. 28(10): p. 1217-22.

100. Wang, J., et al., Molecular epidemiology and mechanisms of carbapenem resistance in Pseudomonas aeruginosa isolates from Chinese hospitals. Int J Antimicrob Agents, 2010. 35(5): p. 486-91.

101. Salabi, A.E., et al., First report of the metallo-beta-lactamase SPM-1 in Europe. Antimicrob Agents Chemother, 2010. 54(1): p. 582.

102. van den Broek, P.J., et al., Endemic and epidemic acinetobacter species in a university hospital: an 8-year survey. J Clin Microbiol, 2009. 47(11): p. 3593-9.

103. Appleman, M.D., et al., In vitro activities of nontraditional antimicrobials against multiresistant Acinetobacter baumannii strains isolated in an intensive care unit outbreak. Antimicrob Agents Chemother, 2000. 44(4): p. 1035-40.

104. Bou, G., et al., PCR-based DNA fingerprinting (REP-PCR, AP-PCR) and pulsed-field gel electrophoresis characterization of a nosocomial outbreak caused by imipenem- and meropenem-resistant Acinetobacter baumannii. Clin Microbiol Infect, 2000. 6(12): p. 635-43.

105. Corbella, X., et al., Emergence and rapid spread of carbapenem resistance during a large and sustained hospital outbreak of multiresistant Acinetobacter baumannii. J Clin Microbiol, 2000. 38(11): p. 4086-95.

106. D'Agata, E.M., V. Thayer, and W. Schaffner, An outbreak of Acinetobacter baumannii: the importance of cross-transmission. Infect Control Hosp Epidemiol, 2000. 21(9): p. 588-91.

107. Menichetti, F., et al., [Clinical and molecular epidemiology of an outbreak of infusion-related Acinetobacter baumannii bacteremia in an Intensive Care Unit]. Infez Med, 2000. 1(8): p. 24-29.

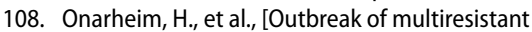
Acinetobacter baumannii infection]. Tidsskr Nor Laegeforen, 2000. 120(9): p. 1028-33.

109. Penzak, S.R., et al., Investigation of an outbreak of gram-negative bacteremia among hematology-oncology outpatients. Infect Control Hosp Epidemiol, 2000. 21(9): p. 597-9.

110. Barnaud, G., et al., Two sequential outbreaks caused by multidrug-resistant Acinetobacter baumannii isolates producing OXA-58 or OXA-72 oxacillinase in an intensive care unit in France. $J$ Hosp Infect, 2010. 76(4): p. 358-60.
111. Choi, W.S., et al., Nosocomial outbreak of carbapenem-resistant Acinetobacter baumannii in intensive care units and successful outbreak control program. J Korean Med Sci, 2010. 25(7): p. 999-1004.

112. Culebras, E., et al., Outbreak of Acinetobacter baumannii producing OXA-66 in a Spanish hospital: epidemiology and study of patient movements. Microb Drug Resist, 2010. 16(4): p. 309-15.

113. D'Arezzo, S., et al., Changing carbapenemase gene pattern in an epidemic multidrug-resistant Acinetobacter baumannii lineage causing multiple outbreaks in central Italy. J Antimicrob Chemother, 2011. 66(1): p. 54-61.

114. Doidge, M., et al., Control of an outbreak of carbapenem-resistant Acinetobacter baumannii in Australia after introduction of environmental cleaning with a commercial oxidizing disinfectant. Infect Control Hosp Epidemiol, 2010. 31(4): p. 418-20.

115. Frickmann, $\mathrm{H}_{\text {., }}$ et al., [Management of an Outbreak with Cases of Nosocomial Pneumonia Caused by a Novel Multi-Drug-Resistant Acinetobacter baumannii Clone]. Pneumologie, 2010. 64(11): p. 686-93.

116. Garlantezec, R., et al., Cost-analysis of an intensive care unit closure due to an imipenem-resistant oxa-23 Acinetobacter baumannii outbreak. J Hosp Infect, 2011. 77(2): p. 174-5.

117. Gulati, R.K., et al., Outbreak of carbapenem-resistant Acinetobacter baumannii among nonburn patients in a burn intensive care unit. J Hosp Infect, 2010. 76(4): p. 357-8.

118. La Forgia, C., et al., Management of a multidrug-resistant Acinetobacter baumannii outbreak in an intensive care unit using novel environmental disinfection: a 38-month report. Am J Infect Control, 2010. 38(4): p. 259-63.

119. Lewis, T., et al., High-throughput whole-genome sequencing to dissect the epidemiology of Acinetobacter baumannii isolates from a hospital outbreak. J Hosp Infect, 2010. 75(1): p. 37-41.

120. McGrath, E.J., et al., An outbreak of carbapenem-resistant Acinetobacter baumannii infection in a neonatal intensive care unit: investigation and control. Infect Control Hosp Epidemiol, 2011. 32(1): p. 34-41.

121. Merino, M., et al., OXA-24 carbapenemase gene flanked by XerC/XerD-like recombination sites in different plasmids from different Acinetobacter species isolated during a nosocomial outbreak. Antimicrob Agents Chemother, 2010. 54(6): p. 2724-7.

122. Munoz-Price, LS, et al Clinical outcomes of carbapenem-resistant Acinetobacter baumannii bloodstream infections: study of a 2-state monoclonal outbreak. Infect Control Hosp Epidemiol, 2010. 31(10): p. 1057-62.

123. Nunley, D.R., et al., Mortality associated with Acinetobacter baumannii infections experienced by lung transplant recipients. Lung, 2010. 188(5): p. 381-5.

124. Prates, C.G., et al., Risk factors for 30-day mortality in patients with carbapenem-resistant Acinetobacter baumannii during an outbreak in an intensive care unit. Epidemiol Infect, 2011. 139(3): p. 411-8.

125. Ray, A., et al., Use of vaporized hydrogen peroxide decontamination during an outbreak of multidrug-resistant Acinetobacter baumannii infection at a long-term acute care hospital. Infect Control Hosp Epidemiol, 2010. 31(12): p. 1236-41.
126. Tankovic, J., et al., Characterization of a hospital outbreak of imipenem-resistant Acinetobacter baumannii by phenotypic and genotypic typing methods. J Clin Microbiol, 1994. 32(11): p. 267781.

127. Wadl, M., et al., Increasing occurrence of multidrug-resistance in Acinetobacter baumannii isolates from four German University Hospitals, 2002-2006. Infection, 2010. 38(1): p. 47-51.

128. Higgins, P.G., et al., Global spread of carbapenem-resistant Acinetobacter baumannii. J Antimicrob Chemother, 2010. 65(2): p. 233-8.

129. Maragakis, L.L. and T.M. Perl, Acinetobacter baumannii: epidemiology, antimicrobial resistance, and treatment options. Clin Infect Dis, 2008. 46(8): p. 1254-63.

130. Rodriguez-Bano, J., et al., Clinical features and epidemiology of Acinetobacter baumannii colonization and infection in Spanish hospitals. Infect Control Hosp Epidemiol, 2004. 25(10): p. 819-24.

131. Harris, A.D., et al., How important is patient-topatient transmission in extended-spectrum beta-lactamase Escherichia coli acquisition. Am J Infect Control, 2007. 35(2): p. 97-101.

132. Harris, A.D., et al., Risk factors for colonization with extended-spectrum beta-lactamase-producing bacteria and intensive care unit admission. Emerg Infect Dis, 2007. 13(8): p. 1144-9.

133. Kohlenberg, A., F. Schwab, and H. Ruden, Wide dissemination of extended-spectrum beta-lactamase (ESBL)-producing Escherichia coli and Klebsiella spp. in acute care and rehabilitation hospitals. Epidemiol Infect, 2011: p. 1-7.

134. Fankhauser, C., et al., Surveillance of extendedspectrum-beta-lactamase-producing Enterobacteriaceae in a Swiss Tertiary Care Hospital. Swiss Med Wkly, 2009. 139(51-52): p. 747-51.

135. Willemsen, I., et al., Highly resistant gram-negative microorganisms: incidence density and occurrence of nosocomial transmission (TRIANGLe Study). Infect Control Hosp Epidemiol, 2011. 32(4): p. 333-41.

136. Tschudin-Sutter, S., et al., Extended spectrum ss-lactamase-producing Escherichia coli in neonatal care unit. Emerg Infect Dis, 2010. 16(11): p. 1758-60.

137. Pelly, H., et al., Outbreak of extended spectrum beta-lactamase producing $\mathrm{E}$. coli in a nursing home in Ireland, May 2006. Euro Surveill, 2006. 11(8): p. E060831 1.

138. Moissenet, D., et al., Meningitis caused by Escherichia coli producing TEM-52 extendedspectrum beta-lactamase within an extensive outbreak in a neonatal ward: epidemiological investigation and characterization of the strain. J Clin Microbiol, 2010. 48(7): p. 2459-63.

139. Kola, A., et al., Surveillance of extended-spectrum beta-lactamase-producing bacteria and routine use of contact isolation: experience from a three-year period. J Hosp Infect, 2007. 66(1): p. 46-51.

140. Reddy, P., et al., Screening for extended-spectrum beta-lactamase-producing Enterobacteriaceae among high-risk patients and rates of subsequent bacteremia. Clin Infect Dis, 2007. 45(7): p. 846-52.

141. Pai, H., et al., A nosocomial outbreak of Escherichia coli producing CTX-M-15 and OXA-30 betalactamase. Infect Control Hosp Epidemiol, 2006. 27(3): p. 312-4. 
142. Schwaber, M.J. and Y. Carmeli, Mortality and delay in effective therapy associated with extended-spectrum beta-lactamase production in Enterobacteriaceae bacteraemia: a systematic review and meta-analysis. J Antimicrob Chemother, 2007. 60(5): p. 913-20.

143. Wang, S.S., et al., Clinical manifestations and prognostic factors in cancer patients with bacteremia due to extended-spectrum beta-lactamase-producing Escherichia coli or Klebsiella pneumoniae. J Microbiol Immunol Infect, 2011. 44(4): p. 282-8.

144. Ahmed, S.H., et al., Nosocomial blood stream infection in intensive care units at Assiut University Hospitals (Upper Egypt) with special reference to extended spectrum beta-lactamase producing organisms. BMC Res Notes, 2009. 2: p. 76.

145. Arnan, M., et al., Risk factors for, and clinical relevance of, faecal extended-spectrum beta-lactamase producing Escherichia coli (ESBL-EC) carriage in neutropenic patients with haematological malignancies. Eur J Clin Microbiol Infect Dis, 2011. 30(3): p. 355-60.

146. Coleman, B.L., et al., The role of drinking water in the transmission of antimicrobial-resistant $\mathrm{E}$. coli. Epidemiol Infect, 2011: p. 1-10.

147. Dolejska, M., et al., Extended-spectrum betalactamase-producing Escherichia coli in turkey meat production farms in the Czech Republic: National survey reveals widespread isolates with bla(SHV-12) genes on IncFIl plasmids. Lett Appl Microbiol, 2011. 53(3): p. 271-7.

148. Ewers, C., et al., Emergence of human pandemic 025:H4-ST131 CTX-M-15 extended-spectrum-beta-lactamase-producing Escherichia coli among companion animals. J Antimicrob Chemother, 2010.65(4): p. 651-60.

149. Murphy, C.P., et al., Escherichia coli and selected veterinary and zoonotic pathogens isolated from environmental sites in companion animal veterinary hospitals in southern Ontario. Can Vet J, 2010. 51(9): p. 963-72.

150. Warren, R.E., et al., Imported chicken meat as a potential source of quinolone-resistant Escherichia coli producing extended-spectrum betalactamases in the UK. J Antimicrob Chemother, 2008. 61(3): p. 504-8.

151. Pitout, J.D., et al., Community-wide outbreaks of clonally related CTX-M-14 beta-lactamase-producing Escherichia coli strains in the Calgary health region. J Clin Microbiol, 2005. 43(6): p. 28449.

152. Leflon-Guibout, V., et al., Absence of CTX-M enzymes but high prevalence of clones, including clone ST131, among fecal Escherichia coli isolates from healthy subjects living in the area of $\mathrm{Pa}$ ris, France. J Clin Microbiol, 2008. 46(12): p. 39005.

153. Suzuki, S., et al., Change in the prevalence of extended-spectrum-beta-lactamase-producing Escherichia coli in Japan by clonal spread. J Antimicrob Chemother, 2009. 63(1): p. 72-9.

154. Carattoli, A., et al., Molecular epidemiology of Escherichia coli producing extended-spectrum beta-lactamases isolated in Rome, Italy. J Clin Microbiol, 2008. 46(1): p. 103-8.

155. Potz, N.A., et al., Prevalence and mechanisms of cephalosporin resistance in Enterobacteriaceae in London and South-East England. J Antimicrob Chemother, 2006. 58(2): p. 320-6.
156. Kim, Y.R., et al., Nosocomial transmission of CTX-M-15 and OXA-30 beta-lactamase-producing Escherichia coli in a neurosurgical intensive care unit. Ann Clin Lab Sci, 2005. 35(3): p. 297301.

157. Nseir, S., et al., Risk of acquiring multidrug-resistant Gram-negative bacilli from prior room occupants in the intensive care unit. Clin Microbiol Infect, 2011. 17(8): p. 1201-8.

158. Alsterlund, R., et al., Multiresistant CTX-M-15 ESBL-producing Escherichia coli in southern Sweden: Description of an outbreak. Scand J Infect Dis, 2009. 41(6-7): p. 410-5.

159. Oteo, J., et al., Extended spectrum \{beta\}-lactamase-producing Escherichia coli as a cause of pediatric infections: Report of a neonatal intensive care unit outbreak due to a CTX-M-14-producing strain. Antimicrob Agents Chemother, 2011.

160. March, A., et al., Colonization of residents and staff of a long-term-care facility and adjacent acute-care hospital geriatric unit by multiresistant bacteria. Clin Microbiol Infect, 2010. 16(7): p. 934-44.

161. Rooney, P.J., et al., Nursing homes as a reservoir of extended-spectrum beta-lactamase (ESBL)producing ciprofloxacin-resistant Escherichia coli. J Antimicrob Chemother, 2009. 64(3): p. 635-41.

162. Rodriguez-Bano, J., et al., Faecal carriage of extended-spectrum beta-lactamase-producing Escherichia coli: prevalence, risk factors and molecular epidemiology. J Antimicrob Chemother, 2008. 62(5): p. 1142-9.

163. Friedmann, R., et al., Prospective evaluation of colonization with extended-spectrum betalactamase (ESBL)-producing enterobacteriaceae among patients at hospital admission and of subsequent colonization with ESBL-producing enterobacteriaceae among patients during hospitalization. Infect Control Hosp Epidemiol, 2009. 30(6): p. 534-42.

164. Hsieh, C.J., Y.H. Shen, and K.P. Hwang, Clinical implications, risk factors and mortality following community-onset bacteremia caused by extended-spectrum beta-lactamase (ESBL) and nonESBL producing Escherichia coli. J Microbiol Immunol Infect, 2010. 43(3): p. 240-8.

165. Slim, E., et al., Nosocomial transmission of highly resistant microorganisms on a spinal cord rehabilitation ward. J Spinal Cord Med, 2009. 32(4): p. 422-7.

166. Tangden, T., et al., Foreign travel is a major risk factor for colonization with Escherichia coli producing CTX-M-type extended-spectrum beta-lactamases: a prospective study with Swedish volunteers. Antimicrob Agents Chemother, 2010. 54(9): p. 3564-8.

167. Kaier, K., et al., Epidemiology meets econometrics: using time-series analysis to observe the impact of bed occupancy rates on the spread of multidrug-resistant bacteria. J Hosp Infect, 2010. 76(2): p. 108-13

168. Detection of Enterobacteriaceae isolates carrying metallo-beta-lactamase - United States, 2010. MMWR Morb Mortal Wkly Rep, 2010. 59(24): p. 750.

169. Calbo, E., et al., Foodborne nosocomial outbreak of SHV1 and CTX-M-15-producing Klebsiella pneumoniae: epidemiology and control. Clin Infect Dis, 2011. 52(6): p. 743-9.

170. Cetre, J.C., et al., Outbreaks of contaminated broncho-alveolar lavage related to intrinsically defective bronchoscopes. J Hosp Infect, 2005. 61(1): p. 39-45.
171. Velasco, C., et al., Eradication of an extensive outbreak in a neonatal unit caused by two sequential Klebsiella pneumoniae clones harbouring related plasmids encoding an extendedspectrum beta-lactamase. J Hosp Infect, 2009. 73(2): p. 157-63.

172. Vranic-Ladavac, M., et al., Clonal spread of CTXM-15-producing Klebsiella pneumoniae in a Croatian hospital. J Med Microbiol, 2010.59(Pt 9): p. 1069-78

173. Martins, I.S., et al., Endemic extended-spectrum beta-lactamase-producing Klebsiella pneumoniae at an intensive care unit: risk factors for colonization and infection. Microb Drug Resist, 2006. 12(1): p. 50-8

174. Willemsen, I., et al., Highly resistant microorganisms in a teaching hospital: the role of horizontal spread in a setting of endemicity. Infect Control Hosp Epidemiol, 2008. 29(12): p. 1110-7.

175. Mammina, C., et al., Outbreak of infection with Klebsiella pneumoniae sequence type 258 producing Klebsiella pneumoniae Carbapenemase 3 in an intensive care unit in Italy. J Clin Microbiol, 2010. 48(4): p. 1506-7.

176. Pournaras, S., et al., Clonal spread of KPC-2 carbapenemase-producing Klebsiella pneumoniae strains in Greece. J Antimicrob Chemother, 2009. 64(2): p. 348-52.

177. Zarkotou, O., et al., Predictors of mortality in patients with bloodstream infections caused by KPC-producing Klebsiella pneumoniae and impact of appropriate antimicrobial treatment. Clin Microbiol Infect, 2011.

178. Carrer, A., et al., Outbreak of CTX-M-15-producing Klebsiella pneumoniae in the intensive care unit of a French hospital. Microb Drug Resist, 2009. 15(1): p. 47-54

179. Demirdag, K. and S. Hosoglu, Epidemiology and risk factors for ESBL-producing Klebsiella pneumoniae: a case control study. J Infect Dev Ctries, 2010. 4(11): p. 717-22.

180. Wener, K.M., et al., Treatment with fluoroquinolones or with beta-lactam-beta-lactamase inhibitor combinations is a risk factor for isolation of extended-spectrum-beta-lactamase-producing Klebsiella species in hospitalized patients. Antimicrob Agents Chemother, 2010. 54(5): p. 2010-6.

181. Mosqueda-Gomez, J.L., et al., Molecular epidemiology and risk factors of bloodstream infections caused by extended-spectrum beta-lactamase-producing Klebsiella pneumoniae A case-control study. Int J Infect Dis, 2008. 12(6): p. 653-9.

182. Ramphal, R. and P.G. Ambrose, Extended-spectrum beta-lactamases and clinical outcomes: current data. Clin Infect Dis, 2006. 42 Suppl 4: p. S164-72.

183. Ben-David, D., et al., Outcome of carbapenem resistant Klebsiella pneumoniae bloodstream infections. Clin Microbiol Infect, 2011.

184. Daikos, G.L., et al., Prospective observational study of the impact of VIM-1 metallo-beta-lactamase on the outcome of patients with Klebsiella pneumoniae bloodstream infections. Antimicrob Agents Chemother, 2009. 53(5): p. 1868-73.

185. Falagas, M.E., et al., Risk factors of carbapenem-resistant Klebsiella pneumoniae infections: a matched case control study. J Antimicrob Chemother, 2007.60(5): p. 1124-30.

186. Gasink, L.B., et al., Risk factors and clinical impact of Klebsiella pneumoniae carbapenemaseproducing K. pneumoniae. Infect Control Hosp Epidemiol, 2009. 30(12): p. 1180-5. 
187. Gregory, C.J., et al., Outbreak of carbapenemresistant Klebsiella pneumoniae in Puerto Rico associated with a novel carbapenemase variant Infect Control Hosp Epidemiol, 2010. 31(5): p. 476-84.

188. Mouloudi, E., et al., Bloodstream infections caused by metallo-beta-lactamase/Klebsiella pneumoniae carbapenemase-producing K. pneumoniae among intensive care unit patients in Greece: risk factors for infection and impact of type of resistance on outcomes. Infect Control Hosp Epidemiol, 2010. 31(12): p. 1250-6.

189. Schwaber, M.J., et al., Predictors of carbapenem-resistant Klebsiella pneumoniae acquisition among hospitalized adults and effect of acquisition on mortality. Antimicrob Agents Chemother, 2008. 52(3): p. 1028-33.

190. Qureshi, Z.A., et al., Clinical characteristics of bacteraemia caused by extended-spectrum beta-lactamase-producing Enterobacteriaceae in the era of CTX-M-type and KPC-type beta-lactamases. Clin Microbiol Infect, 2011.

191. Harris, A.D., et al., Methodological principles of case-control studies that analyzed risk factors for antibiotic resistance: a systematic review. Clin Infect Dis, 2001. 32(7): p. 1055-61.

192. Behar, P.R., et al., The effect of control group selection in the analysis of risk factors for extended spectrum beta-lactamase-producing Klebsiella pneumoniae infections. A prospective controlled study. J Hosp Infect, 2008. 68(2): p. 123-9.

193. Tumbarello, M., et al., Bloodstream infections caused by extended-spectrum-beta-lactamase-producing Klebsiella pneumoniae: risk factors, molecular epidemiology, and clinical outcome. Antimicrob Agents Chemother, 2006. 50(2): p. 498-504.

194. Sanchez-Romero, l., et al., Nosocomial Outbreak of VIM-1-producing Klebsiella pneumoniae of multilocus sequence type 15: Molecular basis, clinical risk factors, and outcome. Antimicrob Agents Chemother, 2011.

195. Quirante, O.F., S.G. Cerrato, and S.L. Pardos, Risk factors for bloodstream infections caused by extended-spectrum beta-lactamase-producing Escherichia coli and Klebsiella pneumoniae. Braz J Infect Dis, 2011. 15(4): p. 370-6.

196. Saely, S., et al., Investigating the impact of the definition of previous antibiotic exposure related to isolation of extended spectrum beta-lactamase-producing Klebsiella pneumoniae. Am J Infect Control, 2011. 39(5): p. 390-5.

197. Kang, C.I., et al., Risk factors for infection and treatment outcome of extended-spectrum betalactamase-producing Escherichia coli and Klebsiella pneumoniae bacteremia in patients with hematologic malignancy. Ann Hematol, 2011.

198. Patel, G., et al., Outcomes of carbapenem-resistant Klebsiella pneumoniae infection and the impact of antimicrobial and adjunctive therapies. Infect Control Hosp Epidemiol, 2008. 29(12): p. 1099-106.

199. Barbier, F., et al., Genesis of a KPC-producing Klebsiella pneumoniae after in vivo transfer from an imported Greek strain. Euro Surveill, 2010. 15(1).

200. Bogaerts, P., et al., Emergence of clonally related Klebsiella pneumoniae isolates of sequence type 258 producing KPC-2 carbapenemase in Belgium. J Antimicrob Chemother, 2010. 65(2): p. 361-2.
201. Cuzon, G., et al., Plasmid-mediated carbapenem-hydrolyzing beta-lactamase KPC-2 in Klebsiella pneumoniae isolate from Greece. Antimicrob Agents Chemother, 2008. 52(2): p. 796-7.

202. Samuelsen, O., et al., Emergence of clonally related Klebsiella pneumoniae isolates of sequence type 258 producing plasmid-mediated KPC carbapenemase in Norway and Sweden. J Antimicrob Chemother, 2009. 63(4): p. 654-8.

203. Kuhn, I., et al., The use of colonization rate and epidemic index as tools to illustrate the epidemiology of faecal Enterobacteriaceae strains in Swedish neonatal wards. J Hosp Infect, 1993. 23(4): p. 287-97.

204. von Baum, H., D. Lin, and C. Wendt, Prevalence of colonisation with third-generation cephalosporin-resistant Enterobacteriaceae in ICU patients of Heidelberg University Hospitals. Clin Microbiol Infect, 2004. 10(5): p. 436-40.

205. Piagnerelli, M., et al., Risk factors for infection and molecular typing in patients in the intensive care unit colonized with nosocomial Enterobacter aerogenes. Infect Control Hosp Epidemiol, 2002. 23(8): p. 452-6.

206. De Gheldre, Y., et al., Molecular epidemiology of an outbreak of multidrug-resistant Enterobacter aerogenes infections and in vivo emergence of imipenem resistance. J Clin Microbiol, 1997. 35(1): p. 152-60

207. Meyer, E., et al., Should we screen patients for extended-spectrum beta-lactamase-producing enterobacteriaceae in intensive care units? Infect Control Hosp Epidemiol, 2009. 30(1): p. 103-5.

208. Cosgrove, S.E., et al., Health and economic outcomes of the emergence of third-generation cephalosporin resistance in Enterobacter species. Arch Intern Med, 2002. 162(2): p. 185-90.

209. Kang, C.I., et al., Bloodstream infections caused by Enterobacter species: predictors of 30-day mortality rate and impact of broad-spectrum cephalosporin resistance on outcome. Clin Infect Dis, 2004. 39(6): p. 812-8.

210. Chang, E.P., et al., Clinical characteristics and predictors of mortality in patients with Enterobacter aerogenes bacteremia. J Microbiol Immunol Infect, 2009. 42(4): p. 329-35.

211. Ye, Y., et al., Enterobacter bacteremia: Clinical features, risk factors for multiresistance and mortality in a Chinese University Hospital. Infection, 2006. 34(5): p. 252-7.

212. Lye, D.C., et al., The impact of multidrug resistance in healthcare-associated and nosocomial Gram-negative bacteraemia on mortality and length of stay: cohort study. Clin Microbiol Infect, 2011

213. Aubron, C., et al., High level cephalosporin-resistant Enterobacteriaceae ventilator-associated pneumonia: prognostic factors based on a cohort study. J Hosp Infect, 2011. 77(1): p. 64-9.

214. Marchaim, D., et al., Outcomes and genetic relatedness of carbapenem-resistant enterobacteriaceae at Detroit medical center. Infect Control Hosp Epidemiol, 2011. 32(9): p. 861-71.

215. Stumpf, A., Dissertation - Molekular-epidemiologische Untersuchung klinischer Isolate des Enterobacter cloacae Komplexes und Identifizierung eines Genotyp-spezifischen Fitnessfaktors mit Krankenhaus-hygienischer Relevanz. LMU München: Medizinische Fakultät, 2008.

216. van Rossem, M.C., et al., Enterobacter colonisation in newborn infants: predictors, follow-up and implications for infection control. J Hosp Infect, 2007. 67(2): p. 142-8.
217. Vidal-Navarro, L., et al., Faecal carriage of multidrug-resistant Gram-negative bacilli during a non-outbreak situation in a French university hospital. J Antimicrob Chemother, 2010. 65(11): p. 2455-8.

218. Dalben, M., et al., Investigation of an outbreak of Enterobacter cloacae in a neonatal unit and review of the literature. J Hosp Infect, 2008. 70(1): p. 7-14.

219. Watson, J.T., et al., Outbreak of catheter-associated Klebsiella oxytoca and Enterobacter cloacae bloodstream infections in an oncology chemotherapy center. Arch Intern Med, 2005. 165(22): p. 2639-43.

220. Kang, C.I., et al., Clinical predictors of Enterobacter bacteremia among patients admitted to the ED. Am J Emerg Med, 2010.

221. Qureshi, Z.A., et al., Risk factors and outcome of extended-spectrum beta-lactamase-producing Enterobacter cloacae bloodstream infections. Int J Antimicrob Agents, 2011. 37(1): p. 26-32.

222. Liu, C.P., et al., Nosocomial and community-acquired Enterobacter cloacae bloodstream infection: risk factors for and prevalence of SHV- 12 in multiresistant isolates in a medical centre. J Hosp Infect, 2004. 58(1): p. 63-77.

223. Ong, D.S., et al., Antibiotic exposure and resistance development in Pseudomonas aeruginosa and Enterobacter species in intensive care units. Crit Care Med, 2011.

224. Gbaguidi-Haore, H., et al., Molecular epidemiology of Enterobacter cloacae in a neonatal department: a 2-year surveillance study. Eur J Clin Microbiol Infect Dis, 2008. 27(8): p. 643-8.

225. Patel, N., et al., Clinical epidemiology of carbapenem-intermediate or -resistant Enterobacteriaceae. J Antimicrob Chemother, 2011. 66(7): p. 1600-8.

226. Al Jarousha, A.M., et al., An outbreak of Serratia marcescens septicaemia in neonatal intensive care unit in Gaza City, Palestine. J Hosp Infect, 2008. 70(2): p. 119-26.

227. Dessi, A., et al., Serratia marcescens infections and outbreaks in neonatal intensive care units. J Chemother, 2009. 21(5): p. 493-9.

228. Byrne, A.H., et al., Rate of carriage of Serratia marcescens in patients with and without evidence of infection. Scand J Infect Dis, 2001. 33(11): p. 822-6.

229. Lee, Y.L., et al., Low-level colonization and infection with ciprofloxacin-resistant gram-negative bacilli in a skilled nursing facility. Am J Infect Control, 1998. 26(6): p. 552-7.

230. Samonis, G, et al., Serratia infections in a general hospital: characteristics and outcomes. Eur J Clin Microbiol Infect Dis, 2011. 30(5): p. 653-60.

231. Bizzarro, M.J., et al., Case-control analysis of endemic Serratia marcescens bacteremia in a neonatal intensive care unit. Arch Dis Child Fetal Neonatal Ed, 2007. 92(2): p. F120-6.

232. Choi, S.H., et al., Serratia bacteremia in a large university hospital: trends in antibiotic resistance during 10 years and implications for antibiotic use. Infect Control Hosp Epidemiol, 2002. 23(12): p. 740-7.

233. Liu, J.W., Y.M. Hsu, and Y.F. Huang, Independent prognostic factors for fatality in patients with urinary tract infection caused by Serratia marcescens. Infect Control Hosp Epidemiol, 2004. 25(1): p. 80-2.

234. Shih, H.I., et al., Serratia marcescens bacteremia at a medical center in southern Taiwan: high prevalence of cefotaxime resistance. J Microbiol Immunol Infect, 2005. 38(5): p. 350-7. 
235. Cheng, K.C., et al., Clinical experiences of the infections caused by extended-spectrum betalactamase-producing Serratia marcescens at a medical center in Taiwan. Jpn J Infect Dis, 2006. 59(3): p. 147-52.

236. Cohen-Nahum, K., et al., Urinary tract infections caused by multi-drug resistant Proteus mirabilis: Risk factors and clinical outcomes. Infection, 2010. 38(1): p. 41-6.

237. Endimiani, A., et al., Proteus mirabilis bloodstream infections: risk factors and treatment outcome related to the expression of extendedspectrum beta-lactamases. Antimicrob Agents Chemother, 2005. 49(7): p. 2598-605.

238. Samonis, G., et al., Citrobacter infections in a general hospital: characteristics and outcomes. Eur J Clin Microbiol Infect Dis, 2009. 28(1): p. 61-8.

239. Kim, B.N., et al., Bacteraemia due to tribe Proteeae: a review of 132 cases during a decade (1991-2000). Scand J Infect Dis, 2003. 35(2): p. 98-103.

240. Lai, C.C., et al., Bacteraemia caused by nonfreundii, non-koseri Citrobacter species in Taiwan. J Hosp Infect, 2010. 76(4): p. 332-5.

241. Deal, E.N., et al., Predictors of in-hospital mortality for bloodstream infections caused by Enterobacter species or Citrobacter freundii. Pharmacotherapy, 2007. 27(2): p. 191-9.

242. Lee, I.K. and J.W. Liu, Clinical characteristics and risk factors for mortality in Morganella morganii bacteremia. J Microbiol Immunol Infect, 2006. 39(4): p. 328-34.

243. Chen, S., et al., Detection and spread of carbapenem-resistant Citrobacter freundii in a teaching hospital in China. Am J Infect Control, 2011. 39(9): p. e55-60.

244. Fairfax, M.R., et al., Detection of 2 SME- 1 carbapenemase-producing Serratia marcescens in Detroit. Diagn Microbiol Infect Dis, 2011. 71(3): p. 325-6.

245. Tibbetts, R., et al., Detection of KPC-2 in a clinical isolate of Proteus mirabilis and first reported description of carbapenemase resistance caused by a KPC beta-lactamase in P. mirabilis. J Clin Microbiol, 2008. 46(9): p. 3080-3.

246. Tsakris, A., et al., Characterization of In3Mor, a new integron carrying VIM-1 metallo-beta-lactamase and sat 1 gene, from Morganella morganii. J Antimicrob Chemother, 2007. 59(4): p. 739-41.

247. Hejazi, A. and F.R. Falkiner, Serratia marcescens. J Med Microbiol, 1997. 46(11): p. 903-12.

248. Blossom, D., et al., Multistate outbreak of Serratia marcescens bloodstream infections caused by contamination of prefilled heparin and isotonic sodium chloride solution syringes. Arch Intern Med, 2009. 169(18): p. 1705-11.

249. Tanaka, T., et al., A nosocomial outbreak of febrile bloodstream infection caused by heparinized-saline contaminated with Serratia marcescens, Tokyo, 2002. Jpn J Infect Dis, 2004. 57(5): p. 189-92.

250. Vonberg, R.P. and P. Gastmeier, Hospital-acquired infections related to contaminated substances. J Hosp Infect, 2007. 65(1): p. 15-23.

251. Al-Hasan, M.N., J.E. Eckel-Passow, and L.M. Baddour, Impact of healthcare-associated acquisition on community-onset Gram-negative bloodstream infection: a population-based study : Healthcare-associated Gram-negative BSI. Eur J Clin Microbiol Infect Dis, 2011.

252. Chow, A.W., et al., A nosocomial outbreak of infections due to multiply resistant Proteus mirabilis: role of intestinal colonization as a major reservoir. J Infect Dis, 1979. 139(6): p. 621-7.
253. Doran, T.I., The role of Citrobacter in clinical disease of children: review. Clin Infect Dis, 1999. 28(2): p. 384-94.

254. Dance, D.A., et al., A hospital outbreak caused by a chlorhexidine and antibiotic-resistant Proteus mirabilis. J Hosp Infect, 1987. 10(1): p. 10-6.

255. McDermott, C. and J.M. Mylotte, Morganella morganii: epidemiology of bacteremic disease. Infect Control, 1984. 5(3): p. 131-7.

256. Voelz, A., et al., Outbreaks of Serratia marcescens in neonatal and pediatric intensive care units: clinical aspects, risk factors and management. Int J Hyg Environ Health, 2010. 213(2): p. 79-87.

257. Tsakris, A., et al., Transmission in the community of clonal Proteus mirabilis carrying VIM-1 metallo-beta-lactamase. J Antimicrob Chemother, 2007. 60(1): p. 136-9.

258. Tumbarello, M., et al., Identifying patients harboring extended-spectrum-beta-lactamase-producing Enterobacteriaceae on hospital admission: derivation and validation of a scoring system. Antimicrob Agents Chemother, 2011. 55(7): p. 3485-90.

259. Kim, B.N., et al., Resistance to extended-spectrum cephalosporins and mortality in patients with Citrobacter freundii bacteremia. Infection, 2003. 31(4): p. 202-7.

260. Bonten, M.J., et al., Characteristics of polyclonal endemicity of Pseudomonas aeruginosa colonization in intensive care units. Implications for infection control. Am J Respir Crit Care Med, 1999. 160(4): p. 1212-9.

261. Thuong, M., et al., Epidemiology of Pseudomonas aeruginosa and risk factors for carriage acquisition in an intensive care unit. J Hosp Infect, 2003. 53(4): p. 274-82.

262. Bergmans, D.C., et al., Cross-colonisation with Pseudomonas aeruginosa of patients in an intensive care unit. Thorax, 1998. 53(12): p. 1053-8.

263. Pena, C., et al., Effects of carbapenem exposure on the risk for digestive tract carriage of intensive care unit-endemic carbapenem-resistant Pseudomonas aeruginosa strains in critically ill patients. Antimicrob Agents Chemother, 2007. 51(6): p. 1967-71.

264. Agodi, A., et al., Pseudomonas aeruginosa carriage, colonization, and infection in ICU patients. Intensive Care Med, 2007. 33(7): p. 1155-61.

265. Johnson, J.K., et al., The role of patient-to-patient transmission in the acquisition of imipenem-resistant Pseudomonas aeruginosa colonization in the intensive care unit. J Infect Dis, 2009. 200(6): p. 900-5.

266. Bertrand, X., et al., Endemicity, molecular diversity and colonisation routes of Pseudomonas aeruginosa in intensive care units. Intensive Care Med, 2001. 27(8): p. 1263-8.

267. Lampati, L., et al., Can routine surveillance samples from tracheal aspirate predict bacterial flora in cases of ventilator-associated pneumonia? Minerva Anestesiol, 2009. 75(10): p. 555-62.

268. Yang, K., et al., Multidrug-resistant Pseudomonas aeruginosa ventilator-associated pneumonia: the role of endotracheal aspirate surveillance cultures. Ann Pharmacother, 2009. 43(1): p. 28-35.

269. Osmon, S., et al., Hospital mortality for patients with bacteremia due to Staphylococcus aureus or Pseudomonas aeruginosa. Chest, 2004. 125(2): p. 607-16.
270. Kang, C.I., et al., Risk factors for antimicrobial resistance and influence of resistance on mortality in patients with bloodstream infection caused by Pseudomonas aeruginosa. Microb Drug Resist, 2005. 11(1): p. 68-74.

271. Orsi, G.B., M. Falcone, and M. Venditti, Surveillance and management of multidrug-resistant microorganisms. Expert Rev Anti Infect Ther, 2011. 9(8): p. 653-79.

272. Gasink, L.B., et al., Fluoroquinolone-resistant Pseudomonas aeruginosa: assessment of risk factors and clinical impact. Am J Med, 2006. 119(6): p. 526 e19-25.

273. Eagye, K.J., J.L. Kuti, and D.P. Nicolau, Risk factors and outcomes associated with isolation of meropenem high-level-resistant Pseudomonas aeruginosa. Infect Control Hosp Epidemiol, 2009. 30(8): p. 746-52.

274. Joo, E.J., et al., Risk factors for mortality in patients with Pseudomonas aeruginosa bacteremia: clinical impact of antimicrobial resistance on outcome. Microb Drug Resist, 2011. 17(2): p. 305-12.

275. Suarez, C., et al., Influence of carbapenem resistance on mortality and the dynamics of mortality in Pseudomonas aeruginosa bloodstream infection. Int J Infect Dis, 2010. 14 Suppl 3: p. e73-8.

276. Suarez, C., et al., Clinical impact of imipenemresistant Pseudomonas aeruginosa bloodstream infections. J Infect, 2009. 58(4): p. 285-90.

277. Cao, B., et al., Risk factors and clinical outcomes of nosocomial multi-drug resistant Pseudomonas aeruginosa infections. J Hosp Infect, 2004. 57(2): p. 112-8.

278. Berdal, J.E., et al., Does Pseudomonas aeruginosa colonization influence morbidity and mortality in the intensive care unit patient? Experience from an outbreak caused by contaminated oral swabs. Acta Anaesthesiol Scand, 2006. 50(9): p. 1095-102.

279. Hota, S., et al., Outbreak of multidrug-resistant Pseudomonas aeruginosa colonization and infection secondary to imperfect intensive care unit room design. Infect Control Hosp Epidemiol, 2009. 30(1): p. 25-33.

280. Reuter, S., et al., Analysis of transmission pathways of Pseudomonas aeruginosa between patients and tap water outlets. Crit Care Med, 2002. 30(10): p. 2222-8.

281. Trautmann, M., et al., [Reservoirs of Pseudomonas aeruginosa in the intensive care unit. The role of tap water as a source of infection]. Bundesgesundheitsblatt Gesundheitsforschung Gesundheitsschutz, 2009. 52(3): p. 339-44.

282. Schelenz, S. and G. French, An outbreak of multidrug-resistant Pseudomonas aeruginosa infection associated with contamination of bronchoscopes and an endoscope washer-disinfector. J Hosp Infect, 2000. 46(1): p. 23-30.

283. Srinivasan, A., et al., An outbreak of Pseudomonas aeruginosa infections associated with flexible bronchoscopes. N Engl J Med, 2003. 348(3): p. 221-7.

284. Kramer, A., I. Schwebke, and G. Kampf, How long do nosocomial pathogens persist on inanimate surfaces? A systematic review. BMC Infect Dis, 2006. 6: p. 130.

285. Foca, M., et al., Endemic Pseudomonas aeruginosa infection in a neonatal intensive care unit. $\mathrm{N}$ Engl J Med, 2000. 343(10): p. 695-700.

286. Moolenaar, R.L., et al., A prolonged outbreak of Pseudomonas aeruginosa in a neonatal intensive care unit: did staff fingernails play a role in disease transmission? Infect Control Hosp Epidemiol, 2000. 21(2): p. 80-5. 
287. Parkins, M.D., et al., Population-based study of the epidemiology and the risk factors for Pseudomonas aeruginosa bloodstream infection. Infection, 2010. 38(1): p. 25-32.

288. Ortega, B., A.B. Groeneveld, and C. Schultsz, Endemic multidrug-resistant Pseudomonas aeruginosa in critically ill patients. Infect Control Hosp Epidemiol, 2004. 25(10): p. 825-31.

289. Ohmagari, N., et al., Risk factors for infections with multidrug-resistant Pseudomonas aeruginosa in patients with cancer. Cancer, 2005. 104(1): p. 205-12.

290. Defez, C., et al., Risk factors for multidrug-resistant Pseudomonas aeruginosa nosocomial infection. J Hosp Infect, 2004. 57(3): p. 209-16.

291. Mikura, S., et al., Risk factors for bacteraemia attributable to Pseudomonas aeruginosa resistant to imipenem, levofloxacin, or gentamicin. J Hosp Infect, 2011. 79(3): p. 267-8.

292. Agodi, A., et al., Alert surveillance of intensive care unit-acquired Acinetobacter infections in a Sicilian hospital. Clin Microbiol Infect, 2006. 12(3): p. 241-7.

293. Rodriguez-Bano, J., et al., Long-term control of hospital-wide, endemic multidrug-resistant Acinetobacter baumannii through a comprehensive "bundle" approach. Am J Infect Control, 2009. 37(9): p. 715-22.

294. Fournier, P.E. and H. Richet, The epidemiology and control of Acinetobacter baumannii in health care facilities. Clin Infect Dis, 2006. 42(5): p. 692-9.

295. Apisarnthanarak, A., et al., A multifaceted intervention to reduce pandrug-resistant Acinetobacter baumannii colonization and infection in 3 intensive care units in a Thai tertiary care center: a 3-year study. Clin Infect Dis, 2008. 47(6): p. 760-7.

296. Falagas, M.E., I.A. Bliziotis, and Siempos, II, Attributable mortality of Acinetobacter baumannii infections in critically ill patients: a systematic review of matched cohort and case-control studies. Crit Care, 2006. 10(2): p. R48.

297. Eberle, B.M., et al., The impact of Acinetobacter baumannii infections on outcome in trauma patients: a matched cohort study. Crit Care Med, 2010. 38(11): p. 2133-8.

298. Falagas, M.E. and P. Kopterides, Risk factors for the isolation of multi-drug-resistant Acinetobacter baumannii and Pseudomonas aeruginosa: a systematic review of the literature. J Hosp Infect, 2006. 64(1): p. 7-15.

299. Playford, E.G., J.C. Craig, and J.R. Iredell, Carbapenem-resistant Acinetobacter baumannii in intensive care unit patients: risk factors for acquisition, infection and their consequences. J Hosp Infect, 2007. 65(3): p. 204-11.

300. Wisplinghoff, H., et al., Nosocomial bloodstream infections caused by Acinetobacter species in United States hospitals: clinical features, molecular epidemiology, and antimicrobial susceptibility. Clin Infect Dis, 2000. 31(3): p. 690-7.

301. Siempos, II, et al., Predictors of mortality in adult patients with ventilator-associated pneumonia: a meta-analysis. Shock, 2010. 33(6): p. 590-601.

302. Abbo, A., et al., Impact of multi-drug-resistant Acinetobacter baumannii on clinical outcomes. Eur J Clin Microbiol Infect Dis, 2007. 26(11): p. 793-800.

303. Lee, N.Y., et al., Clinical and economic impact of multidrug resistance in nosocomial Acinetobacter baumannii bacteremia. Infect Control Hosp Epidemiol, 2007. 28(6): p. 713-9.
304. Daniels, T.L., et al., Mortality rates associated with multidrug-resistant Acinetobacter baumannii infection in surgical intensive care units. Infect Control Hosp Epidemiol, 2008. 29(11): p. 1080-3.

305. Lambert, M.L., et al., Clinical outcomes of health-care-associated infections and antimicrobial resistance in patients admitted to European intensive-care units: a cohort study. Lancet Infect Dis, 2011. 11(1): p. 30-8.

306. Sunenshine, R.H., et al., Multidrug-resistant Acinetobacter infection mortality rate and length of hospitalization. Emerg Infect Dis, 2007. 13(1): p. 97-103.

307. Sheng, W.H., et al., A multicenter study of risk factors and outcome of hospitalized patients with infections due to carbapenem-resistant Acinetobacter baumannii. Int J Infect Dis, 2010. 14(9): p. e764-9.

308. Routsi, C., et al., Carbapenem-resistant versus carbapenem-susceptible Acinetobacter baumannii bacteremia in a Greek intensive care unit: risk factors, clinical features and outcomes. Infection, 2010. 38(3): p. 173-80.

309. Lautenbach, E., et al., Epidemiology and impact of imipenem resistance in Acinetobacter baumannii. Infect Control Hosp Epidemiol, 2009. 30(12): p. 1186-92.

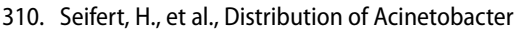
species on human skin: comparison of phenotypic and genotypic identification methods. J Clin Microbiol, 1997. 35(11): p. 2819-25.

311. Doughari, H.J., et al., The ecology, biology and pathogenesis of Acinetobacter spp.: an overview. Microbes Environ, 2011. 26(2): p. 101-12.

312. Corbella, X., et al., Relevance of digestive tract colonization in the epidemiology of nosocomial infections due to multiresistant Acinetobacter baumannii. Clin Infect Dis, 1996. 23(2): p. 329-34

313. Wendt, C., et al., Survival of Acinetobacter baumannii on dry surfaces. J Clin Microbiol, 1997. 35(6): p. 1394-7.

314. Bureau-Chalot, F., et al., Blood pressure cuffs as potential reservoirs of extended-spectrum beta-lactamase VEB-1-producing isolates of Acinetobacter baumannii. J Hosp Infect, 2004. 58(1): p. 91-2.

315. De Jong, G., et al., Back to basics--optimizing the use of available resources during an outbreak of multi-drug resistant Acinetobacter spp. J Hosp Infect, 2004. 57(2): p. 186-7.

316. El Shafie, S.S., M. Alishaq, and M. Leni Garcia, Investigation of an outbreak of multidrug-resistant Acinetobacter baumannii in trauma intensive care unit. J Hosp Infect, 2004. 56(2): p. 101-5.

317. Guducuoglu, H., et al., Spread of a single clone Acinetobacter baumannii strain in an intensive care unit of a teaching hospital in Turkey. New Microbiol, 2005. 28(4): p. 337-43.

318. Huang, Y.C., et al., Outbreak of Acinetobacter baumannii bacteremia in a neonatal intensive care unit: clinical implications and genotyping analysis. Pediatr Infect Dis J, 2002. 21(12): p. 1105-9.

319. Jamal, W., et al., Role of tigecycline in the control of a carbapenem-resistant Acinetobacter baumannii outbreak in an intensive care unit. J Hosp Infect, 2009. 72(3): p. 234-42.

320. Levidiotou, S., et al., A multi-resistant Acinetobacter baumannii outbreak in a general intensive care unit. In Vivo, 2002. 16(2): p. 117-22.

321. Tien, H.C., et al., Multi-drug resistant Acinetobacter infections in critically injured Canadian forces soldiers. BMC Infect Dis, 2007. 7: p. 95.
322. Wang, S.H., et al., Healthcare-associated outbreak due to pan-drug resistant Acinetobacter baumannii in a surgical intensive care unit. J Hosp Infect, 2003. 53(2): p. 97-102.

323. Wilks, M., et al., Control of an outbreak of multidrug-resistant Acinetobacter baumannii-calcoaceticus colonization and infection in an intensive care unit (ICU) without closing the ICU or placing patients in isolation. Infect Control Hosp Epidemiol, 2006. 27(7): p. 654-8.

324. Bernards, A.T., et al., Persistent Acinetobacter baumannii? Look inside your medical equipment. Infect Control Hosp Epidemiol, 2004. 25(11): p. 1002-4.

325. Marino, C.G., et al., An outbreak of pyrogenic events connected with intravenous infusion devices in patients admitted to hospital Sao Paulo. J Hosp Infect, 2001. 47(2): p. 166-7.

326. Pimentel, J.D., et al., Control of an outbreak of multi-drug-resistant Acinetobacter baumannii in an intensive care unit and a surgical ward. J Hosp Infect, 2005. 59(3): p. 249-53.

327. Go, E.S., et al., Clinical and molecular epidemiology of acinetobacter infections sensitive only to polymyxin B and sulbactam. Lancet, 1994. 344(8933): p. 1329-32.

328. Roberts, S.A., R. Findlay, and S.D. Lang, Investigation of an outbreak of multi-drug resistant Acinetobacter baumannii in an intensive care burns unit. J Hosp Infect, 2001. 48(3): p. 228-32.

329. Wagenvoort, J.H., et al., Epidemic Acinetobacter baumannii strain with MRSA-like behaviour carried by healthcare staff. Eur J Clin Microbiol Infect Dis, 2002. 21(4): p. 326-7.

330. Joseph, N.M., et al., Role of intensive care unit environment and health-care workers in transmission of ventilator-associated pneumonia. J Infect Dev Ctries, 2010. 4(5): p. 282-91.

331. Jung, J.Y., et al., Risk factors for multi-drug resistant Acinetobacter baumannii bacteremia in patients with colonization in the intensive care unit. BMC Infect Dis, 2010. 10: p. 228.

332. Mirza, I.A., et al., Ambu bag as a source of Acinetobacter baumannii outbreak in an intensive care unit. J Coll Physicians Surg Pak, 2011. 21(3): p. 176-8.

333. Stone, J.W. and B.C. Das, Investigation of an outbreak of infection with Acinetobacter calcoaceticus in a special care baby unit. J Hosp Infect, 1986. 7(1): p. 42-8.

334. Bernards, A.T., et al., Methicillin-resistant Staphylococcus aureus and Acinetobacter baumannii: an unexpected difference in epidemiologic behavior. Am J Infect Control, 1998. 26(6): p. 54451.

335. Moultrie, D., J. Hawker, and S. Cole, Factors associated with multidrug-resistant Acinetobacter transmission: an integrative review of the literature. AORN J, 2011. 94(1): p. 27-36.

336. Park, Y.S., et al., Extensively drug-resistant Acinetobacter baumannii: risk factors for acquisition and prevalent OXA-type carbapenemases--a multicentre study. Int J Antimicrob Agents, 2010. 36(5): p. 430-5.

337. Acosta, J., et al., Multidrug-resistant Acinetobacter baumannii Harboring OXA-24 carbapenemase, Spain. Emerg Infect Dis, 2011. 17(6): p. 1064-7.

338. Christiaens, G., et al., Implementation of an infection control programme to limit the spread of extended-spectrum beta-lactamase-producing Enterobacteriaceae in a Belgian university hospital. J Hosp Infect, 2008. 68(4): p. 366-7. 
339. Lu, P.L., et al., How carbapenem-resistant Acinetobacter spp. established in a newly constructed hospital. Int J Antimicrob Agents, 2008. 31(5): p. 463-6.

340. Morgan, D.J., et al., Multidrug-resistant Acinetobacter baumannii in New York City - 10 years into the epidemic. Infect Control Hosp Epidemiol, 2009. 30(2): p. 196-7.

341. Woodford, N., J.F. Turton, and D.M. Livermore, Multiresistant Gram-negative bacteria: the role of high-risk clones in the dissemination of antibiotic resistance. FEMS Microbiol Rev, 2011 35(5): p. 736-55.

342. Warren, R.E., et al., Control of infections due to extended-spectrum beta-lactamase-producing organisms in hospitals and the community. Clin Microbiol Infect, 2008. 14 Suppl 1: p. 124-33.

343. Eveillard, M., et al., Evaluation of the contribu tion of isolation precautions in prevention and control of multi-resistant bacteria in a teaching hospital. J Hosp Infect, 2001. 47(2): p. 116-24.

344. Cheng, V.C., et al., Sequential introduction of single room isolation and hand hygiene campaign in the control of methicillin-resistant Staphylococcus aureus in intensive care unit. BMC Infect Dis, 2010. 10: p. 263.

345. Ofner-Agostini, M., et al., Infection control and antimicrobial restriction practices for antimicrobial-resistant organisms in Canadian tertiary care hospitals. Am J Infect Control, 2007. 35(9): p. 5638.

346. Woerther, P.L., et al., Emergence and dissemination of extended-spectrum beta-lactamase-producing Escherichia coli in the community: lessons from the study of a remote and controlled population. J Infect Dis, 2010. 202(4): p. 515-23.

347. ECDC, Technical reports - 13 Sep 2011 Risk assessment on the spread of carbapenemase-producing Enterobacteriaceae (CPE) through patient transfer between healthcare facilities, with special emphasis on cross-border transfer. http://ecdc. europa.eu/en/publications/Publications/110913_ Risk_assessment_resistant_CPE.pdf, Zugriff 12.11.2011, 2011

348. CLSI, Performance standards for antimicrobial susceptibility testing; fifteenth informational supplement. Clinical and Laboratory Standards Institute. 2003.

349. Murk, J.L., et al., Enrichment broth improved detection of extended-spectrum-beta-lactamase-producing bacteria in throat and rectal surveillance cultures of samples from patients in intensive care units. J Clin Microbiol, 2009. 47(6): p. 1885-7.

350. Buehlmann, M., et al., The inguinal skin: an important site of colonization with extended-spectrum beta-lactamase-producing Enterobacteriaceae. Infect Control Hosp Epidemiol, 2010. 31(4): p. 427-8.

351. Thouverez, M., D. Talon, and X. Bertrand, Control of Enterobacteriaceae producing extendedspectrum beta-lactamase in intensive care units: rectal screening may not be needed in non-epidemic situations. Infect Control Hosp Epidemiol, 2004. 25(10): p. 838-41.

352. Hospenthal, D.R., et al., Multidrug-resistant bacterial colonization of combat-injured personnel at admission to medical centers after evacuation from Afghanistan and Iraq. J Trauma, 2011. 71(1 Suppl): p. S52-7.

353. Alsterlund, R., C. Axelsson, and B. Olsson-Liljequist, Long-term carriage of extended-spectrum beta-lactamase-producing Escherichia coli. Scand J Infect Dis, 2011.
354. Buehlmann, M., et al., Effectiveness of a new decolonisation regimen for eradication of extended-spectrum beta-lactamase-producing Enterobacteriaceae. J Hosp Infect, 2011. 77(2): p. 113-7.

355. Troche, G., et al., Detection and treatment of antibiotic-resistant bacterial carriage in a surgical intensive care unit: a 6-year prospective survey. Infect Control Hosp Epidemiol, 2005. 26(2): p. 161-5.

356. Laurent, C., et al., Intensive care unit outbreak of extended-spectrum beta-lactamase-producing Klebsiella pneumoniae controlled by cohorting patients and reinforcing infection control measures. Infect Control Hosp Epidemiol, 2008. 29(6): p. 517-24

357. Lipworth, A.D., et al., Limiting the emergence of extended-spectrum Beta-lactamase-producing enterobacteriaceae: influence of patient population characteristics on the response to antimicrobial formulary interventions. Infect Control Hosp Epidemiol, 2006. 27(3): p. 279-86.

358. Lee, S.O., et al., Reduced use of third-generation cephalosporins decreases the acquisition of extended-spectrum beta-lactamase-producing Klebsiella pneumoniae. Infect Control Hosp Epidemiol, 2004. 25(10): p. 832-7.

359. Johnson, P.D., et al., Efficacy of an alcohol/ chlorhexidine hand hygiene program in a hospital with high rates of nosocomial methicillin-resistant Staphylococcus aureus (MRSA) infection. Med J Aust, 2005. 183(10): p. 509-14.

360. Raymond, J., et al., Multidrug-resistant bacteria in hospitalized children: a 5-year multicenter study. Pediatrics, 2007. 119(4): p. e798-803.

361. Schwaber, M.J., et al., Containment of a country-wide outbreak of carbapenem-resistant Klebsiella pneumoniae in Israeli hospitals via a nationally implemented intervention. Clin Infect Dis, 2011. 52(7): p. 848-55.

362. Cohen, M.J., et al., Institutional control measures to curtail the epidemic spread of carbapenem-resistant Klebsiella pneumoniae: a 4-year perspective. Infect Control Hosp Epidemiol, 2011. 32(7): p. 673-8.

363. Ben-David, D., et al., Potential role of active surveillance in the control of a hospital-wide outbreak of carbapenem-resistant Klebsiella pneumoniae infection. Infect Control Hosp Epidemiol, 2010. 31(6): p. 620-6.

364. Kochar, S., et al., Success of an infection control program to reduce the spread of carbapenemresistant Klebsiella pneumoniae. Infect Contro Hosp Epidemiol, 2009. 30(5): p. 447-52.

365. Agodi, A., et al., Containment of an Outbreak of KPC-3-Producing Klebsiella pneumoniae in Italy. J Clin Microbiol, 2011. 49(11): p. 3986-9.

366. Endimiani, A., et al., Characterization of blaKPCcontaining Klebsiella pneumoniae isolates detected in different institutions in the Eastern USA.J Antimicrob Chemother, 2009. 63(3): p. 427-37.

367. Munoz-Price, L.S., et al., Successful eradication of a monoclonal strain of Klebsiella pneumoniae during a K. pneumoniae carbapenemase-producing K. pneumoniae outbreak in a surgical intensive care unit in Miami, Florida. Infect Control Hosp Epidemiol, 2010. 31(10): p. 1074-7.

368. Munoz-Price, L.S., et al., Successful control of an outbreak of Klebsiella pneumoniae carbapenemase-producing K. pneumoniae at a long-term acute care hospital. Infect Control Hosp Epidemiol, 2010. 31(4): p. 341-7.
369. Wiener-Well, Y., et al., Carriage rate of carbapenem-resistant Klebsiella pneumoniae in hospitalised patients during a national outbreak. J Hosp Infect, 2010. 74(4): p. 344-9.

370. Calfee, D. and S.G. Jenkins, Use of active surveillance cultures to detect asymptomatic colonization with carbapenem-resistant Klebsiella pneumoniae in intensive care unit patients. Infect Control Hosp Epidemiol, 2008. 29(10): p. 966-8.

371. Landman, D., et al., Evaluation of techniques for detection of carbapenem-resistant Klebsiella pneumoniae in stool surveillance cultures. J Clin Microbiol, 2005. 43(11): p. 5639-41.

372. Overdevest, I.T., et al., Laboratory detection of extended-spectrum-beta-lactamase-producing Enterobacteriaceae: evaluation of two screening agar plates and two confirmation techniques. J Clin Microbiol, 2011. 49(2): p. 519-22.

373. Zuckerman, T., et al., SCT in patients with carbapenem resistant Klebsiella pneumoniae: a single center experience with oral gentamicin for the eradication of carrier state. Bone Marrow Transplant, 2011. 46(9): p. 1226-30.

374. v Dijk, Y., et al., Management of an outbreak of Enterobacter cloacae in a neonatal unit using simple preventive measures. J Hosp Infect, 2002. 51(1): p. 21-6.

375. Kac, G., et al., Molecular epidemiology of extended-spectrum beta-lactamase-producing Enterobacteriaceae isolated from environmental and clinical specimens in a cardiac surgery intensive care unit. Infect Control Hosp Epidemiol, 2004. 25(10): p. 852-5.

376. Davin-Regli, A., et al., Molecular epidemiology of Enterobacter aerogenes acquisition: one-year prospective study in two intensive care units. J Clin Microbiol, 1996. 34(6): p. 1474-80.

377. Shi, Z.Y., et al., Epidemiological typing of isolates from an outbreak of infection with multidrug-resistant Enterobacter cloacae by repetitive extragenic palindromic unit b1-primed PCR and pulsed-field gel electrophoresis. J Clin Microbiol, 1996. 34(11): p. 2784-90.

378. Naesens, R., et al., Screening to select patients carrying extended-spectrum beta-lactamaseproducing Enterobacteriaceae for isolation in Flemish intensive care units: a Swiss cheese strategy? J Hosp Infect, 2010. 76(4): p. 354-5.

379. Stuart, J.C., et al., Method for phenotypic detection of extended-spectrum beta-lactamases in enterobacter species in the routine clinical setting. J Clin Microbiol, 2011. 49(7): p. 2711-3.

380. Leverstein-van Hall, M.A., et al., Extensive hospital-wide spread of a multidrug-resistant enterobacter cloacae clone, with late detection due to a variable antibiogram and frequent patient transfer. J Clin Microbiol, 2006. 44(2): p. 518-24.

381. Choi, Y., et al., Routine skin cultures in predicting sepsis pathogens among hospitalized preterm neonates in Bangladesh. Neonatology, 2008. 94(2): p. 123-31.

382. Parm, U., et al., Mucosal surveillance cultures in predicting Gram-negative late-onset sepsis in neonatal intensive care units. J Hosp Infect, 2011. 78(4): p. 327-32.

383. Abecasis, F., et al., Is selective digestive decontamination useful in controlling aerobic gram-negative bacilli producing extended spectrum beta-lactamases? Microb Drug Resist, 2011. 17(1): p. 17-23.

384. Giles, M., et al., What is the best screening method to detect Serratia marcescens colonization during an outbreak in a neonatal intensive care nursery? J Hosp Infect, 2006. 62(3): p. 349-52. 
385. O'Fallon, E., S. Gautam, and E.M. D'Agata, Colonization with multidrug-resistant gram-negative bacteria: prolonged duration and frequent cocoIonization. Clin Infect Dis, 2009. 48(10): p. 137581.

386. Dedeic-Ljubovic, A. and M. Hukic, Catheter-related urinary tract infection in patients suffering from spinal cord injuries. Bosn J Basic Med Sci, 2009. 9(1): p. 2-9.

387. Nagano, N., et al., Nosocomial outbreak of infections by Proteus mirabilis that produces extended-spectrum CTX-M-2 type beta-lactamase. J Clin Microbiol, 2003. 41(12): p. 5530-6.

388. Suarez, C., et al., A large sustained endemic outbreak of multiresistant Pseudomonas aeruginosa: a new epidemiological scenario for nosocomial acquisition. BMC Infect Dis, 2011. 11: p. 272.

389. Furtado, G.H., et al., Clinical culture surveillance of carbapenem-resistant Pseudomonas aeruginosa and Acinetobacter species in a teaching hospital in Sao Paulo, Brazil: a 7-year study. Infect Control Hosp Epidemiol, 2006. 27(11): p. 1270-3.

390. Olson, B., et al., Epidemiology of endemic Pseudomonas aeruginosa: why infection control efforts have failed. J Infect Dis, 1984. 150(6): p. 80816.

391. Pereira, G.H., et al., Controlling the clonal spread of Pseudomonas aeruginosa infection. Infect Control Hosp Epidemiol, 2008. 29(6): p. 549-52.

392. Petignat, C., et al., Exogenous sources of pseudomonas aeruginosa in intensive care unit patients: implementation of infection control measures and follow-up with molecular typing. Infect Control Hosp Epidemiol, 2006. 27(9): p. 953-7.

393. Trautmann, M., et al., Point-of-use water filtration reduces endemic Pseudomonas aeruginosa infections on a surgical intensive care unit. Am J Infect Control, 2008. 36(6): p. 421-9.

394. Forestier, C., et al., Oral probiotic and prevention of Pseudomonas aeruginosa infections: a randomized, double-blind, placebo-controlled pilot study in intensive care unit patients. Crit Care, 2008. 12(3): p. R69.

395. Dalben, M.F., et al., Swab cultures across three different body sites among carriers of carbapenem-resistant $P$. aeruginosa and Acinetobacter species: a poor surveillance strategy. J Hosp Infect, 2010. 74(4): p. 395-6.

396. Motoshima, M., et al., Quantitative detection of metallo-beta-lactamase of blalMP-cluster-producing Pseudomonas aeruginosa by real-time polymerase chain reaction with melting curve analysis for rapid diagnosis and treatment of nosocomial infection. Diagn Microbiol Infect Dis, 2008. 61(2): p. 222-6.

397. Vonberg, R.P., et al., Epidemiology of multidrug-resistant gram-negative bacteria: data from an university hospital over a 36-month period. Int J Hyg Environ Health, 2008. 211(3-4): p. 251-7.

398. Hayes, D., Jr., et al., Eradication of Pseudomonas aeruginosa in an adult patient with cystic fibrosis. Am J Health Syst Pharm, 2011. 68(4): p. 319-22.

399. Langton Hewer, S.C. and A.R. Smyth, Antibiotic strategies for eradicating Pseudomonas aeruginosa in people with cystic fibrosis. Cochrane Database Syst Rev, 2009(4): p. CD004197.

400. Stuart, B., J.H. Lin, and P.J. Mogayzel, Jr., Early eradication of Pseudomonas aeruginosa in patients with cystic fibrosis. Paediatr Respir Rev, 2010. 11(3): p. 177-84.
401. Hansen, S., et al., Closure of medical departments during nosocomial outbreaks: data from a systematic analysis of the literature. J Hosp Infect, 2007. 65(4): p. 348-53.

402. Denton, M., et al., Role of environmental cleaning in controlling an outbreak of Acinetobacter baumannii on a neurosurgical intensive care unit. Intensive Crit Care Nurs, 2005. 21(2): p. 94-8.

403. Lin, W.R., et al., Rapid control of a hospital-wide outbreak caused by extensively drug-resistant OXA-72-producing Acinetobacter baumannii. Kaohsiung J Med Sci, 2011. 27(6): p. 207-14.

404. Otter, J.A., S. Yezli, and G.L. French, The role played by contaminated surfaces in the transmission of nosocomial pathogens. Infect Control Hosp Epidemiol, 2011. 32(7): p. 687-99.

405. Garcia-Ortega, L., et al., Control measures for Acinetobacter baumannii: a survey of Spanish hospitals. Enferm Infecc Microbiol Clin, 2011. 29(1): p. 36-8.

406. Marchaim, D., et al., Surveillance cultures and duration of carriage of multidrug-resistant Acinetobacter baumannii. J Clin Microbiol, 2007. 45(5): p. 1551-5.

407. Doi, Y., et al., Screening for Acinetobacter baumannii colonization by use of sponges. J Clin Microbiol, 2011.49(1): p. 154-8.

408. Ajao, A.O., et al., Comparison of culture media for detection of Acinetobacter baumannii in surveillance cultures of critically-ill patients. Eur J Clin Microbiol Infect Dis, 2011.

409. Akers, K.S., et al., CHROMagar Acinetobacter is not selective for carbapenem-resistant Acinetobacter baumannii-calcoaceticus complex. Diagn Microbiol Infect Dis, 2010. 67(2): p. 209-11.

410. Gordon, N.C. and D.W. Wareham, Evaluation of CHROMagar Acinetobacter for detection of enteric carriage of multidrug-resistant Acinetobacter baumannii in samples from critically ill patients. J Clin Microbiol, 2009. 47(7): p. 2249-51.

411. Abbo, A., et al., Multidrug-resistant Acinetobacter baumannii. Emerg Infect Dis, 2005. 11(1): p. 22-9.

412. Valencia, R., et al., Nosocomial outbreak of infection with pan-drug-resistant Acinetobacter baumannii in a tertiary care university hospital. Infect Control Hosp Epidemiol, 2009. 30(3): p. 257-63.

413. Webster, C.A., et al., Surveillance of an adult intensive care unit for long-term persistence of a multi-resistant strain of Acinetobacter baumannii. Eur J Clin Microbiol Infect Dis, 1998. 17(3): p. 171-6.

414. Harris, A.D., J.C. McGregor, and J.P. Furuno, What infection control interventions should be undertaken to control multidrug-resistant gramnegative bacteria? Clin Infect Dis, 2006. 43 Suppl 2: p. S57-61.

415. Lee, B.Y., et al., Economic value of Acinetobacter baumannii screening in the intensive care unit. Clin Microbiol Infect, 2011.

416. Borer, A., et al., Impact of $4 \%$ chlorhexidine whole-body washing on multidrug-resistant Acinetobacter baumannii skin colonisation among patients in a medical intensive care unit. J Hosp Infect, 2007. 67(2): p. 149-55.

417. Agusti, C., et al., Short-term effect of the application of selective decontamination of the digestive tract on different body site reservoir ICU patients colonized by multi-resistant Acinetobacter baumannii. J Antimicrob Chemother, 2002. 49(1): p. 205-8.
418. Kommission für Krankenhaushygiene und Infektionsprävention, Ergänzende Empfehlung (2011) zur "Prävention nosokomialer Infektionen bei neonatologischen Intensivpflegepatienten mit einem Geburtsgewicht unter $1.500 \mathrm{~g}^{\prime \prime}$ (2007). Epidemiologische Bulletin, 2012. 2: p. 13-15.

419. Robert, J., et al., Implementation of isolation precautions: role of a targeted information flyer. J Hosp Infect, 2006. 62(2): p. 163-5.

420. Kac, G., et al., Impact of electronic alerts on isolation precautions for patients with multidrug-resistant bacteria. Arch Intern Med, 2007. 167(19): p. 2086-90.

421. Goldmann, D.A., The role of barrier precautions in infection control. J Hosp Infect, 1991. 18 Suppl A: p. 515-23.

422. Dellit, T.H., et al., Infectious Diseases Society of America and the Society for Healthcare Epidemiology of America guidelines for developing an institutional program to enhance antimicrobial stewardship. Clin Infect Dis, 2007. 44(2): p. 15977. 